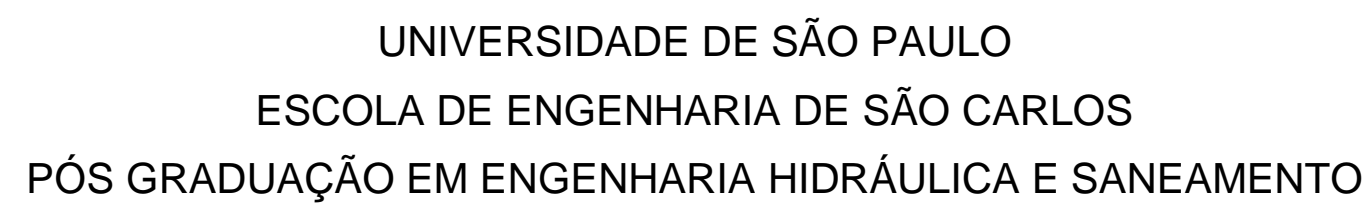

ANA CLAUDIA EMERENCIANO GUEDES

ESTUDO TEÓRICO E EXPERIMENTAL EM ESCALA REDUZIDA DE UMA BARREIRA VERTICAL DE ALTA PERMEABILIDADE PARA ENCAPSULAMENTO DE ÁREAS CONTAMINADAS EM AQUÍFEROS

VERSÃO CORRIGIDA

São Carlos 

ANA CLAUDIA EMERENCIANO GUEDES

\title{
ESTUDO TEÓRICO E EXPERIMENTAL EM ESCALA REDUZIDA DE UMA BARREIRA VERTICAL DE ALTA PERMEABILIDADE PARA ENCAPSULAMENTO DE ÁREAS CONTAMINADAS EM AQUÍFEROS
}

\author{
Dissertação apresentada à Escola de \\ Engenharia de São Carlos da \\ Universidade de São Paulo como parte \\ dos requisitos para obtenção do título de \\ Mestre em Ciências: Engenharia \\ Hidráulica e Saneamento.
}

Orientador: Prof. Tit. Edson Wendland

VERSÃO CORRIGIDA

São Carlos

2018 
AUTORIZO A REPRODUÇÃO TOTAL OU PARCIAL DESTE TRABALHO, POR QUALQUER MEIO CONVENCIONAL OU ELETRÔNICO, PARA FINS DE ESTUDO E PESQUISA, DESDE QUE CITADA A FONTE.

Ficha catalográfica elaborada pela Biblioteca Prof. Dr. Sérgio Rodrigues Fontes da EESC/USP com os dados inseridos pelo(a) autor(a).

Emerenciano Guedes, Ana Claudia

E924e ESTUDO TEÓRICO E EXPERIMENTAL EM ESCALA REDUZIDA DE UMA BARREIRA VERTICAL DE ALTA PERMEABILIDADE PARA ENCAPSULAMENTO DE ÁREAS CONTAMINADAS EM AQUÍFEROS / Ana Claudia Emerenciano Guedes; orientador Edson Cezar Wendland. São Carlos, 2018.

Dissertação (Mestrado) - Programa de Pós-Graduação em Engenharia Hidráulica e Saneamento e Área de Concentração em Hidráulica e Saneamento -- Escola de Engenharia de São Carlos da Universidade de São Paulo, 2018 .

1. Aterro de resíduos sólidos. 2. Contaminação de águas subterrâneas. 3. Barreira vertical. I. Título. 


\section{FOLHA DE JULGAMENTO}

Candidata: Engenheira ANA CLAUDIA EMERENCIANO GUEDES.

Título da dissertação: "Estudo teórico e experimental em escala reduzida de uma barreira vertical de alta permeabilidade para encapsulamento de áreas contaminadas em aquíferos".

Data da defesa: 23/05/2018.

Comissão Julgadora:

Prof. Titular Edson Cezar Wendland (Orientador)

(Escola de Engenharia de São Carlos/EESC)

Prof. Titular Ricardo Cesar Aoki Hirata

(Instituto de Geociências-IGC/USP)

Prof. Dr. José Anderson do Nascimento Batista

(Universidade Estadual de Campinas/UNICAMP)
Resultado:

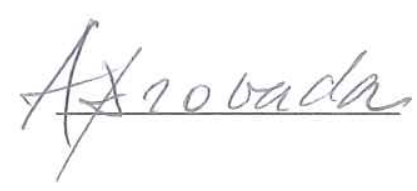

apmank

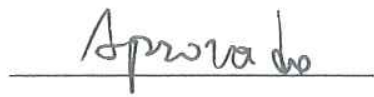

Coordenador do Programa de Pós-Graduação em Engenharia Hidráulica e Saneamento:

Prof. Dr. Eduardo Mario Mendiondo

Presidente da Comissão de Pós-Graduação:

Prof. Associado Luís Fernando Costa Alberto 



\section{AGRADECIMENTOS}

Meus agradecimentos à todas as pessoas e instituições que contribuíram para a conclusão deste trabalho, em especial:

Ao Prof. Edson Wendland, pela orientação, paciência e todas as oportunidades proporcionadas a mim durante esses dois anos.

Aos amigos do Laboratório de Hidráulica Computacional (LHC), pela ótima convivência, amizade e ajuda: Alice, Camila, Davi, David, Gabriel, Guardabaxo, Jamil, Jaqueline, Jean, Lívia e Natália; aos técnicos de laboratório Luis Carlos Muzzeti e Roberto Bérgamo, por terem me ajudado na montagem e funcionamento do meu experimento.

À Escola de Engenharia de São Carlos da Universidade de São Paulo (EESC/USP) e seus funcionários, pela infraestrutura e suporte institucional.

Ao Conselho Nacional de Desenvolvimento Científico e Tecnológico (CNPq) pela bolsa de estudo (processo 131532/2016-2), à Coordenação de Aperfeiçoamento de Pessoal de Nível Superior (CAPES) pelos auxílios concedidos através do Programa de Excelência Acadêmica (PROEX) e à Fundação de Amparo à Pesquisa do Estado de São Paulo (FAPESP) pelo auxílio à pesquisa concedido (processo 2015/03806-1).

Aos meus pais Joel Bezerra Guedes e Jaqueline Emerenciano Guedes e aos meus irmãos Ana Carolina Emerenciano Guedes e Rafael Emerenciano Guedes, por todo o suporte familiar. Não tenho palavras para descrever o quanto eu os amo e quão importantes vocês são para mim. Obrigada por todo o apoio e por estarem sempre me encorajando em todas as minhas decisões.

Por fim, agradeço ao Gustavo Matana Aguiar, que no começo dessa jornada era meu namorado e agora se tornou meu marido. A pessoa que mais me apoiou nesse mestrado, desde o processo seletivo até a escrita da dissertação. Meu melhor amigo, que me ajudou nos momentos de desespero, stress e tristeza, e comemorou comigo todas as alegrias e vitórias desses dois anos. Meu coorientador, que revisou comigo os mais diversos conceitos, me ensinou a soldar, a gostar de Matlab e discutiu comigo as ideias do meu projeto, da metodologia aos resultados... Enfim, essa conquista também é sua! 



\section{RESUMO}

GUEDES, Ana Claudia Emerenciano. Estudo teórico e experimental em escala reduzida de uma barreira vertical de alta permeabilidade para encapsulamento de áreas contaminadas em aquíferos. 2018. 100 f. Dissertação de Mestrado Escola de Engenharia de São Carlos, Universidade de São Paulo, São Carlos, 2018.

A preocupação com a contaminação das águas subterrâneas está relacionada principalmente aos aquíferos não confinados, especialmente nos casos em que o nível freático é raso. Para evitar o escoamento subterrâneo lateral através de aterros de resíduos sólidos, o objetivo deste trabalho é avaliar - teoricamente e experimentalmente - uma técnica alternativa de encapsulamento, que consiste em uma barreira vertical de alta permeabilidade. Foi desenvolvida uma solução analítica para modelar o escoamento em uma barreira vertical cilíndrica instalada no entorno de um aterro localizado abaixo do nível d'água, em um campo de fluxo uniforme, onde cada domínio (aquífero, barreira e área encapsulada) possui uma condutividade hidráulica diferente. Os resultados do estudo teórico mostram que nos casos em que o maciço de resíduos possui condutividade hidráulica maior do que o aquífero, a barreira de alta permeabilidade é a solução mais eficaz. Já nos problemas em que o aterro possui condutividade hidráulica menor do que o aquífero, a técnica mais indicada é a barreira de baixa permeabilidade. A partir do experimento em escala reduzida, conclui-se que a barreira de alta permeabilidade é uma técnica de encapsulamento eficiente para impedir o transporte advectivo através de determinada região. Segundo os resultados, a velocidade média do fluido na área encapsulada é consideravelmente menor do que a velocidade média no aquífero. Comparando com a barreira de baixa permeabilidade, a vantagem da barreira de alta permeabilidade é que o seu preenchimento é muito menos sensível às falhas, resultando em um melhor desempenho em longo prazo.

Palavras-chave: Aterro de resíduos sólidos. Contaminação de águas subterrâneas. Barreira vertical de alta permeabilidade. 



\begin{abstract}
GUEDES, Ana Claudia Emerenciano. Theoretical and small-scale experimental study of a high permeability vertical barrier to encapsulate contaminated areas in aquifers. 2018. 100 p. Master Dissertation - São Carlos School of Engineering, University of São Paulo, São Carlos, 2018.
\end{abstract}

The concern about groundwater contamination is mainly related to unconfined aquifers, especially in the cases where the water table is shallow. Therefore, in order to prevent the groundwater lateral flow through landfills, this research evaluates theoretically and experimentally - an alternative encapsulation technique, which consists in a vertical barrier of high permeability. An analytical solution was developed to model the flow for a cylindrical barrier installed around a landfill located below the groundwater table, in a field of uniform flow, where each domain (aquifer, barrier and encapsulated area) has a different hydraulic conductivity. The results from the theoretical study show that in situations where the landfill has a hydraulic conductivity higher than the aquifer, the high permeability barrier is more efficient. In contrast, in the cases where the landfill has a hydraulic conductivity lower than the aquifer, the Iw permeability barrier is a more suitable technique. From the small-scale experiment, it is possible to conclude that the permeable barrier is an efficient encapsulation technique to prevent the advective transport through a certain region. According to the results, the fluid mean velocity at the encapsulated area is considerably lower than the aquifer mean velocity. Comparing to the low permeability barrier, the advantage of the high permeability barrier is that its backfill material is less sensitive to defects, resulting in a better long-term performance.

Keywords: Landfill. Groundwater contamination. High permeability vertical barrier. 



\section{LISTA DE FIGURAS}

Figura 1. Pluma de contaminação em aquífero livre originada por chorume .25

Figura 2. Barreira de baixa permeabilidade - Vista em planta e corte .27

Figura 3. Barreira vertical cilíndrica em um campo de fluxo uniforme .37

Figura 4. Escoamento de água subterrânea nos casos em que $K 1 / K=100$ (A) e

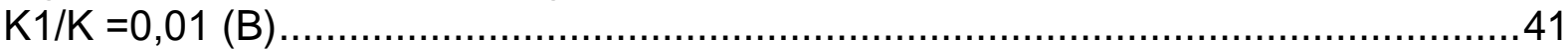

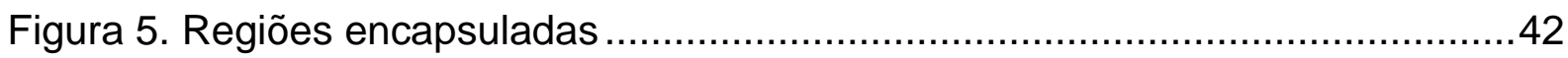

Figura 6. Barreira vertical cilíndrica em um campo de fluxo uniforme .......................43

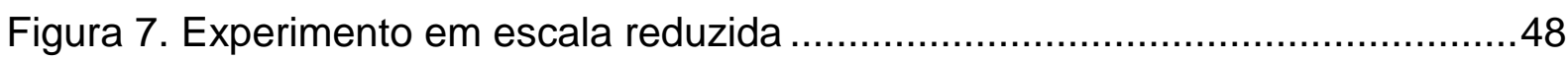

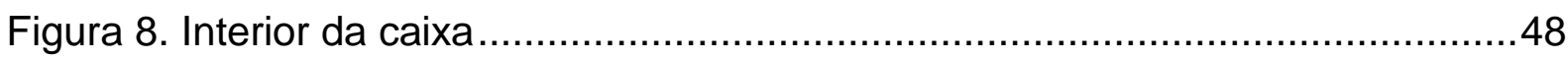

Figura 9. Tubo de PVC perfurado e recoberto com tela.........................................49

Figura 10. Reservatório lateral com extravasor ....................................................49

Figura 11. Materiais porosos e suas condutividades hidráulicas..............................50

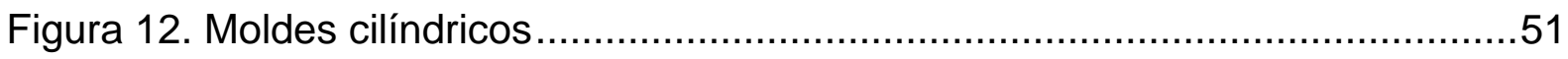

Figura 13. Caixa preenchida com o material poroso ...........................................51

Figura 14. Experimento após os moldes serem retirados ......................................51

Figura 15. Plástico para impedir a evaporação da água .........................................52

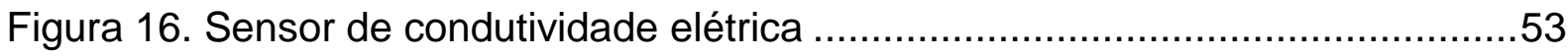

Figura 17. Esquema do sensor de condutividade elétrica .......................................53

Figura 18. Condutivímetro Vernier CON-BTA ……….........................................54

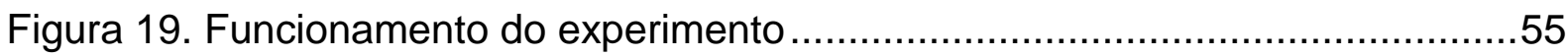

Figura 20. Sensores de condutividade elétrica inseridos nos tubos de PVC ...........56

Figura 21. Monitoramento através dos dataloggers ............................................56

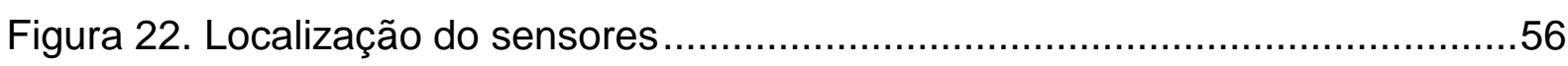

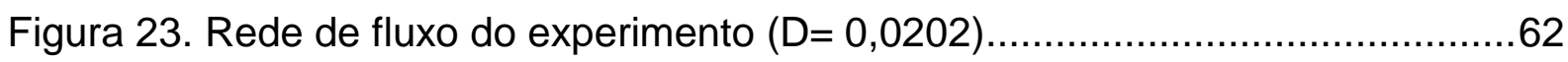

Figura 24. Superfície indicando as cotas piezométricas do experimento ...................63

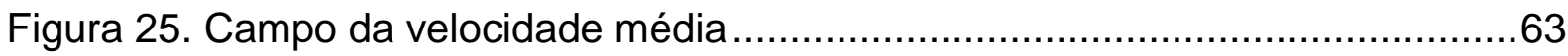


Figura 26. Campo da velocidade média no domínio do aquífero

Figura 27. Campo da velocidade média no domínio da barreira 64

Figura 28. Campo da velocidade média no domínio da área encapsulada 65

Figura 29. Trajetórias do fluido 66

Figura 30. Correlação da condutividade elétrica com a concentração de sal ..... 68

Figura 31. Resultado do monitoramento utilizando os sensores de condutividade elétrica 69

Figura 32. Resultado do monitoramento utilizando o condutivímetro ...................... 70

Figura 33. Material de preenchimento após os testes ......................................... 72

Figura 34. Aquífero e área encapsulada após a retirada do material de preenchimento da barreira 73

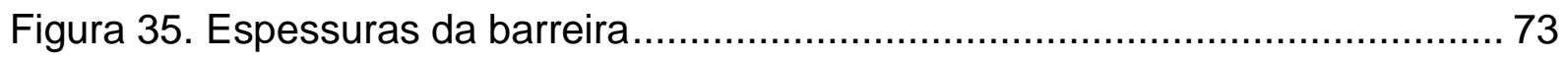

Figura 36. Gráfico do transporte da água com sal na área encapsulada 75 


\section{LISTA DE TABELAS}

Tabela 1. Disposição final adotada nos municípios brasileiros .24

Tabela 2. Efeitos na permeabilidade de barreiras de SB devido à lixiviação de diversos poluentes.

Tabela 3. Estudos sobre os efeitos da incompatibilidade química entre os solos argilosos e diferentes fluidos na condutividade hidráulica de barreiras de baixa permeabilidade.

Tabela 4. Simulação do desempenho das barreiras de baixa e alta permeabilidade no lixão Santa Madalena em São Carlos - S.

Tabela 5. Simulação do desempenho das barreiras de baixa e alta permeabilidade no lixão Babylon em Long Island - NY. 59

Tabela 6. Dados utilizados na simulação do experimento .62

Tabela 7. Tempo de deslocamento entre os pontos localizados em $y=0$ .66

Tabela 8. Coeficientes "a" e "b" da regressão não linear, $R^{2}$ e intervalo de confiança de $95 \%$ da média do erro dos sensores de condutividade elétrica

Tabela 9. Ordem de chegada da água com sal em cada sensor e respectivos valores de condutividade elétrica e concentração de sal após 140 horas.

Tabela 10. Tempo levado pelas partículas do fluido para se deslocar entre os pontos localizados em $\mathrm{y}=0$ .72

Tabela 11. Comparação entre as concentrações finais experimentais e calculadas 76 

LISTA DE ABREVIATURAS E SIGLAS

$\begin{array}{ll}\text { ASTM } & \text { American Society for Testing and Materials } \\ \text { CB } & \text { Cimento-Bentonita } \\ \text { DPH-GCL } & \text { Dense Prehydrated Geosynthetic Clay Liners } \\ \text { EESC } & \text { Escola de Engenharia de São Carlos } \\ \text { MEA } & \text { Método de Elementos Analíticos } \\ \text { MEF } & \text { Método dos Elementos Finitos } \\ \text { MDF } & \text { Método das Diferenças Finitas } \\ \text { MSB } & \text { Multiswellable Bentonite } \\ \text { NAPL } & \text { Non-Aqueous Phase Liquids } \\ \text { PVC } & \text { Polyvinyl chloride } \\ \text { RSU } & \text { Resíduos Sólidos Urbanos } \\ \text { SB } & \text { Solo-Bentonita } \\ \text { SC } & \text { Solo-Cimento } \\ \text { SCB } & \text { Solo-Cimento-Bentonita } \\ \text { STD } & \text { Sólidos Totais Dissolvidos } \\ \text { USP } & \text { Universidade de São Paulo }\end{array}$





\section{LISTA DE SÍMBOLOS}
a (solução analítica) Constante
b (solução analítica) Constante
c (solução analítica) Constante
d (solução analítica) Constante
$d_{s}$
Tamanho médio das partículas de solo
$\mathrm{E}$
Eficiência da barreira vertical
g
Aceleração da gravidade
h
Espessura saturada do aquífero
$\mathrm{p}$
Pressão
$q$
Descarga específica
C
Concentração
$\mathrm{C}_{\mathrm{u}}$
Constante dos aquíferos não confinados
D
Fator de redução do fluxo
$D_{d}$
Coeficiente de difusão molecular
$F Q_{x 0}$
Vetor descarga na área encapsulada
$\mathrm{K}$
Condutividade hidráulica
$\mathrm{K}_{1}$
Condutividade hidráulica da barreira
$\mathrm{K}_{\mathrm{a}}$
Condutividade hidráulica do aquífero
$\mathrm{K}_{\mathrm{b}}$
Condutividade hidráulica da barreira
$\mathrm{K}_{\mathrm{w}}$
Condutividade hidráulica do aterro de resíduos
$\mathrm{Pe}_{\mathrm{d}}$
Número de Peclet da difusão molecular
Q
Vetor descarga
$Q_{x 0}$
$\mathrm{Q}_{\mathrm{x} \mathrm{w}_{\mathrm{w}}}$
Vetor descarga na direção x no campo distante
Vetor descarga na área contaminada (antes da barreira)
$\mathrm{Q}_{\mathrm{x} 0 \mathrm{w}}$
Vetor descarga na área encapsulada (depois da barreira)
$\mathrm{R}$
Raio
$\mathrm{R}_{1}$
Raio da área encapsulada
$R_{\mathrm{w}}$
Raio do aterro de resíduos
$\mathrm{R}^{2}$ (solução analítica)
Raio ao quadrado
$\mathrm{R}^{2}$
Coeficiente de determinação
S01
Ponto de monitoramento da condutividade elétrica 1 
Ponto de monitoramento da condutividade elétrica 2 Ponto de monitoramento da condutividade elétrica 3 Ponto de monitoramento da condutividade elétrica 4 Ponto de monitoramento da condutividade elétrica 5 Ponto de monitoramento da condutividade elétrica 6 Ponto de monitoramento da condutividade elétrica 7 Ponto de monitoramento da condutividade elétrica 8 Ponto de monitoramento da condutividade elétrica 9 Ponto de monitoramento da condutividade elétrica 10 Ponto de monitoramento da condutividade elétrica 11 Ponto de monitoramento da condutividade elétrica 12 Ponto de monitoramento da condutividade elétrica 14 Ponto de monitoramento da condutividade elétrica 15 Velocidade média Cota em relação ao nível de referência Coeficiente de dispersividade longitudinal Coeficiente de dispersividade transversal horizontal Densidade Carga hidráulica Carga hidráulica ao longo do eixo y Potencial de descarga Função de corrente Potencial complexo 


\section{SUMÁRIO}

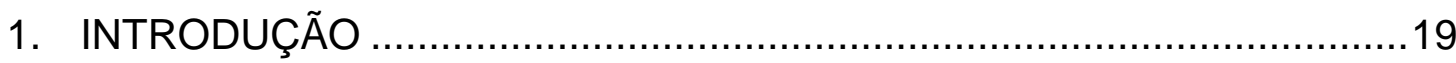

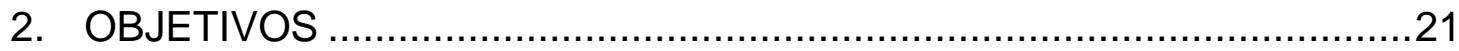

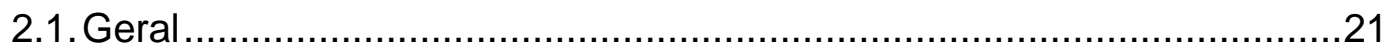

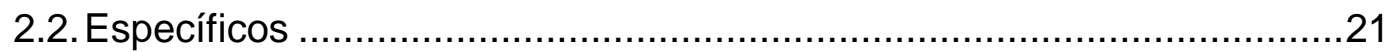

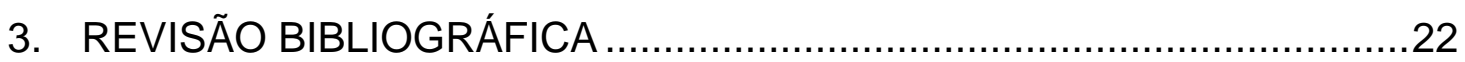

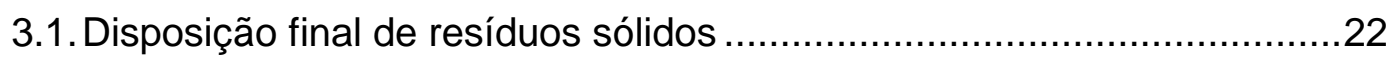

3.2. Contaminação das águas subterrâneas................................................24

3.3. Barreiras verticais de baixa permeabilidade ……................................26

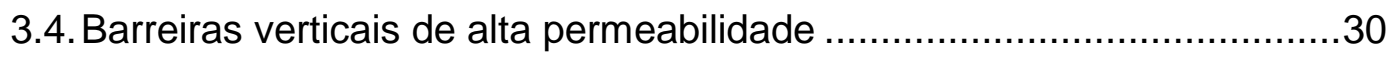

3.5. Solução analítica das barreiras verticais cilíndricas ...............................32

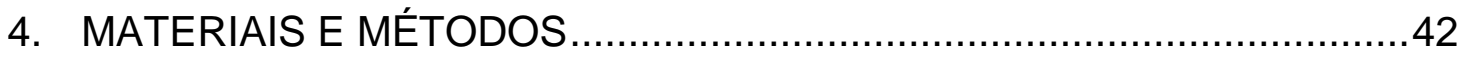

4.1. Solução analítica das barreiras verticais cilíndricas ..............................42

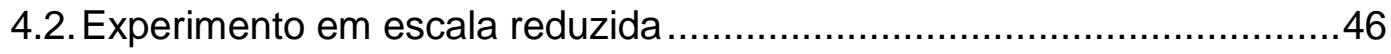

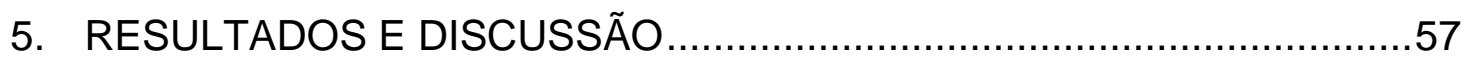

5.1. Aplicações da solução analítica das barreiras verticais cilíndricas...........57

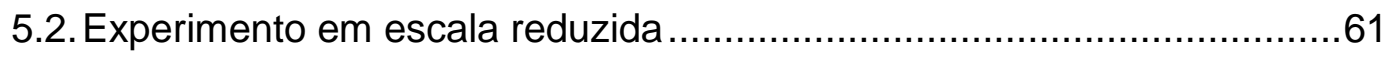

6. CONCLUSÕES E RECOMENDAÇÕES...............................................77

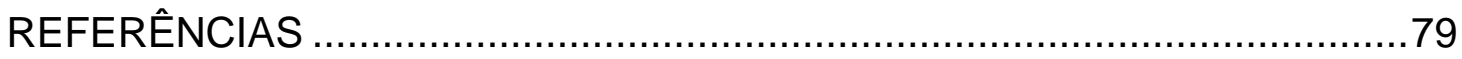

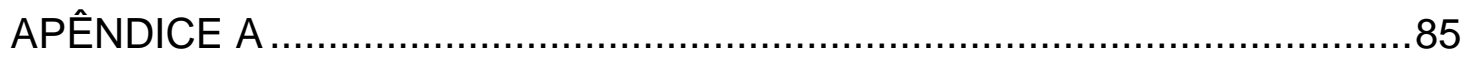

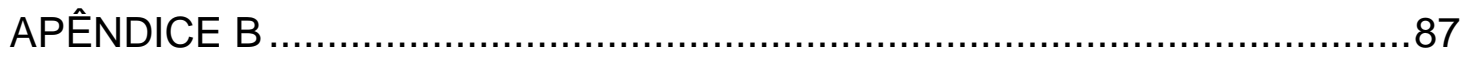

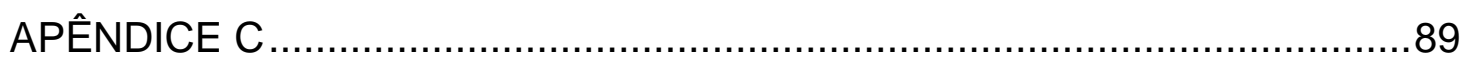

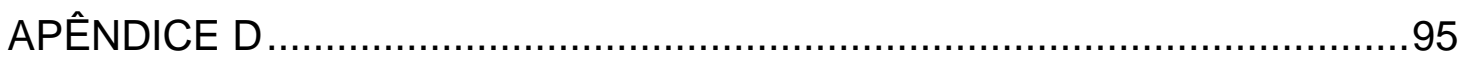





\section{INTRODUÇÃO}

Nos aterros controlados e lixões, os resíduos podem produzir um líquido contaminante denominado chorume, que resulta da percolação da água da chuva na área de disposição inadequada. Segundo Manoel Filho (2008), além de conter uma grande quantidade de sólidos totais dissolvidos (STD), o chorume também pode apresentar muitos contaminantes inorgânicos e orgânicos. Quando esse líquido entra em contato com o solo abaixo do depósito ele pode escoar verticalmente, atingindo a superfície livre do aquífero e contaminando as águas subterrâneas.

Nos casos de contaminação de aquíferos devido à disposição incorreta de resíduos sólidos, uma das alternativas para reduzir a taxa de migração dos poluentes é a construção de uma barreira vertical de baixa permeabilidade (slurry wall) ao redor da área contaminada. Esse tipo de barreira desvia o escoamento para o entorno da estrutura, encapsulando a região do depósito e impedindo que o fluxo do aquífero penetre na área contaminada. A desvantagem dessa técnica é que as barreiras podem ter seu desempenho afetado devido ao aumento da condutividade hidráulica dos materiais de preenchimento, o que pode levar a uma intensificação do fluxo de água subterrânea através da área contaminada. Falhas no momento da construção, ciclos de umedecimento e secagem e, principalmente, os ataques químicos resultam em um aumento da permeabilidade da barreira. Devido aos ambientes agressivos nos quais essas estruturas são inseridas, podem ocorrer incompatibilidades químicas entre os materiais de preenchimento e os contaminantes presentes no lixiviado.

Outra técnica que pode reduzir o fluxo de água subterrânea dentro de áreas contaminadas a um nível aceitável é a barreira vertical de alta permeabilidade. Essa alternativa consiste na construção de uma barreira preenchida com um material de condutividade hidráulica muito maior do que a do ambiente. Diferentemente das barreiras de baixa permeabilidade, a barreira de alta permeabilidade conduz o fluxo por dentro da sua estrutura, direcionando as linhas de fluxo. A vantagem dessa técnica é que obstruções na barreira de alta permeabilidade dificilmente afetarão a habilidade da estrutura em conduzir o fluxo subterrâneo pelo seu interior, enquanto aberturas nas slurry walls são muito mais propensas a permitir que a água escoe para a região encapsulada (STRACK, 2017).

Como a contaminação das águas subterrâneas é ainda mais grave nos casos em que os resíduos sólidos são dispostos abaixo do nível d'água, um dos objetivos 
deste trabalho é ampliar a solução analítica publicada por Strack (2017) para os casos em que o aquífero e a área encapsulada possuem condutividades hidráulicas diferentes. Além disso, pretende-se investigar o escoamento através desse tipo de estrutura e verificar a eficiência da barreira de alta permeabilidade a partir da construção de um experimento em escala reduzida. $O$ tema desta pesquisa tem grande importância no contexto atual, visto que se comprovada a eficiência da barreira vertical de alta permeabilidade, a aplicação dessa técnica in situ representa uma alternativa para reduzir a contaminação das águas subterrâneas em países onde ainda ocorre a disposição inadequada de resíduos sólidos. 


\section{OBJETIVOS}

\subsection{Geral}

Verificar a eficiência da barreira de alta permeabilidade como técnica de encapsulamento de áreas contaminadas em aquíferos a partir de um estudo teórico e experimental.

\subsection{Específicos}

- Desenvolver a solução analítica para o caso em que uma barreira vertical cilíndrica é instalada no entorno de um depósito de resíduos sólidos localizado abaixo do nível d'água em um campo de fluxo uniforme;

- Construir um experimento em escala reduzida para investigar o escoamento através desse tipo de estrutura e verificar a eficiência da barreira como técnica de encapsulamento. 


\section{REVISÃO BIBLIOGRÁFICA}

\subsection{Disposição final de resíduos sólidos}

A Lei ํo 12.305 de 2010 define os resíduos sólidos como materiais, substâncias, objetos ou bens descartados, nos estados sólido ou semissólido, assim como gases contidos em recipientes e líquidos cujas características tornem inviável o seu lançamento na rede pública de esgotos ou em corpos d'água. A NBR 10.004:2004 (Resíduos sólidos - Classificação) divide os resíduos em duas classes: classe I Perigosos e classe II - Não perigosos. Os resíduos perigosos são aqueles que apresentam periculosidade, ou seja, oferecem risco à saúde pública ou ao meio ambiente. Os resíduos não perigosos são divididos em duas classes: classe II A - Não inertes e classe II B - Inertes. Os resíduos não inertes apresentam características como biodegradabilidade, combustibilidade ou solubilidade em água. Os resíduos inertes são aqueles que submetidos ao teste de solubilização, não apresentam seus constituintes solubilizados a concentrações mais elevadas do que os padrões de potabilidade da água (ABNT, 2004).

Devido ao contínuo crescimento da população mundial, da economia e da industrialização, a produção de Resíduos Sólidos Urbanos (RSU) tem aumentado com o passar dos anos. No século passado, a geração de resíduos aumentou dez vezes (HOORNWEG; BHADA-TATA; KENNEDY, 2013) e espera-se que os níveis de produção de resíduos dupliquem até 2025 (HOORNWEG; BHADA-TATA, 2012). Nos Estados Unidos, os dados de 1960 a 2014 também mostram um aumento na produção de resíduos ao longo dos anos, atingindo um total de 234,5 milhões de toneladas em 2014 ou 2 kg/habitante/dia (EPA, 2016). Em 2014, os resíduos gerados na União Europeia totalizaram 2.503 milhões de toneladas, que é o maior número registrado no período de 2004 a 2014 (EUROPEAN COMMISSION, 2017). No Brasil, a geração de RSU em 2016 totalizou aproximadamente 78,3 milhões de toneladas, o que corresponde a $1 \mathrm{~kg} / \mathrm{habitante} / \mathrm{dia}$ (ABRELPE, 2017).

A preocupação em relação à geração de RSU é o método de disposição final adotado. O destino mais comum para a disposição de resíduos sólidos é o aterro, que além de representar uma alternativa de baixo custo é também uma técnica adequada para vários tipos de resíduos (WILLIAMS, 2005). O aterro sanitário é uma das técnicas de disposição final ambientalmente adequada dos resíduos da classe II A (não perigosos e não inertes), em particular os RSU, onde os resíduos são biodegradados 
em condições de anaerobiose (SOUTO; POVINELLI, 2013). De acordo com Bidone e Povinelli (1999), este procedimento de disposição final dos resíduos no solo, se executado de acordo com as normas operacionais, possibilita o confinamento seguro dos resíduos, resultando em uma alternativa viável e de simples execução para países em desenvolvimento, como o Brasil. Segundo os autores, dentre os critérios de construção de um aterro sanitário destacam-se a colocação de sistemas de drenagem e tratamento de gases e lixiviados, dispositivos de drenagem periférica e superficial para as águas de chuva, canalização de nascentes e córregos presentes no local, recobrimento diário dos resíduos após sua compactação, selamento e impermeabilização das células do aterro quanto estas atingem a altura útil e urbanização final da área. No entanto, muitos aterros não são projetados, monitorados e encerrados adequadamente. Além disso, diversas áreas de disposição final foram construídas antes do desenvolvimento de regulamentos para aterros de resíduos sólidos e, por esse motivo, os aspectos ambientais não foram levados em consideração.

Técnicas ambientalmente inadequadas de disposição final dos resíduos sólidos ainda são adotadas em países subdesenvolvidos e em desenvolvimento, resultando em uma fonte de poluição em potencial para os recursos hídricos. No Brasil, 41,6\% dos RSU coletados em 2016 foram destinados aos aterros controlados e lixões, os quais não contam com as medidas necessárias contra a degradação do meio ambiente (ABRELPE, 2017). No aterro controlado, os resíduos geralmente são recobertos diariamente, porém não há camada impermeabilizante no fundo e nem dispositivos para coleta do chorume (PEJON; RODRIGUES; ZUQUETTE, 2013). Já nos lixões, os resíduos sólidos são depositados sobre o solo a céu aberto, sem controle sobre o tipo de resíduo encaminhado para o local e sem qualquer proteção ao meio ambiente ou à saúde pública (BIDONE; POVINELLI, 1999). Tais práticas inadequadas de disposição final dos RSU ocorrem em todas as regiões e estados brasileiros, em um total de 3.331 municípios (ABRELPE, 2017). A Tabela 1 apresenta a quantidade de municípios de cada região brasileira por tipo de disposição final adotada. 
Tabela 1. Disposição final adotada nos municípios brasileiros

\begin{tabular}{lcccccccc}
\hline \multirow{2}{*}{$\begin{array}{c}\text { Disposição } \\
\text { Final }\end{array}$} & Norte & Nordeste & Centro-Oeste & Sudeste & Sul & Brasil & Brasil \\
\cline { 2 - 7 } & 2016-Regiões e Brasil \\
\hline Aterro Sanitário & 92 & 458 & 161 & 822 & 706 & 2239 & 2244 \\
\hline $\begin{array}{l}\text { Aterro } \\
\text { Controlado }\end{array}$ & 112 & 500 & 148 & 644 & 368 & 1772 & 1774 \\
\hline Lixão & 246 & 836 & 158 & 202 & 117 & 1559 & 1552 \\
\hline TOTAL & 450 & 1794 & 467 & 1668 & 1191 & 5570 & 5570 \\
\hline
\end{tabular}

Fonte: adaptado de Abrelpe (2017).

\subsection{Contaminação das águas subterrâneas}

A quantidade de lixões e aterros controlados no Brasil é preocupante, pois muitos deles são simplesmente abandonados após o encerramento. Em seu trabalho, Shinzato (2014) afirma que devido à falta de planos de recuperação, as unidades de disposição final desativadas se transformam em fontes potencialmente poluidoras. De acordo com a autora, o encerramento impróprio permite a contínua produção e lançamento de lixiviado, o qual pode contaminar tanto o solo quanto as águas superficiais e subterrâneas.

Fetter (1994) relata que nos locais de disposição final, a água da chuva que infiltra no maciço de resíduos pode se misturar com os líquidos já presentes no local e dissolver os constituintes dos resíduos sólidos, dando origem ao chorume. Segundo o autor, o chorume pode escoar verticalmente através da camada de solo não saturada e atingir a superfície livre do aquífero, contaminando as águas subterrâneas e formando uma pluma de contaminação na direção do escoamento (Figura 1 - A). É preferível que o depósito seja construído acima do nível de água, pois é possível que ocorra uma atenuação natural do lixiviado quanto este percolar pela zona não saturada. A auto eliminação dos contaminantes durante o transporte pela zona vadosa é resultado da degradação bioquímica e de reações químicas, porém o retardamento dos contaminantes devido aos fenômenos de sorção também é importante, pois aumenta o tempo disponível para os processos (FOSTER et al., 2002). Nos casos em que a disposição final é feita abaixo do nível freático (Figura 1 - B) a contaminação é ainda mais grave, pois a lixiviação ocorre devido à passagem da água subterrânea através do corpo de resíduos (FETTER, 1994). 
Figura 1. Pluma de contaminação em aquífero livre originada por chorume
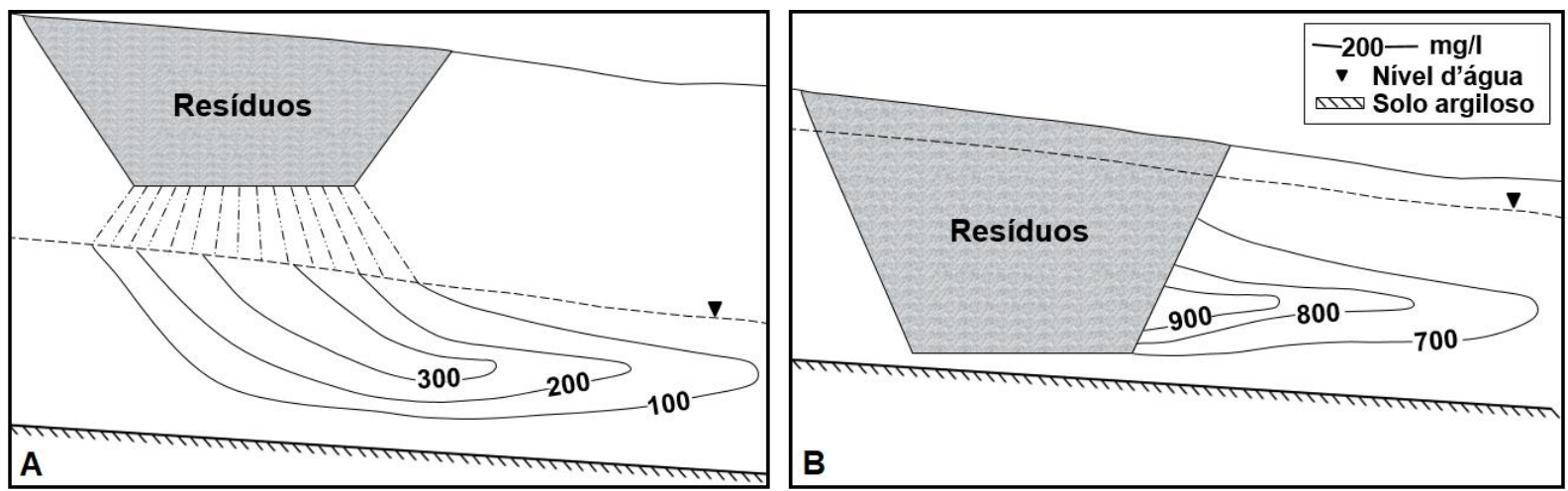

Fonte: Autor.

A preocupação em relação às plumas de contaminação teve início em 1977, quando a Cidade de Niagara Falls e o Estado de Nova York começaram a investigar a migração de lixiviado no aquífero raso localizado na área do Love Canal (MCDOUGALL et al., 1980). De acordo com Hauser e Bromberg (1980), a escavação do canal, que começou em 1894, foi interrompida e o antecessor da Hooker Chemical and Plastics Corporation comprou a região e utilizou-a como aterro de resíduos químicos de 1942 até 1953. Segundo os autores, anos após o encerramento do depósito, as fortes nevascas de inverno, descongelamentos durante a primavera e intensas precipitações levaram os moradores da região a se queixar de diversos problemas, como odores químicos e resíduos oleosos acumulados em alguns porões. Então, em 1978 foi declarada emergência de saúde no Love Canal (DEEGAN, 1987). Após esse desastre, problemas relacionados à contaminação das águas subterrâneas ocorreram em diversos lugares e, consequentemente, os interesses e as percepções públicas mudaram drasticamente (HADLEY; NEWELL, 2012). Como incidentes em aquíferos devido à disposição inadequada dos resíduos sólidos são frequentemente relatados, a contaminação das águas subterrâneas pelo lixiviado tem sido um assunto muito explorado na literatura (KIMMEL; BRAIDS, 1974; REINHARD; BARKER; GOODMAN, 1984; ALBAIGES; CASADO; VENTURA, 1986; ARNETH et al., 1989; HAITJEMA, 1992; LOIZIDOU; KAPETANIOS, 1993; CHRISTENSEN et al., 1994; FATTA; PAPADOPOULOS; LOIZIDOU, 1999; COELHO et al., 2002; OLIVEIRA; PASQUAL, 2004; ROCHA; HORBE, 2006; PIAl et al., 2006; MOR et al., 2006; BESERRA et al., 2007; SINGH et al., 2008; COZZARELLI et al., 2011; GAUTAM; PATHAK; SAHNI, 2011; MATHIAZHAGAN; SELVAKUMAR; GANESAN, 2012, ELSALAM; ABU-ZUID, 2015; HAN et al., 2016; SAMADDER et al., 2017). 
No Brasil, Shinzato e Wendland (2012) avaliaram a composição físico-química de um perfil do lixão da Fazenda Madalena desativado em São Carlos - SP, localizado em uma área de afloramento do Sistema Aquífero Guarani. As análises executadas pelos autores mostram que mesmo após 16 anos da desativação, quando o depósito deveria apresentar baixas concentrações de poluentes, o lixão ainda é uma fonte potencialmente poluidora às águas subterrâneas, pois o chorume armazenado no interior do depósito ainda possui quantidades significativas de contaminantes, os quais podem ser mobilizados devido aos eventos de precipitação, estiagem e variações de temperatura. A partir da instalação de um poço com lisímetros dentro do lixão supracitado, Shinzato (2014) concluiu que o contínuo lançamento de lixiviado polui diretamente o solo abaixo do maciço de resíduos e, além disso, o efluente deveria ser tratado previamente ao lançamento no meio ambiente, pois apresenta concentrações de substâncias superiores às permitidas pelo Decreto Estadual ํo 8.468. Em relação ao monitoramento de poços distribuídos na área do depósito, a pesquisadora constatou que a qualidade das águas subterrâneas da região tem sofrido alterações com o passar do tempo. A autora relata que o aquífero abaixo do depósito de resíduos está contaminado por poluentes oriundos dos efluentes do lixão e parte desta poluição é atenuada a medida que a pluma se afasta do maciço. Além de Shinzato (2014), outros pesquisadores também estudaram os impactos do lixão da Fazenda Madalena na qualidade das águas subterrâneas da região (ELLERT et al., 1990; GONÇALVES; BOSSOLAN; ORLANDO, 1992; MENEZES, 1994; FREITAS, 1996; GADOTTI, 1997; ÁLVARES, 2000; VELOZO, 2006; LOPES, 2007).

\subsection{Barreiras verticais de baixa permeabilidade}

As barreiras verticais de baixa permeabilidade são utilizadas como técnica de encapsulamento para impedir o fluxo lateral de água subterrânea para dentro de áreas contaminadas. Sua função é redirecionar o escoamento para longe ou em torno do depósito (Figura 2), diminuindo a taxa de migração dos contaminantes. As barreiras são tipicamente circunferenciais, já que na maioria das vezes são construídas ao redor do aterro de resíduos, possuem larguras entre 0,60 e 1,50 m e devem ser fixadas em uma camada de solo argiloso ou base rochosa de baixa condutividade hidráulica (EVANS, 1993; MULLIGAN; YONG; GIBBS, 2001), como mostra o corte da Figura 2. As barreiras de baixa permeabilidade do tipo slurry wall, compostas de misturas de solo-bentonita (SB), solo-cimento (SC), cimento-bentonita (CB) ou solo-cimento- 
bentonita (SCB), têm sido empregadas por muitos anos em obras geotécnicas (THOMAS; KOERNER, 1996). Barreiras de geomembrana ou grouteadas e as paredes-cortina de perfis metálicos também são utilizadas, porém as slurry walls são mais comuns devido ao custo inferior (MULLIGAN; YONG; GIBBS, 2001).

Figura 2. Barreira de baixa permeabilidade - Vista em planta e corte
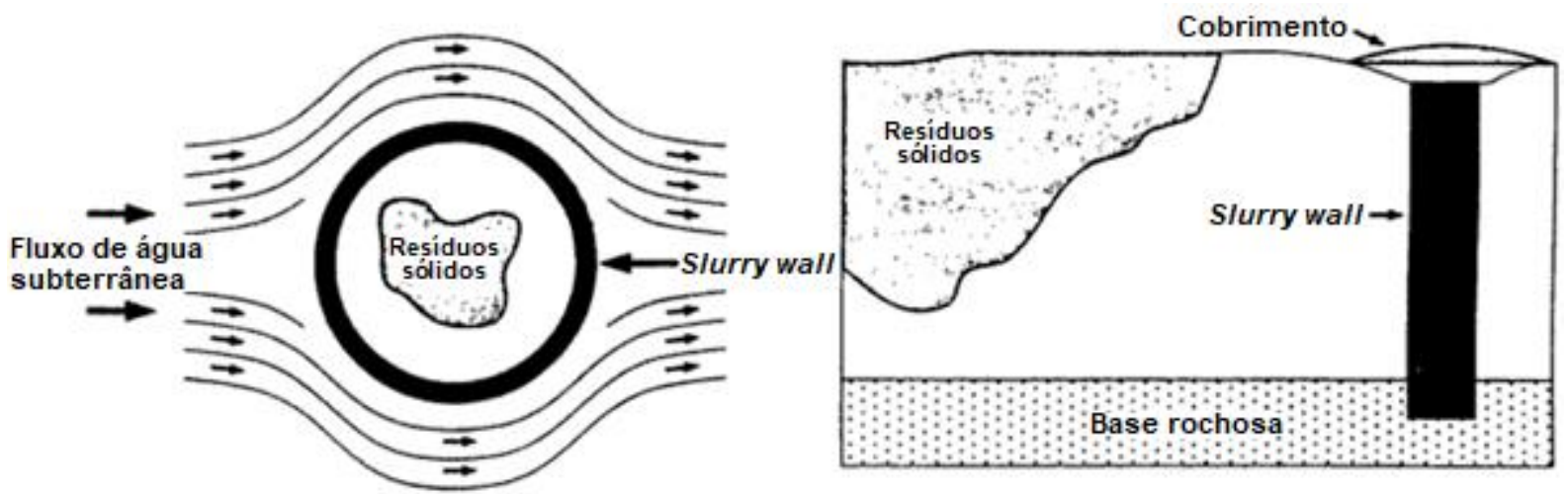

Fonte: Adaptado de Freeman e Harris (1995).

Embora as barreiras de solo-bentonita apresentem condutividades hidráulicas menores ou iguais a $10^{-9} \mathrm{~m} / \mathrm{s}$ (MALUSIS; MCKEEHAN, 2013), a durabilidade e o desempenho em longo prazo dessas estruturas podem ser afetados devido ao ambiente agressivo em que estão inseridas. Gleason, Daniel e Eykholt (1997) citam que as barreiras constituídas de bentonita possuem condutividade hidráulica muito baixa quando o fluido utilizado é a água; porém, quando o líquido em questão está contaminado, as barreiras podem apresentar condutividades hidráulicas bem diferentes. Isso ocorre devido à incompatibilidade química entre os materiais de preenchimento da barreira e o lixiviado, que pode conter substâncias que interagem com as partículas de solo, resultando em um aumento da condutividade hidráulica da barreira e afetando negativamente seu desempenho como método de encapsulamento. De acordo com Evans (1993), a incompatibilidade química pode ser global, devido aos contaminantes dissolvidos na água subterrânea que levam ao aumento da condutividade hidráulica da estrutura, ou local, devido aos orgânicos concentrados (NAPLs) que boiam ou afundam dentro depósito, podendo atacar certas áreas da barreira.

Segundo Sharma e Lewis (1994), o aumento da permeabilidade do preenchimento de solo-bentonita devido à infiltração do lixiviado ou da água poluída pode ser atribuído a dois mecanismos diferentes: I) o líquido infiltrado pode dissolver os minerais do solo, aumentando o volume de poros; II) a substituição do fluido presente nos poros pelo lixiviado pode diminuir a espessura da dupla camada difusa. 
A Tabela 2 apresenta os efeitos de diversos poluentes na permeabilidade dos preenchimentos de solo-bentonita.

Tabela 2. Efeitos na permeabilidade de barreiras de SB devido à lixiviação de diversos poluentes

\begin{tabular}{cc}
\hline Solução & $\begin{array}{c}\text { Preenchimento de SB } \\
\text { (Areia siltosa ou argilosa) } \\
\mathbf{3 0} \text { a 40\% de finos }\end{array}$ \\
\hline $\mathrm{Ca}^{2+} \mathrm{ou} \mathrm{Mg}^{2+}$ a 1.000 ppm & $\mathrm{N}$ \\
\hline $\mathrm{Ca}^{2+} \mathrm{ou} \mathrm{Mg}^{2+}$ a $10.000 \mathrm{ppm}$ & $\mathrm{M}$ \\
\hline $\mathrm{NH}_{4} \mathrm{NO}_{3}$ a $10.000 \mathrm{ppm}$ & $\mathrm{M}$ \\
\hline $\mathrm{HCl}(1 \%)$ & $\mathrm{N}$ \\
\hline $\mathrm{H}_{2} \mathrm{SO}_{4}(1 \%)$ & $\mathrm{N}$ \\
\hline $\mathrm{HCl}(5 \%)$ & $\mathrm{M} / \mathrm{H}^{\mathrm{b}}$ \\
\hline $\mathrm{NaOH}(1 \%)$ & $\mathrm{M}$ \\
\hline $\mathrm{CaOH}(1 \%)$ & $\mathrm{M}$ \\
\hline $\mathrm{NaOH}(5 \%)$ & $\mathrm{M} / \mathrm{H}^{\mathrm{b}}$ \\
\hline Água do mar & $\mathrm{N} / \mathrm{M}$ \\
\hline Salmoura (Gravidade específica= 1,2) & $\mathrm{M}$ \\
\hline Drenagem ácida de mina $\left(\mathrm{FeSO}_{4} ; \mathrm{pH} \sim 3\right)$ & $\mathrm{N}$ \\
\hline Lignina (em solução de $\mathrm{Ca}^{2+}$ ) & $\mathrm{N}$ \\
\hline Álcool & $\mathrm{M} / \mathrm{H}$
\end{tabular}

$\mathrm{N}$ : sem efeito significativo, a permeabilidade aumenta cerca de duas vezes ou menos;

M: efeito moderado, a permeabilidade aumenta cerca de duas a cinco vezes;

$\mathrm{H}$ : a permeabilidade aumenta cerca de cinco a dez vezes;

b: dissolução significante.

Fonte: adaptado de D'Appolonia (1980).

Como interações entre certos líquidos e solos argilosos têm resultado em aumentos significativos na condutividade hidráulica das slurry walls, o grau de incompatibilidade química entre a barreira e o lixiviado é um fator determinante na escolha do material de preenchimento. Em 2004 foi publicada a norma ASTM D7100 (última revisão em 2011) intitulada "Standard Test Method for Hydraulic Conductivity Compatibility Testing of Soils with Aqueous Solutions", que estabelece as diretrizes para avaliação da presença de potenciais interações entre a amostra de solo e a solução aquosa e seus efeitos na condutividade hidráulica da amostra. Como pode ser observado na Tabela 3 , os efeitos dos ataques químicos na condutividade hidráulica das barreiras verticais têm sido amplamente investigados na literatura. 
Tabela 3. Estudos sobre os efeitos da incompatibilidade química entre os solos argilosos e diferentes fluidos na condutividade hidráulica de barreiras de baixa permeabilidade

\begin{tabular}{|c|c|}
\hline $\begin{array}{c}\text { Fernandez e } \\
\text { Quigley } \\
\text { (1985) }\end{array}$ & $\begin{array}{l}\text { Estudaram a influência de hidrocarbonetos líquidos em um solo argiloso } \\
\text { proveniente de Sarnia, Ontario. Testes nos solos naturais misturados com } \\
\text { líquidos puros, com taxa de vazios de } 0,8 \text {, resultaram em condutividades } \\
\text { hidráulicas aumentando de } 5 \times 10^{-9} \text { a } 1 \times 10^{-4} \mathrm{~cm} / \mathrm{s} \text { com a redução da } \\
\text { constante dielétrica do fluido de } 80 \text { a } 2 \text {. Os testes em amostras compactadas } \\
\text { e umidificadas com água ( } \mathrm{k} \approx 10^{-8} \mathrm{~cm} / \mathrm{s} \text { ) não apresentaram mudanças na } \\
\text { condutividade hidráulica quando em contato com hidrocarbonetos de baixa } \\
\text { constante dielétrica e insolúveis em água. A infiltração com álcoois solúveis } \\
\text { em água resultou em uma remoção considerável da água dos poros e } \\
\text { aumentou em até } 10 \text { vezes a condutividade hidráulica. A posterior infiltração } \\
\text { com aromáticos líquidos de constante dielétrica muito baixa resultou em um } \\
\text { aumento de } 1000 \text { vezes na condutividade hidráulica com apenas } 30 \% \text { dos } \\
\text { espaços vazios ocupados pelos aromáticos. }\end{array}$ \\
\hline $\begin{array}{l}\text { Evans, Fang e } \\
\text { Kugelman } \\
\quad(1985)\end{array}$ & $\begin{array}{l}\text { Conduziram ensaios de laboratório para investigar a permeabilidade em } \\
\text { longo prazo do preenchimento de solo-bentonita, utilizando quatro fluidos } \\
\text { orgânicos diferentes como exemplos de resíduos perigosos. Os resultados } \\
\text { indicaram que os fluidos orgânicos concentrados aumentaram a } \\
\text { permeabilidade em pelo menos uma ordem de magnitude. Porém, soluções } \\
\text { diluídas apresentaram efeitos negativos significantemente menores na } \\
\text { permeabilidade do preenchimento de SB. }\end{array}$ \\
\hline $\begin{array}{l}\text { Madsen e } \\
\text { Mitchell } \\
(1989)\end{array}$ & $\begin{array}{l}\text { Sintetizaram as informações disponíveis a respeito das substâncias } \\
\text { químicas e da condutividade hidráulica de solos argilosos para serem } \\
\text { utilizadas na avaliação e na previsão do desempenho das barreiras em } \\
\text { aterros de resíduos. Dentre os tópicos abordados, os autores discutiram } \\
\text { sobre os fatores que afetam a condutividade hidráulica, os efeitos de } \\
\text { substâncias químicas inorgânicas e orgânicas na condutividade hidráulica e } \\
\text { as conclusões em relação ao uso de solos argilosos nos depósitos de } \\
\text { resíduos. }\end{array}$ \\
\hline $\begin{array}{c}\text { Shackelford } \\
(1994)\end{array}$ & $\begin{array}{l}\text { Identificou as propriedades dos solos e líquidos que afetam as interações } \\
\text { entre eles, discutiu sobre a influência dos métodos e procedimentos } \\
\text { utilizados para avaliar o efeito das interações resíduos-solo na condutividade } \\
\text { hidráulica e apresentou resultados de estudos indicando a influência de } \\
\text { diversas interações resíduos-solo na alteração da condutividade hidráulica. }\end{array}$ \\
\hline $\begin{array}{l}\text { Gleason, } \\
\text { Daniel e } \\
\text { Eykholt (1997) }\end{array}$ & $\begin{array}{l}\text { Estudaram o uso da bentonita de cálcio em contenções hidráulicas no meio } \\
\text { ambiente para investigar se ela seria mais hidraulicamente estável do que a } \\
\text { bentonita de sódio quando exposta às substancias químicas. }\end{array}$ \\
\hline $\begin{array}{c}\text { Garvin e } \\
\text { Hayles (1999) }\end{array}$ & $\begin{array}{l}\text { Realizaram experimentos em laboratório com o intuito de investigar as } \\
\text { propriedades das barreiras de CB e analisar os problemas de durabilidade } \\
\text { desse tipo de estrutura. Os pesquisadores conduziram testes para avaliar a } \\
\text { resistência química das misturas de CB expostas às diferentes soluções de } \\
\text { contaminantes. Dentre as conclusões, os autores citaram que as barreiras } \\
\text { podem sofrer ataques químicos, porém o grau de degradação das amostras } \\
\text { variou com as proporções da mistura, o tipo de cimento e a natureza e } \\
\text { concentração dos contaminantes. Além disso, eles constataram que o modo } \\
\text { de ataque foi diferente para cada contaminante. As soluções mais ácidas } \\
\text { descoloriram e amoleceram a mistura de CB devido à lixiviação dos produtos } \\
\text { de hidratação, enquanto as soluções de sulfato causaram expansão e } \\
\text { desintegração das amostras. O melhor desempenho das misturas foi na } \\
\text { solução de fenol, um ácido orgânico fraco, no qual as amostras } \\
\text { apresentaram sinais desprezíveis de ataque químico. }\end{array}$ \\
\hline
\end{tabular}




\begin{tabular}{|c|c|}
\hline $\begin{array}{l}\text { Katsumi et al. } \\
\qquad(2008)\end{array}$ & $\begin{array}{l}\text { Analisaram a condutividade hidráulica em longo prazo de duas bentonitas } \\
\text { modificadas (MSB e DPH-GCL) em contato com soluções químicas } \\
\text { eletrolíticas. Os autores discutiram as compatibilidades químicas do material } \\
\text { com o objetivo de investigar sua aplicabilidade em barreiras de aterros de } \\
\text { resíduos. }\end{array}$ \\
\hline $\begin{array}{c}\text { Malusis e } \\
\text { McKeehan } \\
(2013)\end{array}$ & $\begin{array}{l}\text { Avaliaram a compatibilidade química do preenchimentos de SB contendo } \\
\text { uma bentonita modificada, conhecida como multiswellable (MSB), e } \\
\text { compararam com preenchimentos similares contendo bentonita de sódio ou } \\
\text { bentonita resistente aos contaminantes (SW101). }\end{array}$ \\
\hline $\begin{array}{l}\text { Du et al. } \\
\text { (2015) }\end{array}$ & $\begin{array}{l}\text { Avaliaram os impactos da contaminação por chumbo nas barreiras de argila } \\
\text { e bentonita cálcica. Os experimentos conduzidos pelos pesquisadores } \\
\text { mostraram que a condutividade hidráulica dos materiais de preenchimento } \\
\text { foi afetada significativamente pelos níveis de concentração de chumbo. } \\
\text { Quando comparadas com as misturas de argila e bentonita limpas, as } \\
\text { amostras contaminadas apresentaram um aumento na condutividade } \\
\text { hidráulica de até } 50 \text { vezes. A condutividade hidráulica das amostras limpas } \\
\text { e das contaminadas a baixas concentrações de chumbo ( } 60 \mathrm{mmol} / \mathrm{L}) \text { foi } \\
\text { geralmente menor do que o limite típico de } 10^{-9} \mathrm{~m} / \mathrm{s} \text {, porém a condutividade } \\
\text { hidráulica excedeu o limite quando a concentração de chumbo era maior do } \\
\text { que } 120 \mathrm{mmol} / \mathrm{L} \text {. }\end{array}$ \\
\hline
\end{tabular}

Além dos ataques químicos, outros mecanismos de falha também podem afetar a condutividade hidráulica das slurry walls, tais como heterogeneidades devido à mistura inadequada do preenchimento, ciclos de congelamento e descongelamento, ciclos de umedecimento e secagem, desenvolvimento de camadas de gelo dentro da barreira e dissecação (EVANS, 1993).

Como citado anteriormente, nos casos de contenção de contaminantes as barreiras metálicas e de concreto não são muito utilizadas, visto que o alto custo desses materiais muitas vezes tornam essas técnicas economicamente inviáveis. Além disso, nesses métodos o desempenho da barreira também pode ser afetado devido ao aumento da condutividade hidráulica. As barreiras de concreto de cimento Portland podem sofrer corrosão da armadura, desenvolvimento de rachaduras e incompatibilidade química entre o concreto e as substâncias presentes no lixiviado e (NATIONAL RESEARCH COUNCIL, 2007). No caso das paredes-cortina de perfis metálicos, os principais mecanismos de falha são a corrosão e os vazamentos nas ligações entre as placas, os quais são geralmente mais elevados do que os valores permitidos (EVANS, 1993).

\subsection{Barreiras verticais de alta permeabilidade}

A barreira de alta permeabilidade, também chamada de hydraulic cage, é uma alternativa menos comum para reduzir o fluxo lateral de água subterrânea dentro de áreas contaminadas. Umeki (2007) cita o uso dessa técnica em repositórios finais de 
resíduos radioativos. Segundo o autor, embora pareça contra intuitivo, a estrutura de elevada permeabilidade desvia o fluxo ao redor do repositório de maneira análoga à superfície de alta condutividade elétrica da Gaiola de Faraday para radiação eletromagnética. Noyes (1995) também menciona o uso da barreira de alta permeabilidade em áreas de disposição de resíduos nucleares. De acordo com o pesquisador, a barreira é construída a partir da perfuração de uma série de furos em torno da região de interesse, aumentando a condutividade hidráulica da rocha existente entre eles. Noyes (1995) afirma que se construída adequadamente e em condições apropriadas, a hydraulic cage pode minimizar o gradiente hidráulico através de uma região e conter efetivamente o transporte advectivo dos contaminantes aquosos. Porém, o autor cita que o encapsulamento completo é difícil de ser alcançado e a estrutura pode vir a sofrer obstruções com o passar do tempo. Embora a hydraulic cage seja citada na literatura como técnica de contenção de contaminantes em repositórios de resíduos radioativos, são encontrados poucos trabalhos a respeito de sua aplicação (REINIUS, 1980; HAVERKAMP; BIURRUN, 2006).

O conceito de barreiras de alta permeabilidade também tem sido empregado em aterros de resíduos sólidos. Trincheiras preenchidas com cascalho em conjunto com um sistema localizado na parte inferior para coleta e remoção do lixiviado podem reduzir o fluxo lateral advectivo e difusivo dos contaminantes e, ainda, facilitar a remoção e o tratamento ou disposição final do chorume (NATIONAL RESEARCH COUNCIL, 2007). Em seu trabalho, Mitchell e Mitchell (2004) citam o caso do aterro Hardage, localizado em Criner, Oklahoma, que durante oito anos (1972 - 1980) foi a única área permitida no estado para disposição final de resíduos industriais. Depois de conduzir investigações na região, a Agência de Proteção Ambiental dos Estados Unidos informou que diversas indústrias que descartaram seus resíduos no aterro seriam responsáveis pela limpeza da área. A técnica de remediação adotada incluiu a cobertura da região do aterro e a construção de uma trincheira preenchida com cascalho. A estrutura possui dimensões de $820 \mathrm{~m}$ de comprimento, $20 \mathrm{~m}$ de profundidade e 0,9 $\mathrm{m}$ de espessura, e sua parte inferior é inclinada para uma série de reservatórios com bombas para remoção do fluxo interceptado. A técnica de remediação entrou em operação em setembro de 1995 e o relatório de 2002 indicou que cinco anos após a implementação todas as ameaças imediatas haviam sido abordadas. 
Recentemente, Strack (2017) propôs a modelagem analítica de uma barreira hidráulica cilíndrica de alta permeabilidade para contenção de contaminantes em aterros de resíduos. Seu funcionamento é semelhante ao da hydraulic cage, já que a técnica consiste apenas no redirecionamento do fluxo subterrâneo, não sendo necessária a implantação de um sistema de bombas para a coleta do lixiviado. De acordo o autor, a barreira hidráulica consiste na construção de uma estrutura similar à da slurry wall, porém, nesse caso, o material de preenchimento possui uma condutividade hidráulica muito maior do que a condutividade hidráulica do ambiente de instalação. Essa técnica será discutida mais detalhadamente no tópico a seguir, onde será apresentada a solução analítica desenvolvida pelo autor para modelagem do escoamento subterrâneo através de barreiras cilíndricas instaladas em um campo de fluxo uniforme.

A vantagem da barreira de alta permeabilidade é que o seu preenchimento é muito menos sensível às falhas do que os materiais que compõem as slurry walls. Como discutido anteriormente, a maior preocupação em relação às barreiras de baixa permeabilidade é a deterioração do material de preenchimento devido principalmente aos ataques químicos. Os fatores que podem alterar o desempenho das barreiras de alta permeabilidade são obstruções decorrentes da acumulação de sedimentos, crescimento biológico e precipitação mineral. Porém, como citado por Strack (2017), as obstruções na barreira de alta permeabilidade dificilmente afetarão a habilidade da estrutura em conduzir a água subterrânea pelo seu interior, principalmente porque 0 fluxo é tridimensional; já as aberturas na slurry wall são muito mais propensas a permitir que a água subterrânea penetre dentro da área encapsulada, especialmente se essas falhas ocorrerem em lados opostos da estrutura.

\subsection{Solução analítica das barreiras verticais cilíndricas}

\subsubsection{Método de Elementos Analíticos}

Os programas de modelagem do fluxo de água subterrânea mais utilizados são baseados em um dos três métodos: diferenças finitas, elementos finitos ou elementos analíticos. Como citado por Fitts (2002), nenhum desses métodos representa a ferramenta correta para todos os problemas, pois cada um deles possui vantagens e limitações específicas.

No Método de Elementos Analíticos (MEA), os elementos hidrogeológicos (rio, poço, escoamento uniforme) são representados por soluções analíticas individuais da 
equação governante, chamadas de elementos analíticos. Tais soluções contêm coeficientes desconhecidos que devem ser calculados através das condições de contorno. Neste método, as soluções analíticas individuais podem ser combinadas, segundo o princípio da superposição, para compor a solução final do problema (STRACK, 1989).

O Método das Diferenças Finitas (MDF) é o método numérico mais utilizado atualmente para a modelagem de escoamento subterrâneo. Segundo Fitts (2002), no MDF o domínio estudado é discretizado em uma malha de blocos retangulares. Da mesma maneira, no Método dos Elementos Finitos (MEF) o domínio é subdividido em elementos e nós distintos, porém nessa técnica o formato dos elementos é mais flexível (FITTS, 2002). Em casos onde o número de pontos discretizados é muito elevado, o MDF e o MEF exigem um esforço computacional significativo. Como o MEA não requer a discretização do domínio e a malha de elementos e nós não é necessária nesse método, a resolução do modelo não é afetada devido ao tamanho da área estudada (HAITJEMA, 1995). Portanto, o MEA é relativamente insensível à escala.

De acordo com Haitjema (1995), o MDF e o MEF não satisfazem a continuidade do fluxo automaticamente, enquanto no MEA a continuidade do escoamento é garantida, já que as cargas e velocidades do fluxo de água subterrânea são determinadas em qualquer ponto do domínio. Ainda segundo o autor, outra desvantagem dos métodos numéricos tradicionais é que a solução do fluxo de água subterrânea é definida em termos da carga somente nos nós do grid ou nos nós dos elementos, ou seja, em qualquer outro ponto a carga deve ser estimada por interpolação. Assim, como a superfície de carga piezométrica não é contínua, as linhas de fluxo resultantes podem ser imprecisas.

Em seu trabalho, Strack (2003) cita que o Método de Elementos Analíticos, em princípio, pode ser aplicado para representar qualquer campo vetorial bi ou tridimensional. Segundo o autor, esse método pode ser utilizado em domínios finitos e infinitos e é tipicamente aplicado em problemas que possuem condições de contorno internas. A natureza do método, que se baseia na superposição de expressões analíticas, possibilita o trabalho com modelos de grande escala, mantendo um alto grau de precisão na pequena escala (STRACK, 2003). De acordo com a aproximação de Dupuit-Forchheimer, nesse método a resistência ao escoamento na direção vertical é negligenciada (STRACK, 1989). Tal aproximação, quando aplicada em áreas onde a componente vertical é relativamente alta, produz soluções precisas em termos de 
descarga, porém em termos de carga hidráulica as soluções são apenas aproximadas (STRACK, 2003).

Os itens a seguir apresentam tópicos fundamentais do MEA para o desenvolvimento deste trabalho, como as equações governantes do escoamento em meio poroso, as principais definições e a solução analítica da barreira vertical cilíndrica. Todas as expressões e desenvolvimentos matemáticos apresentados são baseados no trabalho de Strack (2017).

\subsubsection{Definições matemáticas}

- Carga hidráulica

A carga hidráulica em um determinado ponto é a soma da carga de pressão com a carga de elevação, como mostra a Equação 1.

$$
\phi=\frac{p}{\rho g}+Z
$$

na qual:

$\phi(\mathrm{m})$ é a carga hidráulica;

$\mathrm{p}\left(\mathrm{N} / \mathrm{m}^{2}\right)$ é a pressão exercida pela coluna d'água acima do ponto;

$\rho\left(\mathrm{kg} / \mathrm{m}^{3}\right)$ é a massa específica do fluido;

$\mathrm{g}\left(\mathrm{m} / \mathrm{s}^{2}\right)$ é a aceleração da gravidade; e

$Z(m)$ é a cota do ponto em relação ao nível de referência.

- Lei de Darcy

A lei de Darcy é uma relação empírica entre a descarga específica, q (m/s), e a carga hidráulica. Essa lei foi primeiramente formulada para o escoamento retilíneo de um fluido homogêneo em meio poroso. A forma geral da lei de Darcy para o escoamento tridimensional em um meio poroso isotrópico é apresentada nas Equações 2, 3 e 4.

$$
\begin{aligned}
& q_{x}=-K \frac{\partial \phi}{\partial x} \\
& q_{y}=-K \frac{\partial \phi}{\partial y} \\
& q_{z}=-K \frac{\partial \phi}{\partial z}
\end{aligned}
$$

nas quais:

$q_{x}, q_{y}$ e $q_{z}(m / s)$ são as três componentes do vetor de descarga específica;

$\mathrm{K}(\mathrm{m} / \mathrm{s})$ é a condutividade hidráulica; $\mathrm{e}$ 
$\frac{\partial \phi}{\partial x}, \frac{\partial \phi}{\partial y} \mathrm{e} \frac{\partial \phi}{\partial z}$ representam as três componentes do gradiente hidráulico.

- Vetor descarga e o potencial de descarga

O vetor descarga, $Q_{i}\left(m^{2} / s\right)$, é igual à integração da descarga específica ao longo da espessura saturada do aquífero, $\mathrm{h}(\mathrm{m})$ :

$$
Q_{i}=\int_{0}^{h} q_{i} d z
$$

De acordo com a aproximação de Dupuit-Forchheimer, a resistência ao fluxo na direção vertical é desconsiderada, portanto $q_{i}$ não varia ao longo da espessura saturada do aquífero. Na superfície freática, a carga hidráulica é igual à espessura saturada. Logo, nos aquíferos não confinados, a relação do vetor descarga com o fluxo específico é expressa pela Equação 6.

$$
\mathrm{Q}_{\mathrm{i}}=\phi \mathrm{q}_{\mathrm{i}}
$$

Com a aplicação da lei de Darcy, as duas componentes do vetor descarga para um fluxo bidimensional são dadas pelas Equações 7 e 8.

$$
\begin{aligned}
& Q_{x}=\phi\left[-K \frac{\partial \phi}{\partial x}\right]=-\frac{\partial}{\partial x}\left[\frac{K \phi^{2}}{2}+C_{u}\right] \\
& Q_{y}=\phi\left[-K \frac{\partial \phi}{\partial y}\right]=-\frac{\partial}{\partial y}\left[\frac{K \phi^{2}}{2}+C_{u}\right]
\end{aligned}
$$

nas quais $C_{u}$ é uma constante. Assim, o potencial de descarga, $\Phi\left(\mathrm{m}^{3} / \mathrm{s}\right)$, para os aquíferos não confinados é definido como:

$$
\Phi=\frac{1}{2} K \phi^{2}+C_{u}
$$

Logo, o vetor descarga pode ser expresso em termos do potencial de descarga:

$$
\begin{aligned}
& Q_{x}=-\frac{\partial \Phi}{\partial x} \\
& Q_{y}=-\frac{\partial \Phi}{\partial y}
\end{aligned}
$$

- Equação da continuidade e a equação de Laplace

O escoamento em aquíferos obedece à equação da continuidade, ou seja, em um bloco de solo saturado não há armazenamento ou produção de água. A partir do equacionamento dos fluxos de entrada e saída do bloco, obtém-se a equação da continuidade:

$$
\frac{\partial q_{x}}{\partial x}+\frac{\partial q_{y}}{\partial y}+\frac{\partial q_{z}}{\partial z}=0
$$


Para satisfazer a condição de continuidade do fluxo, o divergente do vetor descarga deve ser zero. No caso de escoamento livre e sem recarga, a equação da continuidade para a descarga pode ser escrita para o plano $\mathrm{xy}$ :

$$
\frac{\partial Q_{x}}{\partial x}+\frac{\partial Q_{y}}{\partial y}=0
$$

A substituição de $Q_{x}$ e $Q_{y}$ pelas Equações 10 e 11 resulta na equação de Laplace aplicada ao potencial de descarga:

$$
\frac{\partial^{2} \Phi}{\partial x^{2}}+\frac{\partial^{2} \Phi}{\partial y^{2}}=0
$$

A equação de Laplace é a equação diferencial que descreve o fluxo horizontal, confinado e não confinado sem recarga, em duas dimensões no plano x, y. Assim, todas as soluções para tais problemas de escoamento horizontal devem obedecer a essa equação.

- Variáveis complexas

Uma das vantagens de usar as variáveis complexas é que assim as variáveis independentes são reduzidas de duas para uma. Essa formulação, que pode ser aplicada em qualquer problema bidimensional, simplifica e facilita a programação e implementação de códigos no computador. Nesta seção, o número complexo será denotado como:

$$
z=x+i y
$$

No método das variáveis complexas utiliza-se o potencial complexo, $\Omega(z)$, que é formado pelo potencial de descarga na parte real e pela função de corrente (stream function) na parte imaginária:

$$
\Omega=\Phi+i \Psi
$$

Observa-se que o uso do potencial complexo possibilita, no mesmo cálculo, a definição simultânea das equipotenciais e linhas de fluxo.

\subsubsection{Barreira hidráulica vertical}

Strack (2017) desenvolveu as expressões necessárias para a simulação do escoamento através de uma barreira vertical cilíndrica com condutividade hidráulica $\mathrm{K}_{1}$ inserida em um ambiente de condutividade hidráulica igual a $\mathrm{K}$, como mostra a Figura 3. O fluxo uniforme no campo distante é representado por $Q_{x 0}$ e o fluxo uniforme através da área encapsulada por $F Q_{x 0}$. 
Figura 3. Barreira vertical cilíndrica em um campo de fluxo uniforme
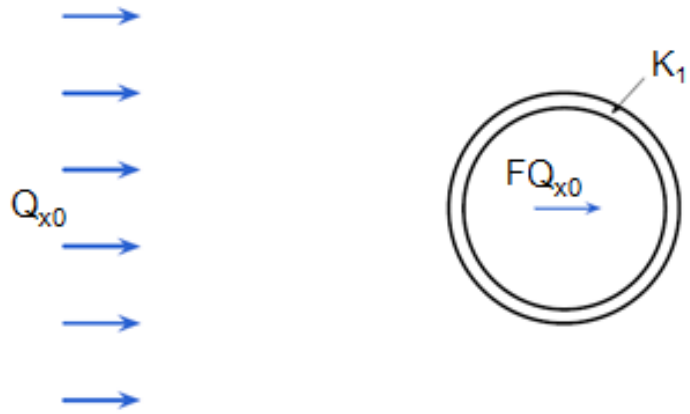

Fonte: Modificado de Strack (2017).

A partir da solução obtida para a inomogeneidade cilíndrica (STRACK, 2017), o autor desenvolveu as seguintes expressões para calcular os potenciais complexos no domínio do lado de fora da barreira (aquífero), no domínio da barreira (anel limitado pelos dois cilindros) e no domínio do lado de dentro da barreira (área encapsulada), considerando que a carga ao longo do eixo y é $\phi_{0}$ e os cilindros são centrados em $z=$ 0 :

$$
\begin{array}{cl}
\Omega=-Q_{x 0}\left(z+a \frac{R^{2}}{z}\right)+\Phi_{0} & R^{2} \leq z \bar{z} \\
\Omega=-Q_{x 0}\left(b z+c \frac{R_{1}{ }^{2}}{z}\right)+\frac{K_{1}}{K} \Phi_{0} & R_{1}{ }^{2} \leq z \bar{z} \leq R^{2} \\
\Omega=-Q_{x 0} d z+\Phi_{0} & z \bar{z} \leq R_{1}{ }^{2}
\end{array}
$$

nas quais $R$ é o raio do cilindro externo, $R_{1}$ é o raio do cilindro interno.

Como a função de fluxo e a carga devem ser contínuas em ambas as fronteiras, as condições de contorno podem ser escritas como mostrado a seguir, em que os sinais + e - representam os lados de dentro e de fora dos cilindros respectivamente.

$$
\begin{array}{ll}
\Psi^{+}-\Psi^{-}=0 & z \bar{z}=R^{2} \text { e } z \bar{z}=R_{1}{ }^{2} \\
\phi^{+}-\phi^{-}=0 & z \bar{z}=R^{2} \text { e } z \bar{z}=R_{1}{ }^{2}
\end{array}
$$

Substituindo $\phi^{+}$por $\sqrt{2 \Phi^{+} / \mathrm{K}_{1}}$ e $\phi^{-}$por $\sqrt{2 \Phi^{-} / \mathrm{K}}$ na condição de contorno da carga do cilindro externo (Equação 21), a expressão resultante é:

$$
\Phi^{+}=\frac{K_{1}}{K} \Phi^{-} \quad z \bar{z}=R^{2}
$$


Da mesma maneira, substituindo $\phi^{+}$por $\sqrt{2 \Phi^{+} / \mathrm{K}}$ e $\phi^{-}$por $\sqrt{2 \Phi^{-} / \mathrm{K}_{1}}$ na condição de contorno da carga do cilindro interno (Equação 21), obtém-se:

$$
\Phi^{+}=\frac{\mathrm{K}}{\mathrm{K}_{1}} \Phi^{-} \quad \mathrm{z} \overline{\mathrm{z}}=\mathrm{R}_{1}{ }^{2}
$$

As equações do potencial complexo do lado de fora e de dentro do cilindro externo são obtidas através das Equações 17 e 18, substituindo $R^{2} / z$ por $\bar{z}$ e z por $\mathrm{R}^{2} / \overline{\mathrm{z}}$ :

$$
\begin{array}{cl}
\Omega^{-}=-Q_{x 0}(z+a \bar{z})+\Phi_{0} & R^{2} \leq z \bar{z} \\
\Omega^{+}=-Q_{x 0}\left(b z+c \frac{R_{1}{ }^{2}}{R^{2}} \bar{z}\right)+\frac{K_{1}}{K} \Phi_{0} & R_{1}{ }^{2} \leq z \bar{z} \leq R^{2}
\end{array}
$$

nas quais $z=x+i y$ e $\bar{z}=x-i y$, resultando $e m$ :

$$
\begin{array}{cl}
\Omega^{-}=-Q_{x 0} \times(1+a)-Q_{x 0} i y(1-a)+\Phi_{0} & R^{2} \leq z \bar{z} \\
\Omega^{+}=-Q_{x 0} \times\left(b+c \frac{R_{1}{ }^{2}}{R^{2}}\right)-Q_{x 0} i y\left(b-c \frac{R_{1}{ }^{2}}{R^{2}}\right)+\frac{K_{1}}{K} \Phi_{0} & R_{1}{ }^{2} \leq z \bar{z} \leq R^{2}
\end{array}
$$

Para satisfazer a primeira condição de contorno, as partes imaginárias das Equações 26 e 27 são subtraídas e o resultado é igual a zero:

$$
\Psi^{+}-\Psi^{-}=-Q_{x 0} y\left(b-c \frac{R_{1}{ }^{2}}{R^{2}}\right)-\left[-Q_{x 0} y(1-a)\right]=0
$$

logo,

$$
a=1-b+c \frac{R_{1}^{2}}{R^{2}}
$$

As partes reais das Equações 26 e 27 são substituídas na segunda condição de contorno (Equação 22):

$$
-Q_{x 0} \times\left(b+c \frac{R_{1}{ }^{2}}{R^{2}}\right)+\frac{K_{1}}{K} \Phi_{0}=\frac{K_{1}}{K}\left[-Q_{x 0} \times(1+a)+\Phi_{0}\right]
$$

resultando em:

$$
a=\frac{K}{K_{1}}\left(b+c \frac{R_{1}{ }^{2}}{R^{2}}\right)-1
$$

Subtraindo a Equação 31 da Equação 29, obtém-se:

$$
\mathrm{b}=2 \frac{\mathrm{K}_{1}}{\mathrm{~K}_{1}+\mathrm{K}}+\mathrm{c} \frac{\mathrm{R}_{1}^{2}}{\mathrm{R}^{2}} \frac{\mathrm{K}_{1}-\mathrm{K}}{\mathrm{K}_{1}+\mathrm{K}}
$$


As equações do potencial complexo do lado de fora e de dentro do cilindro interno são obtidas através das Equações 18 e 19, substituindo $\mathrm{R}_{1}{ }^{2} / \mathrm{z}$ por $\bar{z}$ :

$$
\begin{array}{cc}
\Omega^{-}=-Q_{x 0}(b z+c \bar{z})+\frac{K_{1}}{K} \Phi_{0} & z \bar{z}=R_{1}{ }^{2} \\
\Omega^{+}=-Q_{x 0} d z+\Phi_{0} & z \bar{z}=R_{1}{ }^{2}
\end{array}
$$

nas quais $z=x+i y$ e $\bar{z}=x-i y$, resultando em:

$$
\begin{array}{cc}
\Omega^{-}=-Q_{x 0} \times(b+c)-Q_{x 0} \text { iy }(b-c)+\frac{K_{1}}{K} \Phi_{0} & z \bar{z}=R_{1}{ }^{2} \\
\Omega^{+}=-Q_{x 0} \times d-Q_{x 0} \text { iyd }+\Phi_{0} & z \bar{z}=R_{1}{ }^{2}
\end{array}
$$

Satisfazendo a primeira condição de contorno, obtém-se:

$$
\Psi^{+}-\Psi^{-}=-Q_{x 0} y d-\left[-Q_{x 0} y(b-c)\right]=-Q_{x 0} y(d-b+c)=0
$$

logo,

$$
d=b-c
$$

As partes reais das Equações 35 e 36 são substituídas na segunda condição de contorno (Equação 23):

$$
-Q_{x 0} x d+\Phi_{0}=\frac{K}{K_{1}}\left[-Q_{x 0} x(b+c)+\frac{K_{1}}{K} \Phi_{0}\right]
$$

resultando em:

$$
\mathrm{d}=\frac{\mathrm{K}}{\mathrm{K}_{1}}(\mathrm{~b}+\mathrm{c})
$$

Subtraindo a Equação 40 da Equação 38, obtém-se:

$$
\mathrm{b}=\frac{\mathrm{K}_{1}+\mathrm{K}}{\mathrm{K}_{1}-\mathrm{K}} \mathrm{c}
$$

Então, a partir das Equações 41 e 32, encontra-se a constante "c":

$$
c=\frac{2 \frac{\mathrm{K}_{1}}{\mathrm{~K}_{1}-\mathrm{K}}}{\left(\frac{\mathrm{K}_{1}+\mathrm{K}}{\mathrm{K}_{1}-\mathrm{K}}\right)^{2}-\frac{\mathrm{R}_{1}{ }^{2}}{\mathrm{R}^{2}}}
$$

Substituindo o valor de "c" na Equação 41, obtém-se o valor de "b":

$$
\mathrm{b}=\frac{2 \frac{\mathrm{K}_{1}}{\mathrm{~K}_{1}-\mathrm{K}} \frac{\mathrm{K}_{1}+\mathrm{K}}{\mathrm{K}_{1}-\mathrm{K}}}{\left(\frac{\mathrm{K}_{1}+\mathrm{K}}{\mathrm{K}_{1}-\mathrm{K}}\right)^{2}-\frac{\mathrm{R}_{1}^{2}}{\mathrm{R}^{2}}}
$$


A partir dos valores de "c" e "b", é possível calcular a constante "d" através da Equação 38 :

$$
d=\frac{\left(\frac{K_{1}+K}{K_{1}-K}\right)^{2}-1}{\left(\frac{K_{1}+K}{K_{1}-K}\right)^{2}-\frac{R_{1}^{2}}{R^{2}}}
$$

E substituindo os valores de "b" e "c" na Equação 29, obtém-se o valor de "a":

$$
a=-\frac{\frac{K_{1}+K}{K_{1}-K}\left(1-\frac{R_{1}{ }^{2}}{R^{2}}\right)}{\left(\frac{K_{1}+K}{K_{1}-K}\right)^{2}-\frac{R_{1}{ }^{2}}{R^{2}}}
$$

Substituindo a constante "d" na Equação 19, o potencial complexo dentro da inomogeneidade resulta na seguinte expressão:

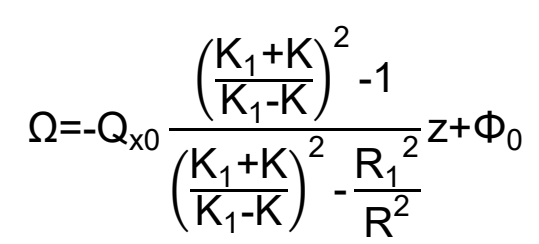

Logo, conclui-se que o escoamento do lado de dentro da barreira é uniforme e seu valor é igual ao fluxo uniforme no campo distante multiplicado por um fator menor que 1 , pois como a razão $R_{1} / R$ é sempre menor que 1 , o denominador é sempre maior do que o numerador.

Strack (2017) cita que a barreira sempre reduzirá o escoamento. Segundo o autor, tal redução depende da razão entre as condutividades hidráulicas e da razão entre os raios dos cilindros externo e interno. $O$ fator de redução $D$ é dado pela Equação 47.

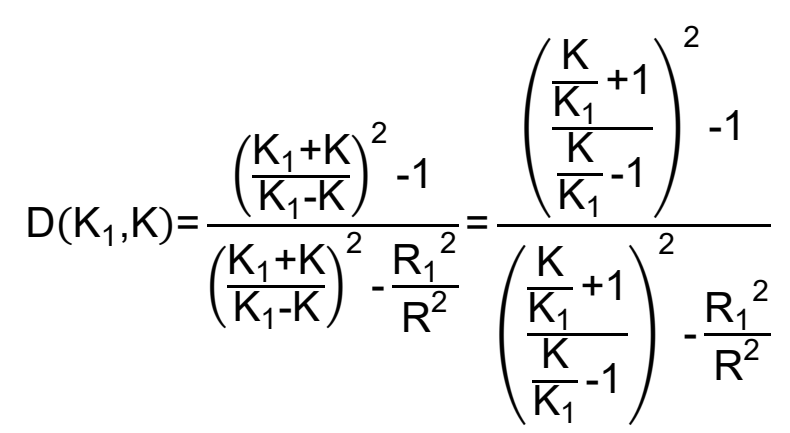

ou seja, é uma função de $\mathrm{K}$ e $\mathrm{K}_{1}$ e possui a seguinte propriedade:

$$
\mathrm{D}\left(\mathrm{K}_{1}, \mathrm{~K}\right)=\mathrm{D}\left(\mathrm{K}, \mathrm{K}_{1}\right)
$$

o que significa que o mesmo fator de redução de fluxo é obtido aumentando a condutividade hidráulica da barreira ou diminuindo a condutividade hidráulica do 
ambiente na mesma proporção. Assim, nos casos em que a área encapsulada possuir uma baixa condutividade hidráulica, a barreira de alta permeabilidade será a alternativa mais eficiente; por outro lado, se a condutividade hidráulica do ambiente for elevada, a melhor solução será a slurry wall (STRACK, 2017).

A partir das Equações 17, 18 e 19 e das constantes a, b, c e d é possível plotar as linhas de fluxo e equipotenciais para os casos em que uma barreira cilíndrica de alta e de baixa permeabilidade são instaladas em um campo de fluxo uniforme, como apresentado na Figura 4. Na Figura 4 - A, a condutividade hidráulica da barreira é igual a 100 vezes a condutividade hidráulica do ambiente, resultando no direcionamento do fluxo subterrâneo pelo interior da estrutura. Já na Figura 4 - B a condutividade hidráulica da barreira é 100 vezes menor do que a do ambiente, logo 0 escoamento é desviado em torno da estrutura. Nesses casos, observa-se que a magnitude do escoamento uniforme através da área encapsulada é igual nas duas redes de fluxo.

Figura 4. Escoamento de água subterrânea nos casos em que $K_{1} / K=100$ (A) e $K_{1} / K=0,01$ (B)

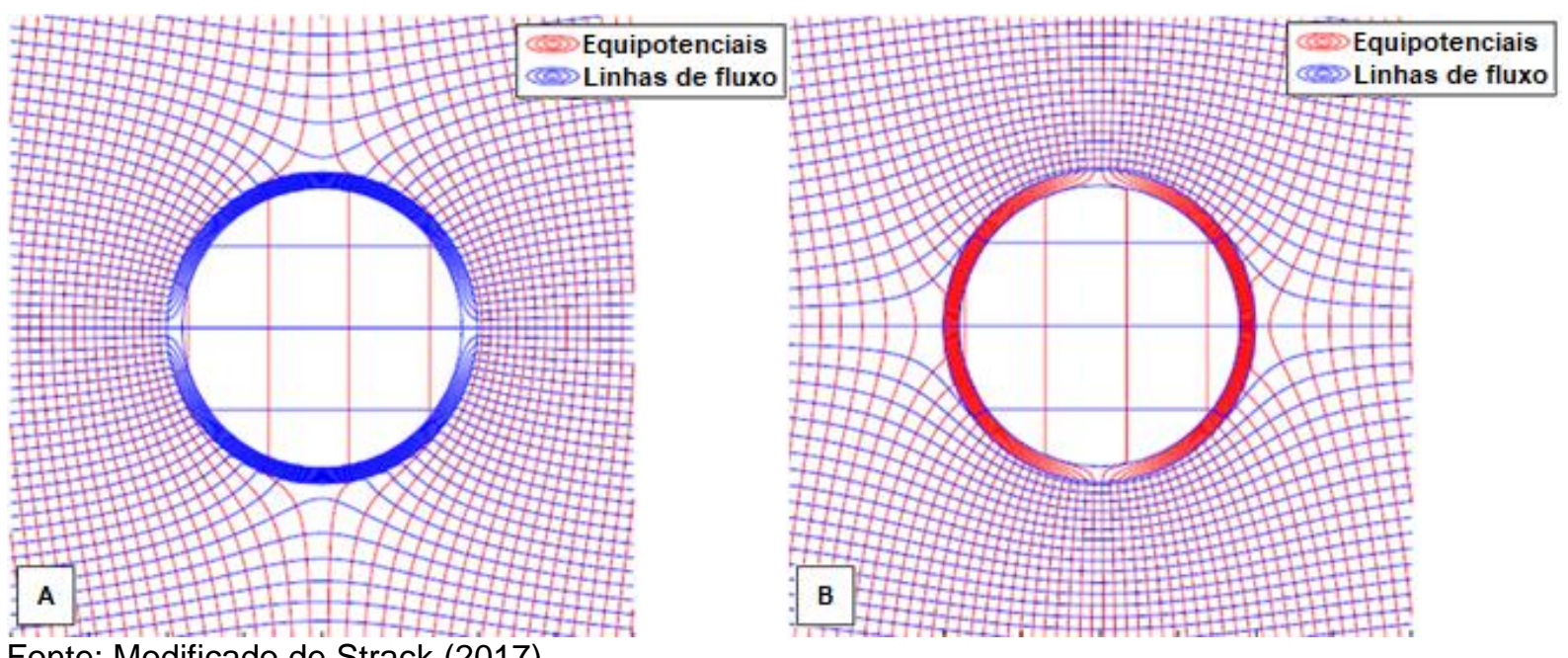

Fonte: Modificado de Strack (2017). 


\section{MATERIAIS E MÉTODOS}

\subsection{Solução analítica das barreiras verticais cilíndricas}

Na solução desenvolvida por Strack (2017), uma barreira de condutividade hidráulica $\mathrm{K}_{1}$ é inserida em um ambiente de condutividade hidráulica igual a $\mathrm{K}$. Essa solução analítica pode ser utilizada nos problemas em que o depósito de resíduos está localizado acima do nível d'água. Nesses casos, o lixiviado escoa pela camada não saturada e atinge o nível da água, formando uma pluma de contaminação (Figura 1-A). Para impedir o desenvolvimento da pluma, uma barreira hidráulica vertical pode ser utilizada para encapsular a região saturada localizada logo abaixo do aterro (Figura 5-A). Quando o depósito de resíduos está abaixo do nível d'água, a lixiviação ocorre devido à passagem da água subterrânea através do corpo de resíduos (Figura 1-B). Nessas situações, a região encapsulada contém o maciço de resíduos saturado (Figura 5-B) e, por esse motivo, possui condutividade hidráulica diferente do aquífero. Assim, um dos objetivos desse trabalho é expandir a solução de Strack (2017) para que as equações analíticas também possam ser aplicadas nos problemas em que os domínios de dentro e de fora da barreira possuem condutividades hidráulicas distintas.

Figura 5. Regiões encapsuladas
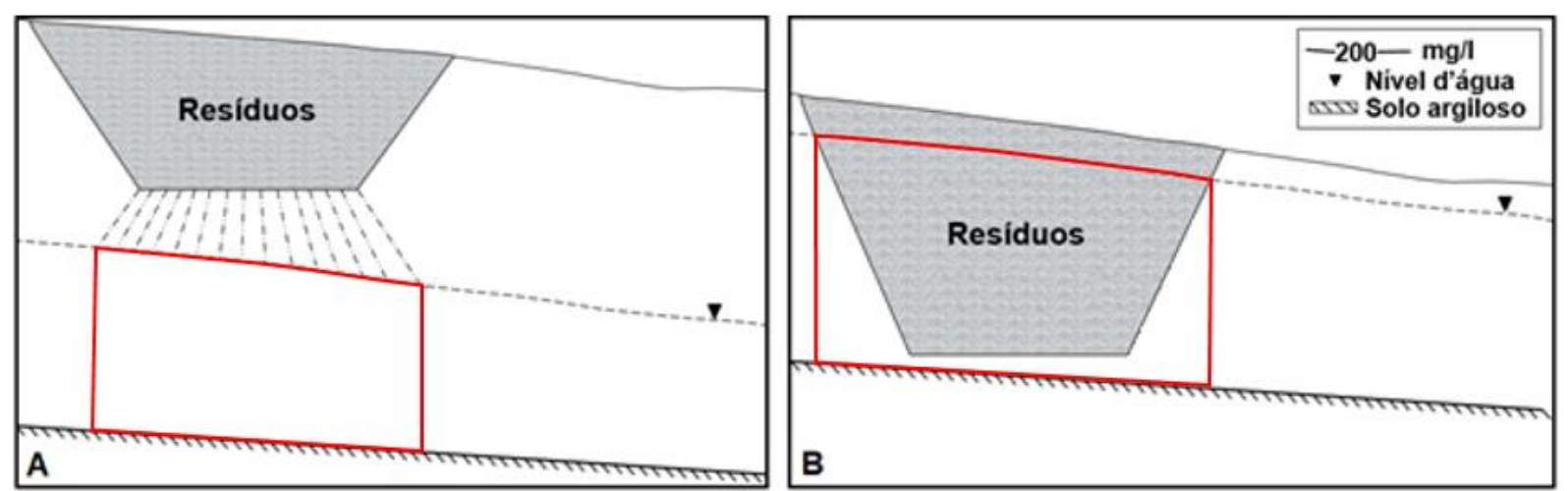

Fonte: Autor.

Como o aterro e o aquífero não possuem a mesma estrutura porosa, eles podem apresentar condutividades hidráulicas consideravelmente diferentes. O RSU é composto principalmente por uma fração biodegradável, que inclui papel, papelão, alimentos, resíduos de jardinagem e têxteis, e substâncias não biodegradáveis, como plásticos, vidros e têxteis (WILLIAMS, 2005). De acordo com Sharma e Lewis (1994), a condutividade hidráulica saturada do RSU é tipicamente $1 \times 10^{-5} \mathrm{~m} / \mathrm{s}$. No entanto, devido à disposição dos resíduos sólidos no solo e a posterior compactação e 
degradação desse material, as propriedades do aterro, como o peso específico, distribuição granulométrica e, consequentemente, a condutividade hidráulica, podem variar. Experimentos em laboratório e in situ publicados na literatura apresentam valores de condutividade hidráulica do RSU variando de $10^{-4} \mathrm{~m} / \mathrm{s}$ a $10^{-10} \mathrm{~m} / \mathrm{s}$ (REDDY et al., 2009).

Para desenvolver a solução analítica desse problema, considerou-se uma estrutura de raio externo $R$ e raio interno $R_{w}$, ambos centrados em $z=0$, e condutividades hidráulicas iguais a $\mathrm{K}_{\mathrm{w}}, \mathrm{K}_{\mathrm{b}}$ e $\mathrm{K}_{\mathrm{a}}$ para a região encapsulada, a barreira e o aquífero respectivamente (Figura 6 ).

Figura 6. Barreira vertical cilíndrica em um campo de fluxo uniforme

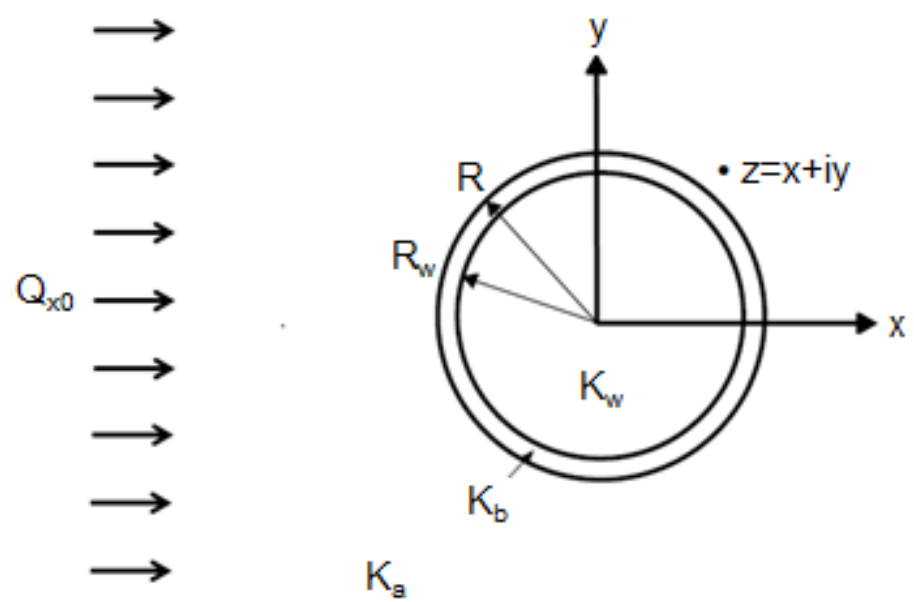

Fonte: Autor.

Sabendo-se que a carga ao longo do eixo y é $\phi_{0}$, os potenciais de descarga nos três domínios são:

$$
\begin{array}{ll}
\Phi_{0}=\frac{1}{2} K_{\mathrm{w}} \phi_{0}{ }^{2} & \mathrm{z} \overline{\mathrm{Z}} \leq \mathrm{R}_{\mathrm{w}}{ }^{2} \\
\Phi_{\mathrm{b}}=\frac{1}{2} \mathrm{~K}_{\mathrm{b}} \phi_{0}{ }^{2} & \mathrm{R}_{\mathrm{w}}{ }^{2} \leq \mathrm{z} \overline{\mathrm{z}} \leq \mathrm{R}^{2} \\
\Phi_{\mathrm{a}}=\frac{1}{2} \mathrm{~K}_{\mathrm{a}} \phi_{0}{ }^{2} & \mathrm{R}^{2} \leq \mathrm{z} \overline{\mathrm{z}}
\end{array}
$$

A Equação 49 pode ser escrita da seguinte maneira:

$$
\frac{\Phi_{0}}{\mathrm{~K}_{\mathrm{w}}}=\frac{1}{2} \phi_{0}^{2}
$$

Assim, os potenciais $\Phi_{\mathrm{b}}$ e $\Phi_{\mathrm{a}}$ podem ser expressos em função de $\Phi_{0}$ :

$$
\Phi_{\mathrm{b}}=\frac{\mathrm{K}_{\mathrm{b}}}{\mathrm{K}_{\mathrm{w}}} \Phi_{0}
$$




$$
\Phi_{\mathrm{a}}=\frac{\mathrm{K}_{\mathrm{a}}}{\mathrm{K}_{\mathrm{w}}} \Phi_{0}
$$

Utilizando as expressões desenvolvidas por Strack (2017) (Equações 17, 18 e 19) e as Equações 53 e 54, as expressões dos potenciais complexos para os três domínios são:

$$
\begin{array}{cl}
\Omega=-Q_{x 0}\left(z+a \frac{R^{2}}{z}\right)+\frac{K_{a}}{K_{w}} \Phi_{0} & R^{2} \leq z \bar{z} \\
\Omega=-Q_{x 0}\left(b z+c \frac{R_{w}{ }^{2}}{z}\right)+\frac{K_{b}}{K_{w}} \Phi_{0} & R_{w}{ }^{2} \leq z \bar{z} \leq R^{2} \\
\Omega=-Q_{x 0} d z+\Phi_{0} & z \bar{z} \leq R_{w}{ }^{2}
\end{array}
$$

Nesse caso, também deve-se aplicar as condições de contorno das Equações 20 e 21. Assim, substituindo $\phi^{+}$por $\sqrt{2 \Phi^{+} / K_{b}}$ e $\phi^{-}$por $\sqrt{2 \Phi^{-} / K_{a}}$ na condição de continuidade da carga do cilindro externo, a equação resulta em:

$$
\Phi^{+}=\frac{\mathrm{K}_{\mathrm{b}}}{\mathrm{K}_{\mathrm{a}}} \Phi^{-}
$$

Da mesma maneira, substituindo $\phi^{+}$por $\sqrt{2 \Phi^{+} / K_{w}}$ e $\phi^{-}$por $\sqrt{2 \Phi^{-} / K_{b}}$ na condição de continuidade da carga do cilindro interno, a expressão resultante é:

$$
\Phi^{+}=\frac{\mathrm{K}_{\mathrm{w}}}{\mathrm{K}_{\mathrm{b}}} \Phi^{-}
$$

Para obter as equações do potencial complexo do lado de fora e de dentro do cilindro externo, substitui-se $R^{2} / z$ por $\bar{z}$ e z por $R^{2} / \bar{z}$ nas Equações 55 e 56:

$$
\begin{array}{cc}
\Omega^{-}=-Q_{x 0}(z+a \bar{z})+\frac{K_{a}}{K_{w}} \Phi_{0} & z \bar{z}=R^{2} \\
\Omega^{+}=-Q_{x 0}\left(b z+c \frac{R_{w}{ }^{2}}{R^{2}} \bar{z}\right)+\frac{K_{b}}{K_{w}} \Phi_{0} & z \bar{z}=R^{2}
\end{array}
$$

nas quais $z=x+i y$ e $\bar{z}=x-i y$, resultando em:

$$
\begin{array}{cc}
\Omega^{-}=-Q_{x 0} \times(1+a)-Q_{x 0} y(1-a)+\frac{K_{a}}{K_{w}} \Phi_{0} & z \bar{z}=R^{2} \\
\Omega^{+}=-Q_{x 0} \times\left(b+c \frac{R_{w}{ }^{2}}{R^{2}}\right)-Q_{x 0} i y\left(b-c \frac{R_{w}{ }^{2}}{R^{2}}\right)+\frac{K_{b}}{K_{w}} \Phi_{0} & z \bar{z}=R^{2}
\end{array}
$$

Subtraindo as partes imaginárias das Equações 62 e 63, de modo que a condição de continuidade do fluxo seja satisfeita, obtém-se: 


$$
a=1+c \frac{R_{w}^{2}}{R^{2}}-b
$$

Substituindo as partes reais das Equações 62 e 63 na Equação 58, o resultado é:

$$
a=\left(b+c \frac{R_{w}{ }^{2}}{R^{2}}\right) \frac{K_{a}}{K_{b}}-1
$$

Assim, subtraindo a Equação 65 da Equação 64, obtém-se a seguinte expressão:

$$
\mathrm{b}=\frac{\mathrm{c} \frac{\mathrm{R}_{\mathrm{w}}{ }^{2}}{\mathrm{R}^{2}}\left(1-\frac{\mathrm{K}_{\mathrm{a}}}{\mathrm{K}_{\mathrm{b}}}\right)+2}{1+\frac{\mathrm{K}_{\mathrm{a}}}{\mathrm{K}_{\mathrm{b}}}}
$$

As equações do potencial complexo do lado de fora e de dentro do cilindro interno são obtidas através das Equações 56 e 57, substituindo $\mathrm{R}_{\mathrm{w}}{ }^{2} / \mathrm{z}$ por $\bar{z}$ :

$$
\begin{array}{cc}
\Omega^{-}=-Q_{x 0}(b z+c \bar{z})+\frac{K_{b}}{K_{w}} \Phi_{0} & z \bar{z}=R_{w}{ }^{2} \\
\Omega^{+}=-Q_{x 0} d z+\Phi_{0} & z \bar{z}=R_{w}{ }^{2}
\end{array}
$$

nas quais $z=x+i y$ e $\bar{z}=x-i y$, resultando em:

$$
\begin{array}{cc}
\Omega^{-}=-Q_{x 0} \times(b+c)-Q_{x 0} i y(b-c)+\frac{K_{b}}{K_{w}} \Phi_{0} & z \bar{z}=R_{w}{ }^{2} \\
\Omega^{+}=-Q_{x 0} \times d-Q_{x 0} i y d+\Phi_{0} & z \bar{z}=R_{w}{ }^{2}
\end{array}
$$

Para satisfazer a condição de continuidade do fluxo, as partes imaginárias das Equações 69 e 70 são subtraídas e o resultado é igual a zero, resultando em:

$$
d=b-c
$$

Substituindo as partes reais das Equações 69 e 70 na Equação 59, encontra-se a seguinte expressão:

$$
d=\frac{K_{w}}{K_{b}}(b+c)
$$

Subtraindo a Equação 72 da Equação 71, obtém-se:

$$
\mathrm{b}=\mathrm{c} \frac{\mathrm{K}_{\mathrm{b}}+\mathrm{K}_{\mathrm{w}}}{\mathrm{K}_{\mathrm{b}}-\mathrm{K}_{\mathrm{w}}}
$$

Igualando as Equações 73 e 66 encontra-se o valor de "c":

$$
c=\frac{2 K_{b}}{\left(K_{b}+K_{a}\right)\left(\frac{K_{b}+K_{w}}{K_{b}-K_{w}}+\frac{R_{w}^{2}\left(K_{a}-K_{b}\right)}{R^{2}\left(K_{a}+K_{b}\right)}\right)}
$$

Substituindo o valor de "c" na Equação 73, obtém-se "b": 


$$
b=\frac{2 K_{b}\left(K_{w}+K_{b}\right)}{\left(K_{b}+K_{a}\right)\left(K_{w}-K_{b}\right)\left(\frac{K_{w}+K_{b}}{K_{w}-K_{b}}+\frac{R_{w}^{2}\left(K_{b}-K_{a}\right)}{R^{2}\left(K_{b}+K_{a}\right)}\right)}
$$

Então, para calcular as constantes "d" e "a", substitui-se os valores de "b" e "c" nas Equações 71 e 64:

$$
\begin{aligned}
& d=\frac{4 R^{2} K_{w} K_{b}}{K_{b}\left(R^{2}+R_{w}^{2}\right)\left(K_{w}+K_{a}\right)+\left(K_{b}^{2}+K_{w} K_{a}\right)\left(R^{2}-R_{w}^{2}\right)} \\
& a=\frac{2 K_{b} K_{a}\left(R^{2}+R_{w}^{2}\right)+2 K_{w} K_{a}\left(R^{2}-R_{w}^{2}\right)}{\left(K_{b}{ }^{2}+K_{w} K_{a}\right)\left(R^{2}-R_{w}^{2}\right)+K_{b}\left(K_{w}+K_{a}\right)\left(R^{2}+R_{w}^{2}\right)}-1
\end{aligned}
$$

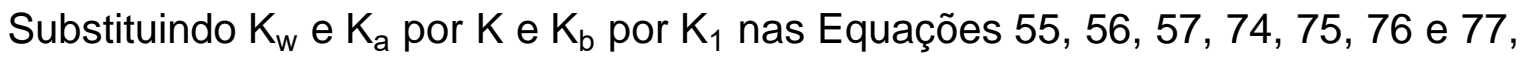
a solução coincide com a publicada por Strack (2017), validando as expressões desenvolvidas nesta seção.

Nesse caso, a eficiência $(E)$ da barreira em reduzir o fluxo através da região encapsulada é dada pela Equação 78 , na qual $Q_{x 0_{w}}$ é o fluxo uniforme através da área contaminada (antes da construção da barreira) e $\mathrm{Q}_{\mathrm{x} 0_{\mathrm{w}}}$ 'é o fluxo uniforme através da área encapsulada (depois da construção da barreira).

$$
E=\frac{Q_{x 0_{w}}-Q_{x 0_{w}}}{Q_{x 0_{w}}} 100
$$

Para calcular $\mathrm{Q}_{\mathrm{x} \mathrm{O}_{\mathrm{w}}}$ ', multiplicou-se $\mathrm{Q}_{\mathrm{x} 0}$ por d (Equação 76):

$$
Q_{x 0_{w}}{ }^{\prime}=\frac{4 R^{2} K_{w} K_{b}}{K_{b}\left(R^{2}+R_{w}^{2}\right)\left(K_{w}+K_{a}\right)+\left(K_{b}^{2}+K_{w} K_{a}\right)\left(R^{2}-R_{w}^{2}\right)} Q_{x 0}
$$

E para obter $Q_{x 0_{w}}$, multiplicou-se $Q_{x 0}$ por d (Equação 76), substituindo $R_{w}$ por $R$ e $K_{b}$ por $\mathrm{K}_{\mathrm{w}}$, para calcular o fluxo anterior à instalação da barreira:

$$
Q_{x 0 w}=\frac{2 K_{w}}{K_{w}+K_{a}} Q_{x 0}
$$

\subsection{Experimento em escala reduzida}

Segundo Bear (1972), o experimento em caixa de areia é uma representação em escala reduzida do meio poroso natural. De acordo com o autor, o sand box model consiste em um recipiente rígido e estanque, equipado com um sistema de abastecimento e instrumentos de medição, que é preenchido com um material poroso (areia ou esferas de vidro) e um ou mais fluidos. A geometria do recipiente é estabelecida de acordo com o domínio do escoamento em estudo. 
Neste trabalho, o experimento em escala reduzida consiste em uma caixa retangular preenchida com areia e uma barreira vertical cilíndrica de cascalho, o fluido utilizado foi água com sal e o monitoramento foi realizado a partir de sensores de condutividade elétrica e dataloggers. A construção do modelo em caixa de areia, a montagem dos sensores e o funcionamento do experimento estão descritos nos itens a seguir.

\subsubsection{Construção do experimento}

O experimento foi feito em uma caixa de ferro de 1,10 x 0,80 x 0,50 m (x, y, z) com face frontal de acrílico, como mostra a Figura 7. O material poroso fica acondicionado entre duas chapas de inox perfuradas (tela moeda) e recobertas com tela de nylon e tecido serigráfico (Figura 8). A caixa contém 17 piezômetros fixados na face de acrílico para monitoramento do nível de água nos dois reservatórios laterais e nos 15 tubos de PVC perfurados e também recobertos com tecido serigráfico (Figura 9) localizados no meio poroso. Os reservatórios de entrada e saída de água (Figura 10) são equipados com extravasores fixados em uma haste vertical móvel, para manter os níveis de água constantes. O projeto do experimento com todas as medidas está no Apêndice A. 
Figura 7. Experimento em escala reduzida

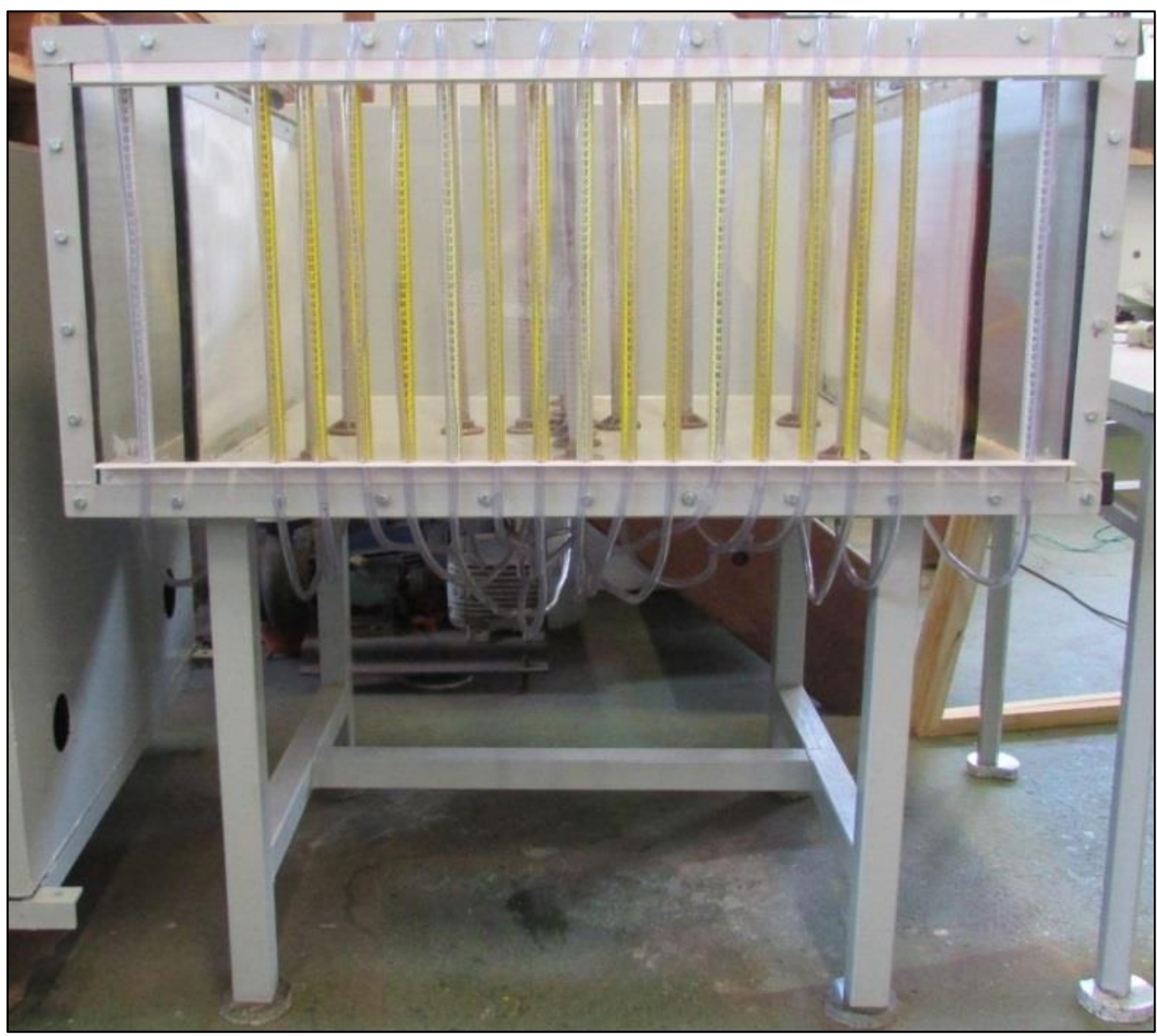

Fonte: Autor.

Figura 8. Interior da caixa

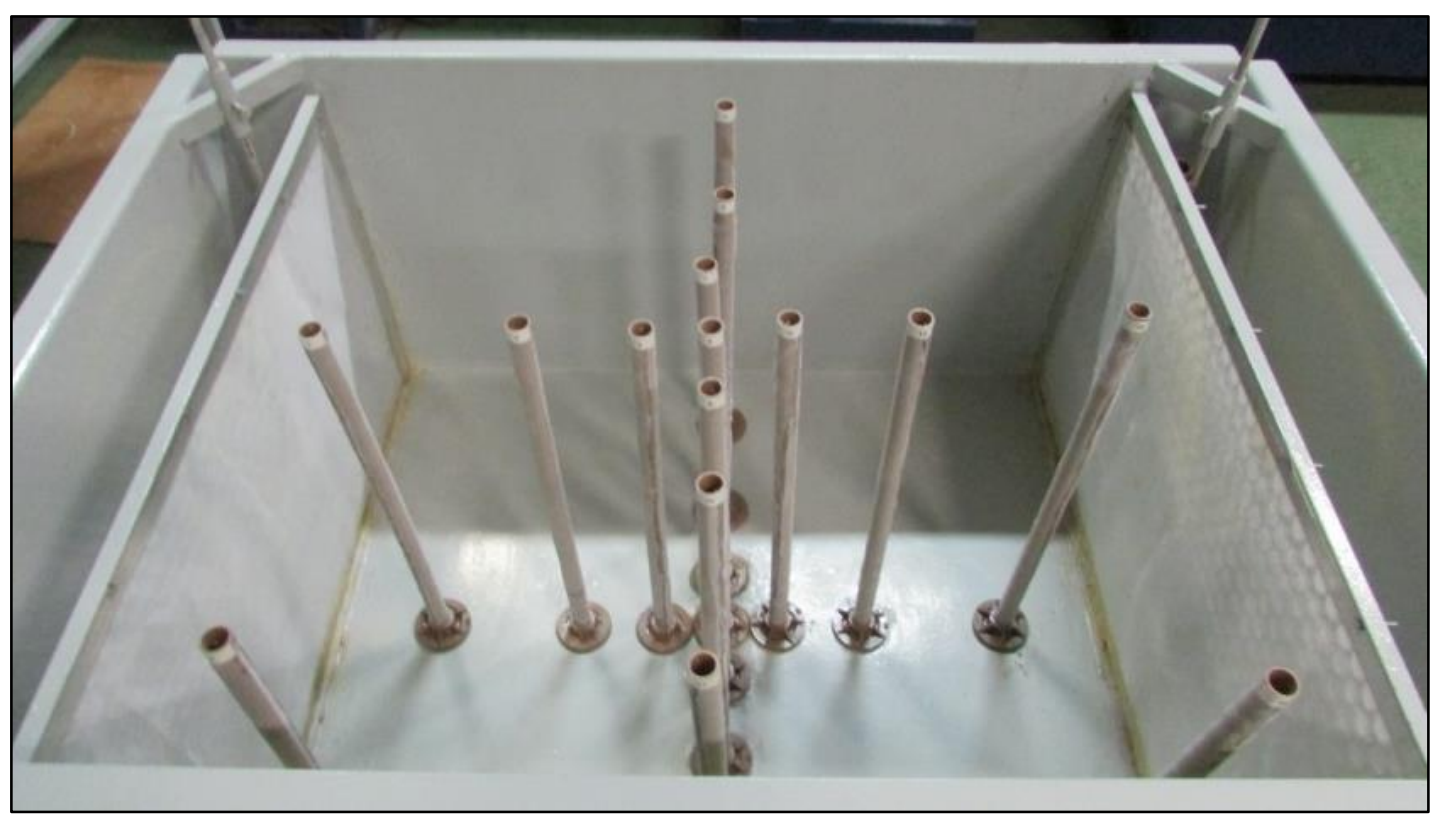

Fonte: Autor. 
Figura 9. Tubo de PVC perfurado e recoberto com tela

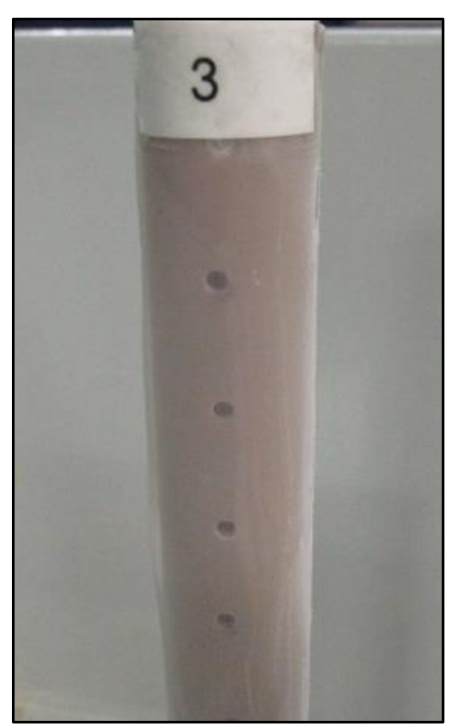

Fonte: Autor.

Figura 10. Reservatório lateral com extravasor

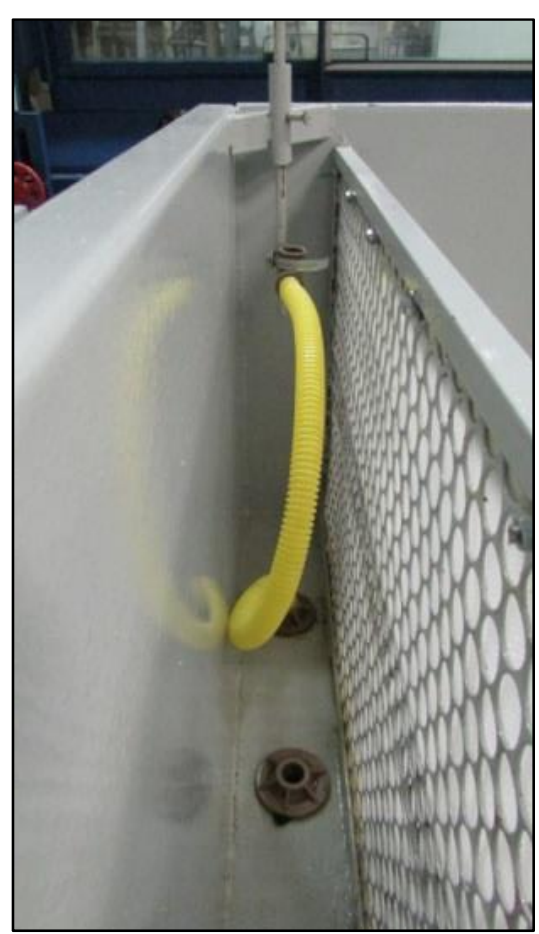

Fonte: Autor.

No experimento, optou-se por utilizar o mesmo material poroso para representar o aquífero e a área encapsulada, e um material de condutividade hidráulica mais elevada para preencher a barreira. A Figura 11 apresenta as condutividades hidráulicas de quatro materiais diferentes, determinadas através de experimentos em um permeâmetro de carga constante. Como o permeâmetro mede a condutividade hidráulica vertical e no experimento o fluxo é predominantemente horizontal, considerou-se que a condutividade horizontal é igual à vertical. 
Figura 11. Materiais porosos e suas condutividades hidráulicas

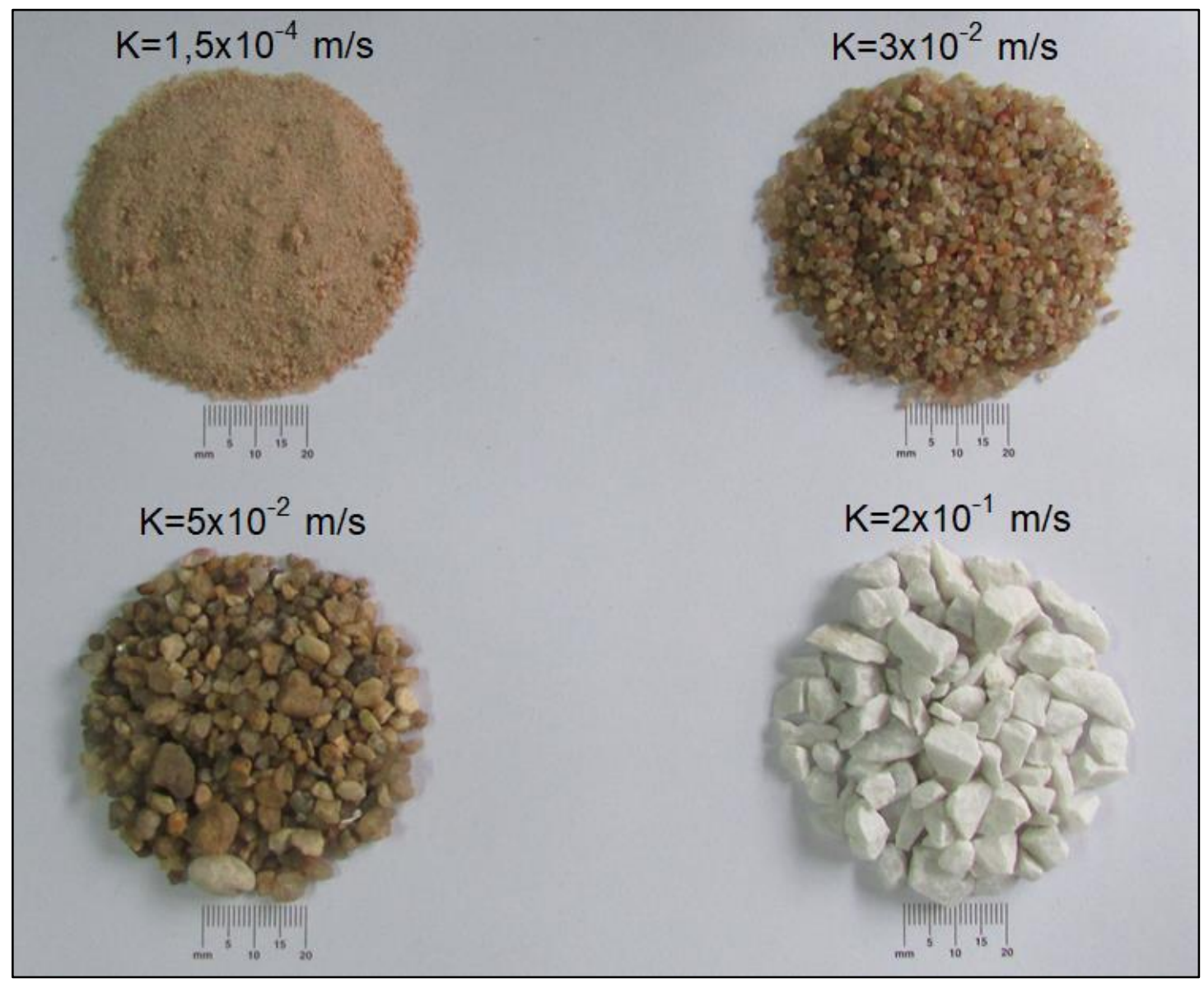

Fonte: Autor.

Os materiais escolhidos foram a areia fina $\left(1,5 \times 10^{-4} \mathrm{~m} / \mathrm{s}\right)$ e o cascalho $\left(5 \times 10^{-2} \mathrm{~m} / \mathrm{s}\right)$, visto que eles possuem condutividades hidráulicas consideravelmente diferentes e são inertes quando imersos em água com sal. Para determinar a porosidade da areia, seis amostras de solo foram saturadas de modo que todos os poros estivessem preenchidos com água. Após isso, as amostras foram pesadas na balança e levadas à estufa. Depois da secagem completa, elas foram pesadas novamente para obtenção do volume de água evaporado, que coincide com o volume de espaços vazios. Assim, a porosidade resultante foi de $30 \%$.

Para preencher a caixa com a areia e o cascalho, dois moldes cilíndricos foram utilizados (Figura 12), sendo que os diâmetros dos cilindros externo e interno eram iguais a $38,00 \mathrm{~cm}$ e $24,50 \mathrm{~cm}$ respectivamente, resultando em uma espessura de $6,75 \mathrm{~cm}$. Na Figura 13 a caixa já havia sido totalmente preenchida com os materiais e a Figura 14 mostra o experimento depois dos moldes serem retirados. Foi colocado um plástico por cima do material poroso para evitar a evaporação da água durante 0 funcionamento do experimento (Figura 15). 
Figura 12. Moldes cilíndricos

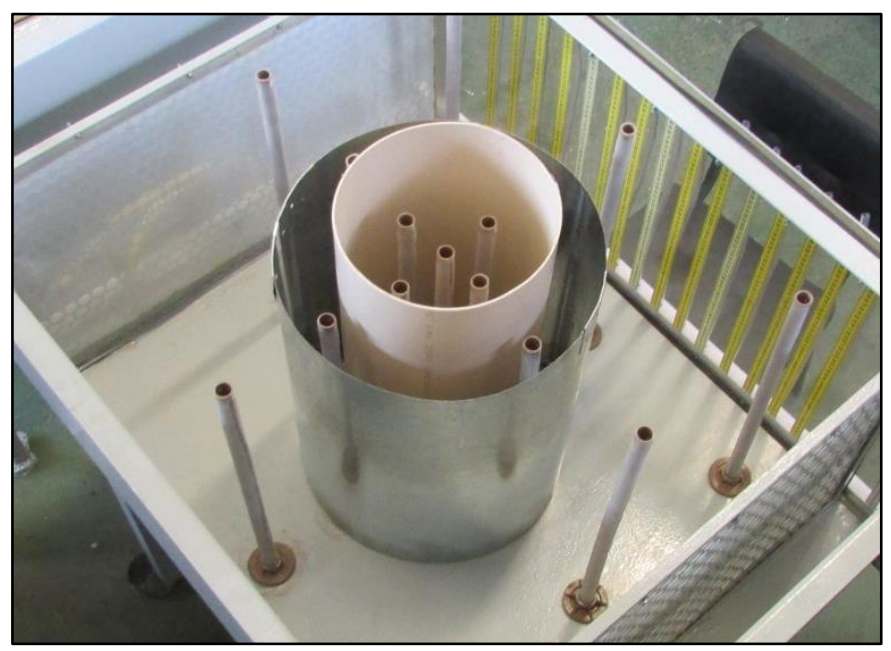

Fonte: Autor.

Figura 13. Caixa preenchida com o material poroso

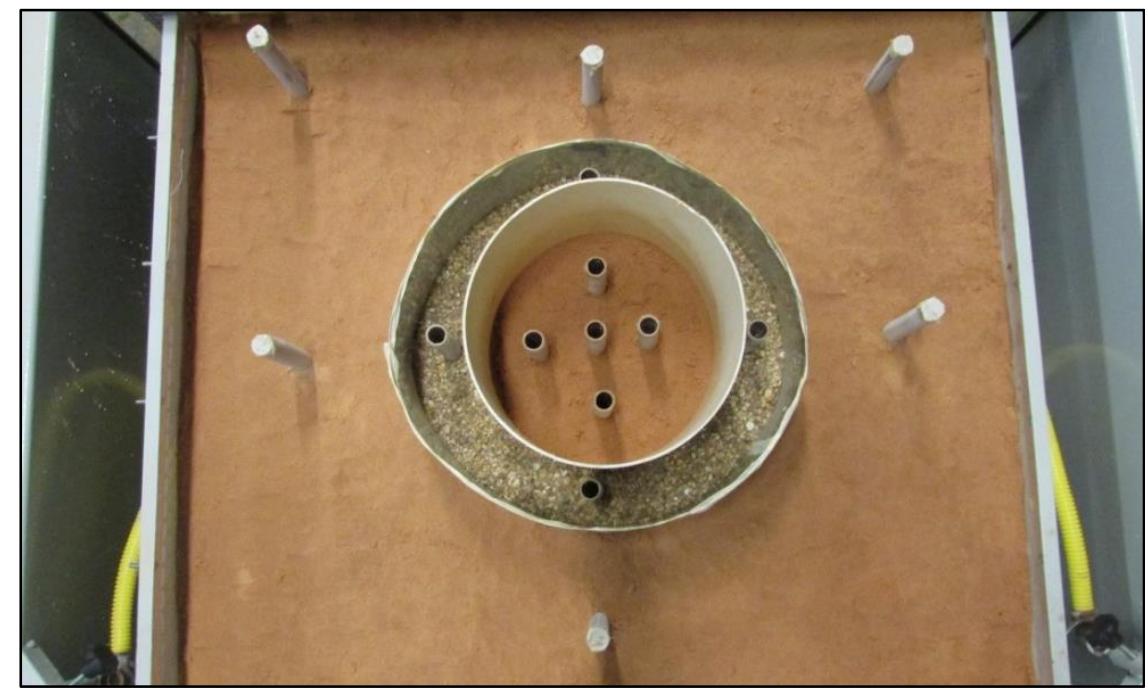

Fonte: Autor.

Figura 14. Experimento após os moldes serem retirados

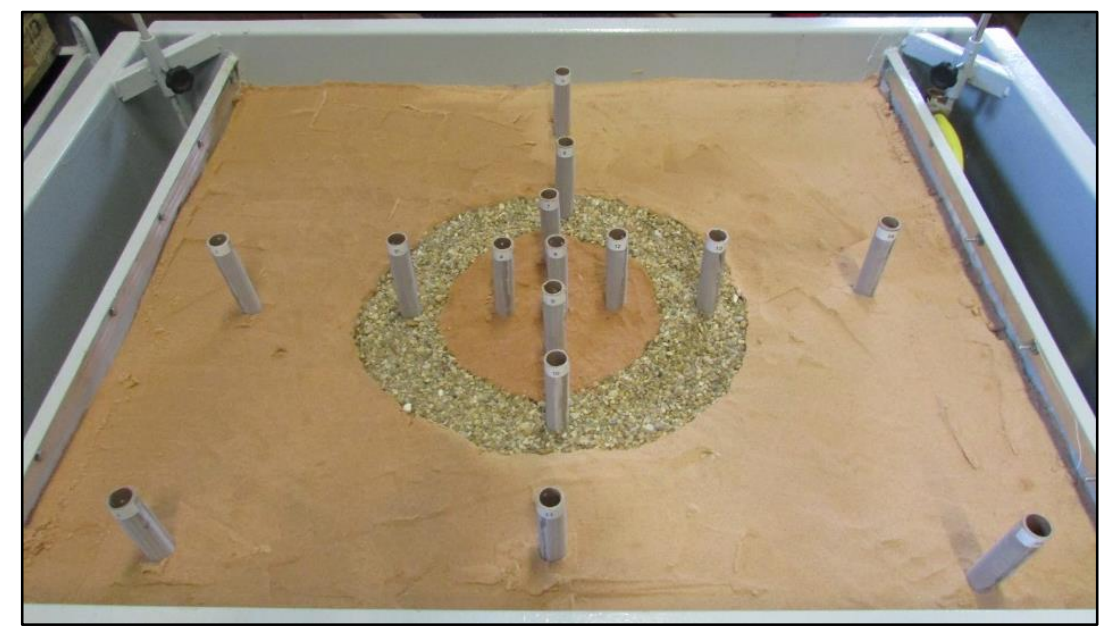

Fonte: Autor. 
Figura 15. Plástico para impedir a evaporação da água

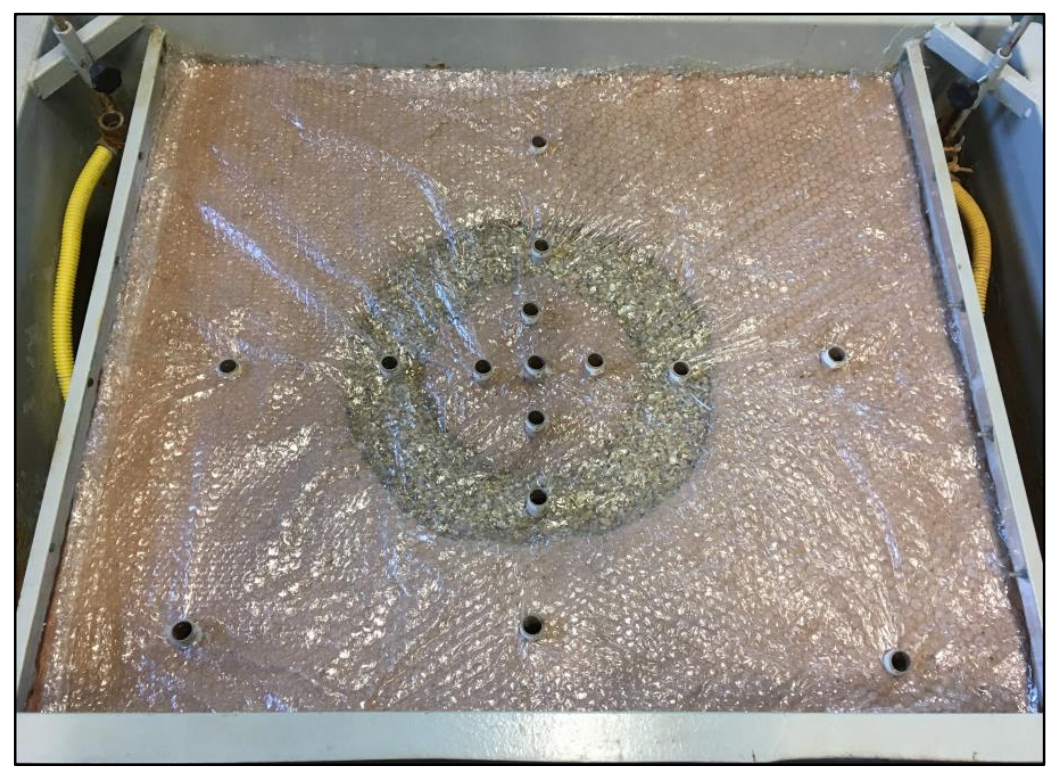

Fonte: Autor.

\subsubsection{Sensores de condutividade elétrica}

Com o objetivo de monitorar o escoamento através da caixa, o traçador escolhido para o experimento foi água com sal e sensores de condutividade elétrica (Figura 16) foram montados e inseridos nos tubos de PVC. Para que doze pontos diferentes pudessem ser monitorados simultaneamente, quatro dataloggers da Campbell Scientific foram utilizados. O funcionamento dos sensores de condutividade elétrica é apresentado no esquema da Figura 17, na qual:

- Os fios de cobre A e B, conectados nas portas ground e V2 (L) respectivamente, foram soldados em dois fios de nicromo;

- Como a distância entre os fios de nicromo deve ser constante, os dois eletrodos foram fixados em lados opostos de um suporte plástico e recobertos com tubo termo retrátil;

- Os fios de nicromo são isolados ao longo do seu comprimento, com exceção de alguns milímetros perto da sua extremidade. Os eletrodos devem ter uma seção exposta para que o sensor faça contato físico com a solução;

- O fio de cobre $\mathrm{C}$ foi conectado na porta V1 $(\mathrm{H})$;

- O fio de cobre $D$, que possui um resistor de $330 \Omega$, foi conectado na porta VX (EX). 
Figura 16. Sensor de condutividade elétrica

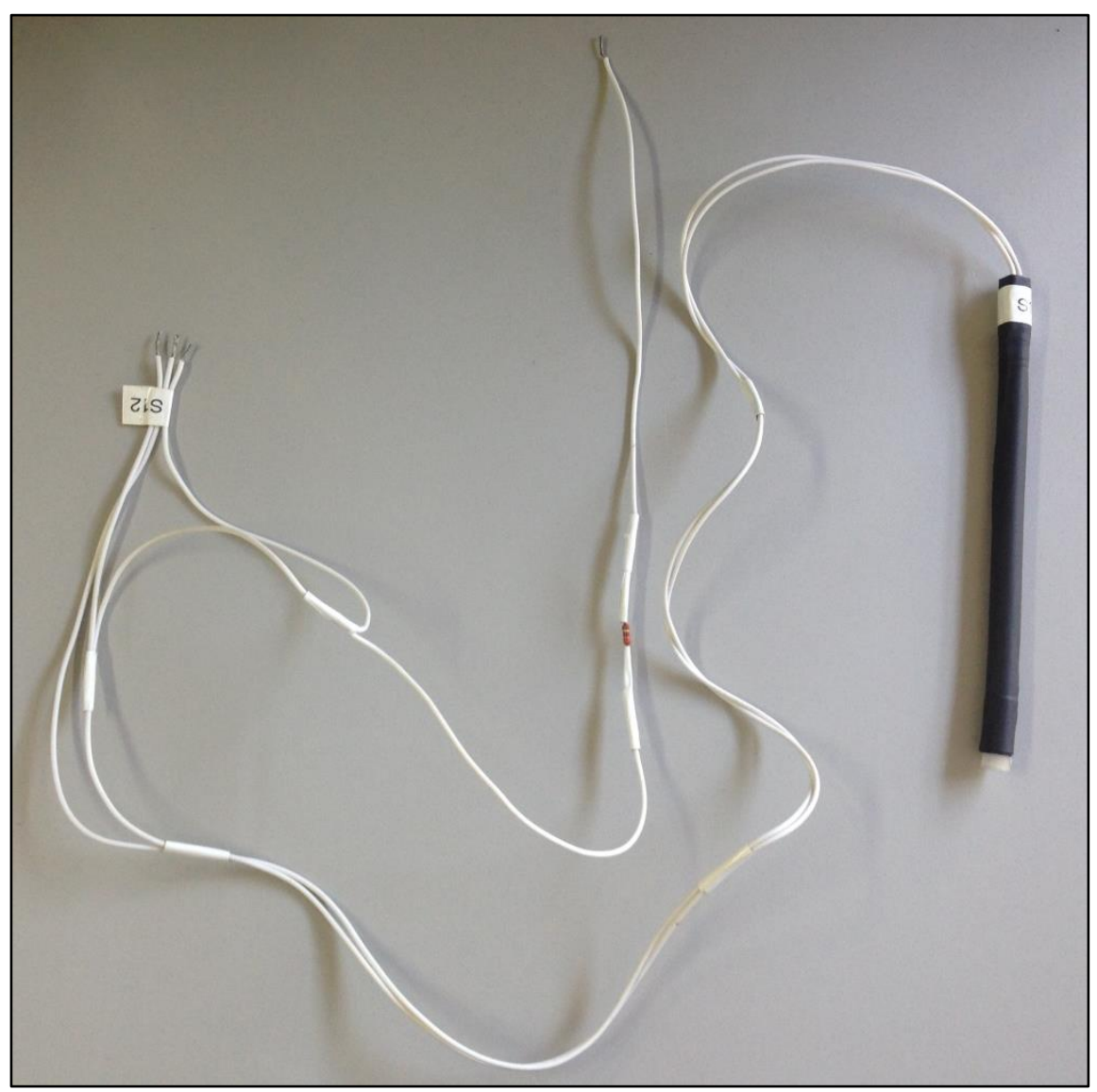

Fonte: Autor.

Figura 17. Esquema do sensor de condutividade elétrica

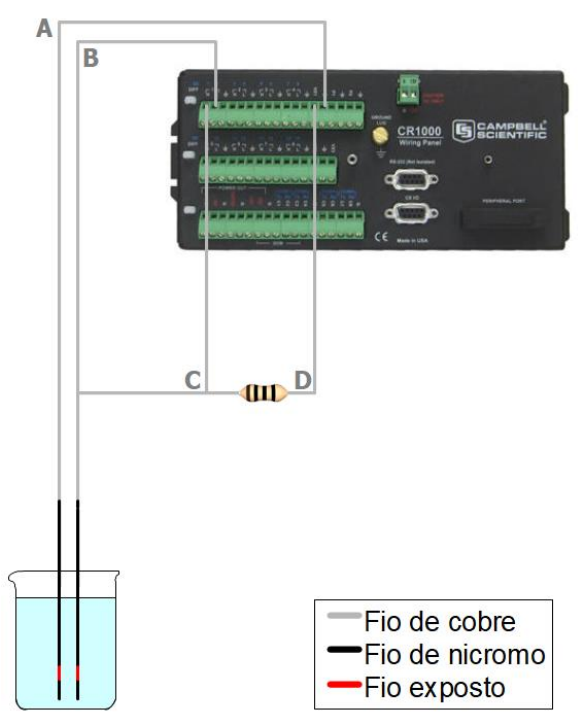

Fonte: Autor.

Através do Short Cut da plataforma LoggerNet, foi gerado o programa Half Bridge - 3 Wire, que é utilizado para determinar a razão entre a resistência do sensor e uma resistência conhecida, ou seja, Resistência sensor $_{\text {Resistência }}$ resistor . No programa, os valores inseridos nos parâmetros "Range of Output Voltage" e 
"Excitation" foram $2500 \mathrm{mV}$ e o intervalo de medição foi de dez minutos. A opção "Reverse Excitation to cancel offsets" foi selecionada como "True" pois assim os canais de excitação fornecem corrente alternada na forma de onda quadrada, já que o uso de corrente contínua durante as medições de condutividade elétrica da água não é recomendado devido ao fenômeno de eletrólise.

Para converter as medidas fornecidas pelo datalogger em condutividade elétrica, todos os sensores foram calibrados utilizando o condutivímetro COM-BTA da Vernier (Figura 18). Durante o experimento, conforme a pluma de água com sal avançava, a condutividade elétrica nos doze pontos foi medida com o condutivímetro e depois esses resultados foram relacionados com os valores obtidos pelo datalogger no mesmo horário, resultando na curva de calibração.

Figura 18. Condutivímetro Vernier CON-BTA

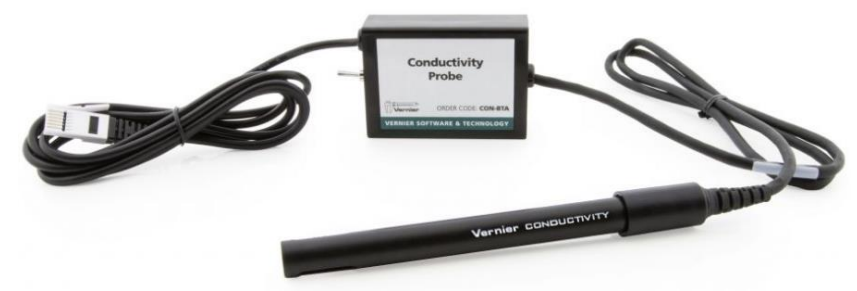

Fonte: Website da Vernier (Acesso em 27/03/2018)

<https://www.vernier.com/products/sensors/conductivity-probes/con-bta/>.

4.2.3. Funcionamento do experimento

Após a montagem do experimento, as etapas de funcionamento foram as seguintes:

1) Com o auxílio de uma caixa d'água elevada (Figura 19), o reservatório de entrada foi preenchido com água da torneira até a completa saturação do sistema. A condutividade elétrica da água utilizada era de aproximadamente 30 a $50 \mu \mathrm{S} / \mathrm{cm}$;

2) Para dar início ao escoamento da esquerda para a direita, foi estabelecida uma diferença de carga hidráulica de $0,70 \mathrm{~cm}$ entre os reservatórios de entrada e saída, ajustando a altura dos extravasores para $31,70 \mathrm{~cm}$ e 31,00 $\mathrm{cm}$ respectivamente;

3) A água que escoava pelos extravasores era coletada na caixa d'água inferior (Figura 19);

4) Durante o experimento foram registradas as vazões que saíam pela torneira da caixa d'água e pelos extravasores; 
5) Doze sensores de condutividade elétrica foram inseridos nos tubos de PVC (Figura 20) e conectados nos dataloggers (Figura 21);

6) Os pontos monitorados a cada 10 minutos pelos sensores de condutividade elétrica estão indicados de vermelho na Figura 22, porém todos os pontos eram monitorados diariamente com o condutivímetro da Vernier;

7) Após a estabilização do escoamento, foi adicionado sal na caixa d'água e no reservatório de entrada até que a água atingisse uma condutividade elétrica entre 1700 e $1900 \mu \mathrm{S} / \mathrm{cm}$, que corresponde a uma concentração de aproximadamente $700 \mathrm{mg} /$;

8) O sistema ficou sendo abastecido até que a água com sal chegasse no reservatório de saída.

Figura 19. Funcionamento do experimento

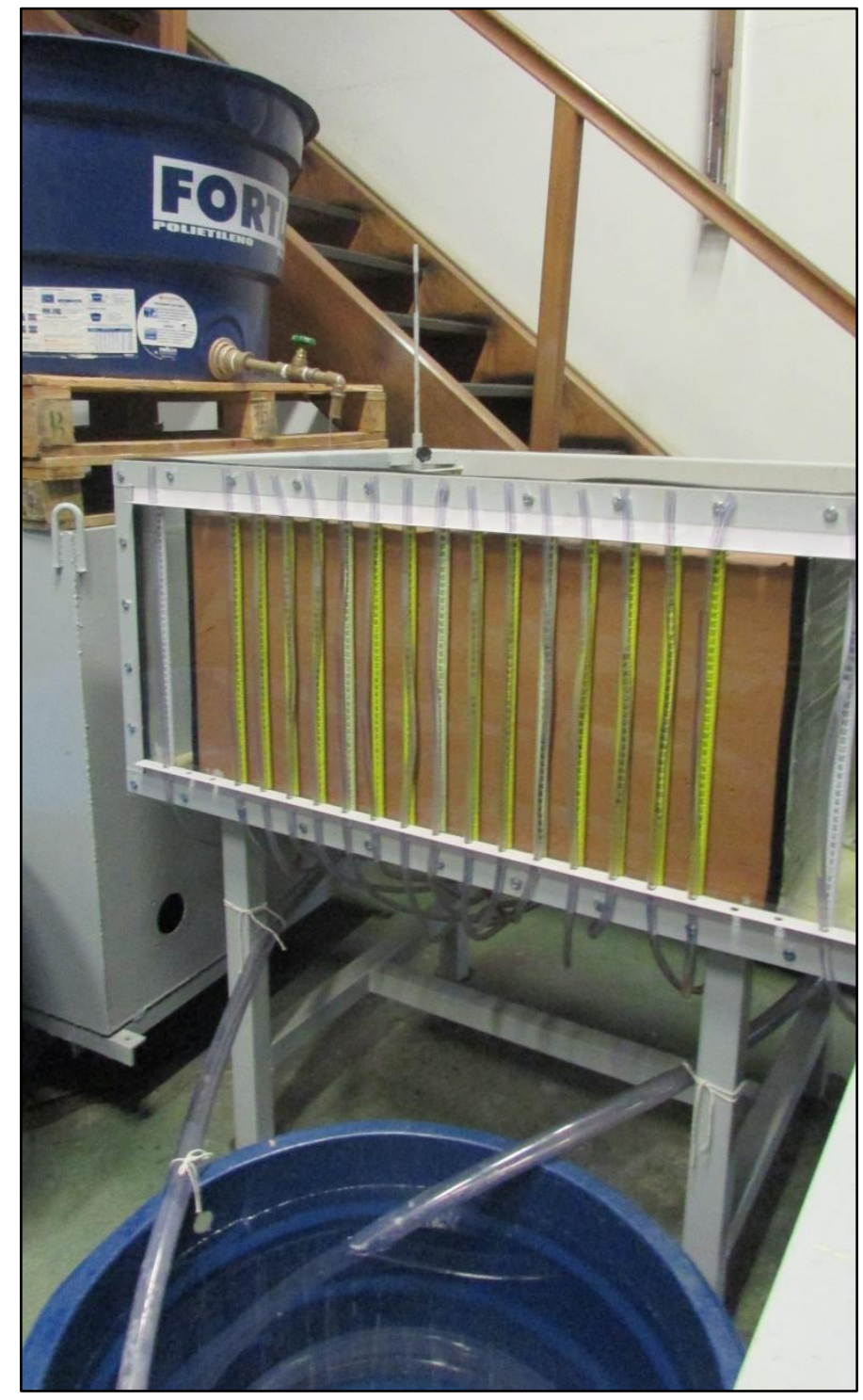

Fonte: Autor. 
Figura 20. Sensores de condutividade elétrica inseridos nos tubos de PVC

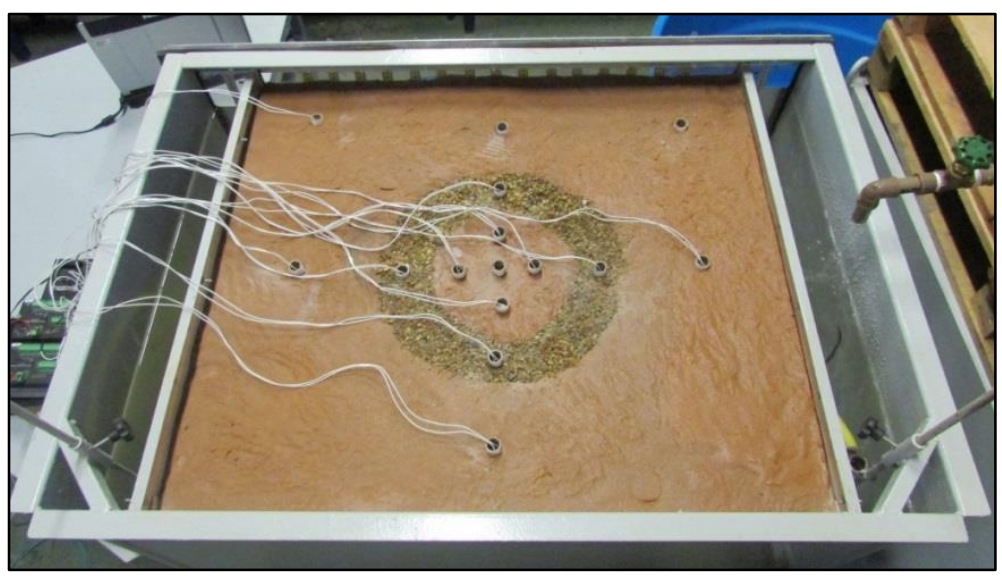

Fonte: Autor.

Figura 21. Monitoramento através dos dataloggers

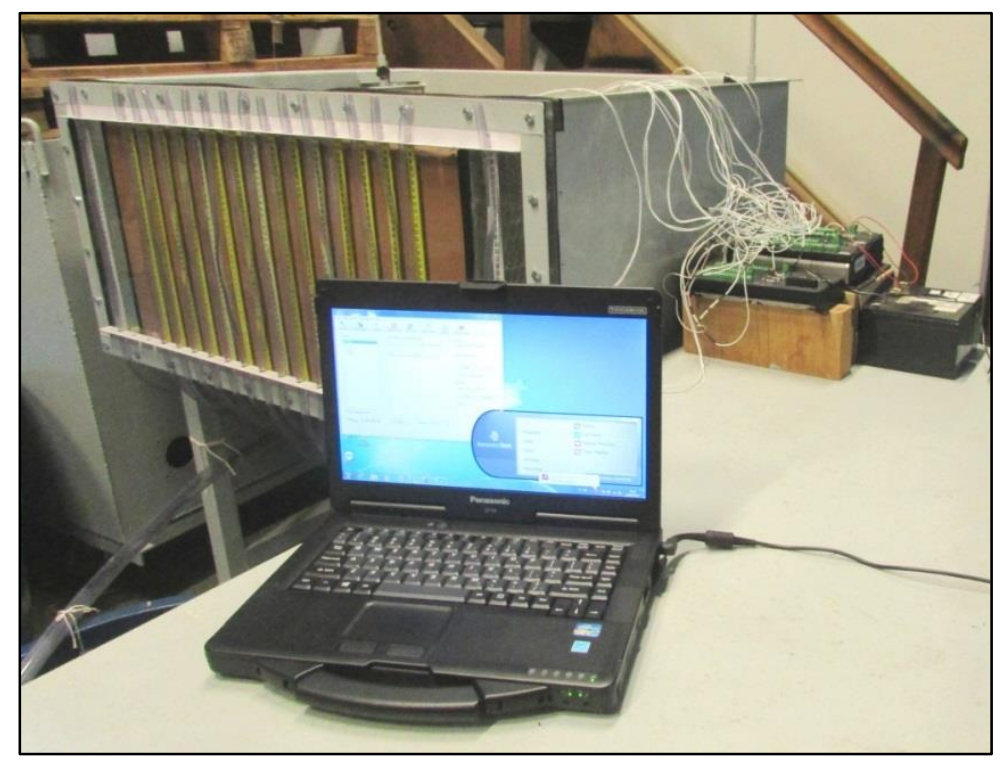

Fonte: Autor.

Figura 22. Localização do sensores

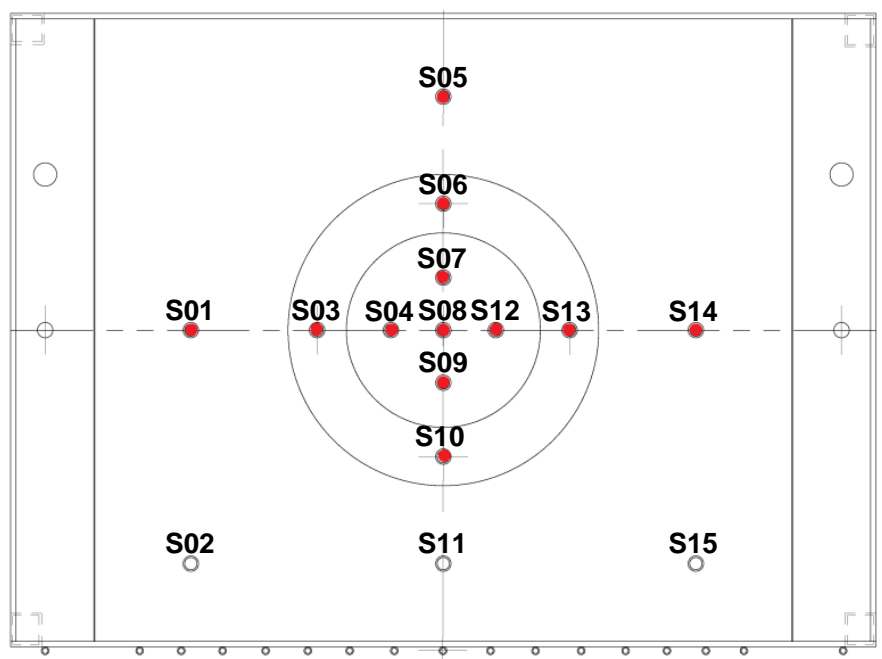

Fonte: Autor. 


\section{RESULTADOS E DISCUSSÃO}

\subsection{Aplicações da solução analítica das barreiras verticais cilíndricas}

Para verificar o desempenho das barreiras de baixa e alta permeabilidade nos casos em que a área encapsulada e o aquífero possuem condutividades hidráulicas distintas, duas simulações diferentes são apresentadas nas Tabelas 4 e 5 . O primeiro caso consiste na contaminação de um aquífero raso devido ao lixiviado produzido em um lixão desativado na cidade de São Carlos - SP, chamado de lixão Santa Madalena. Nesse local, os resíduos sólidos foram dispostos em uma zona de afloramento do aquífero Guarani, onde a condutividade hidráulica é igual a $10^{-7} \mathrm{~m} / \mathrm{s}$ (MENEZES, 1994). No segundo caso, publicado por Kimmel e Braids (1980), o lixiviado do aterro Babylon, localizado em Long Island - NY, é lançado em um aquífero glacial de alta condutividade hidráulica $\left(1,76 \times 10^{-3} \mathrm{~m} / \mathrm{s}\right)$. As simulações foram feitas utilizando condutividades hidráulicas de $10^{-9}$ (EVANS, 1993) e 10-2 m/s (FETTER, 1994) para a slurry wall de solo-bentonita e para a barreira de alta permeabilidade respectivamente. Nos dois casos, a condutividade hidráulica saturada da área de disposição dos RSU foi estabelecida como $10^{-5} \mathrm{~m} / \mathrm{s}$, os raios internos com dimensão de $415 \mathrm{~m}$ e a espessura das barreiras igual a 1 m (MULLIGAN; YONG; GIBBS, 2001). Como as redes de fluxo têm dimensões de 1000 x 1000 m, não é possível ver as barreiras, já que suas espessuras são relativamente pequenas. Para mostrar o fluxo de água subterrânea sendo desviado em torno da slurry wall e conduzido dentro da barreira de alta permeabilidade, cada figura apresenta um zoom (aproximadamente 30 × $30 \mathrm{~m}$ ) de parte da estrutura. O código utilizado para plotar as redes de fluxo estão no Apêndice B. 
Tabela 4. Simulação do desempenho das barreiras de baixa e alta permeabilidade no lixão Santa Madalena em São Carlos - S

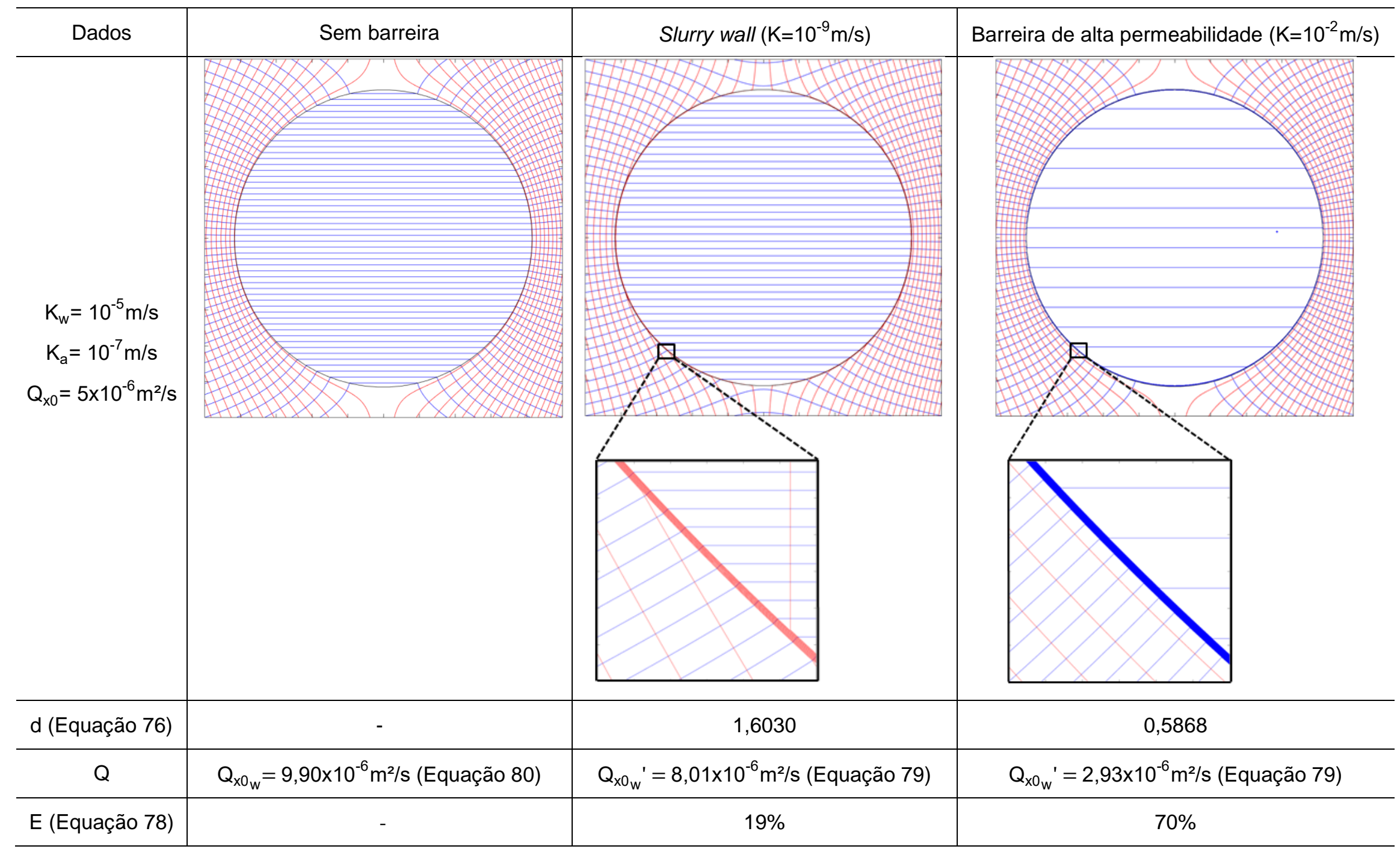


Tabela 5. Simulação do desempenho das barreiras de baixa e alta permeabilidade no lixão Babylon em Long Island - NY

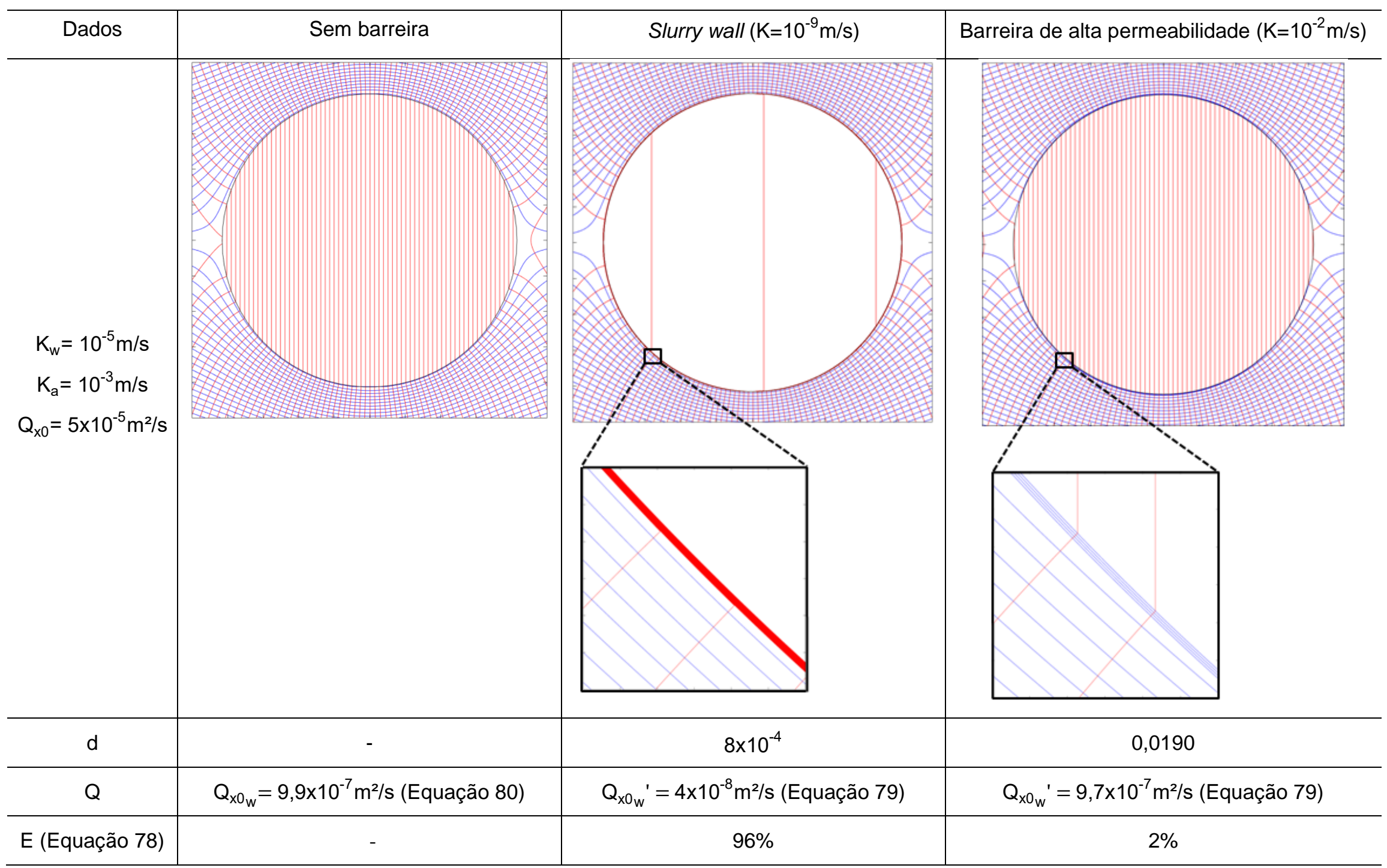


A primeira rede de fluxo da Tabela 4 mostra o depósito de resíduos $\left(K_{w}=10^{-5} \mathrm{~m} / \mathrm{s}\right.$ ) localizado no aquífero de condutividade hidráulica igual a $10^{-7} \mathrm{~m} / \mathrm{s}$. Nesse caso, como a condutividade hidráulica da inomogeneidade é maior, o fluxo uniforme através dela $\left(Q_{x_{\mathrm{w}}}\right)$ é maior do que o fluxo uniforme no campo distante $\left(Q_{\mathrm{x} 0}\right)$. A segunda rede de fluxo mostra o resultado da construção de uma slurry wall $\left(\mathrm{K}=10^{-9} \mathrm{~m} / \mathrm{s}\right)$ de $1 \mathrm{~m}$ de espessura em torno do aterro. Observa-se que o fluxo através da área encapsulada $\left(Q_{x 0_{w}}{ }^{\prime}\right)$ continua sendo maior do que $Q_{x 0}$, porém, comparando os valores de $Q$ antes $\left(Q_{x 0_{w}}\right)$ e depois $\left(Q_{x 0_{w}}{ }^{\prime}\right)$ da instalação da barreira, a redução do fluxo foi de $19 \%$. Nesse exemplo, a barreira de alta permeabilidade foi mais eficaz, reduzindo o fluxo uniforme através da área encapsulada em $70 \%$, resultando em um valor de $Q_{\mathrm{xO}_{\mathrm{w}}}{ }^{\prime}$ menor do que $\mathrm{Q}_{\mathrm{x} 0}$. Além disso, é possível observar que da primeira para a terceira rede de fluxo, as linhas de corrente na região do aterro ficam cada vez mais distantes umas das outras.

$\mathrm{Na}$ Tabela 5, a primeira rede de fluxo apresenta o depósito de resíduos localizado no aquífero de condutividade hidráulica igual a $10^{-3} \mathrm{~m} / \mathrm{s}$. Como nesse caso a condutividade hidráulica da inomogeneidade é menor, as linhas de corrente contornam a região, resultando em um fluxo uniforme $\left(\mathrm{Q}_{\mathrm{xO}_{\mathrm{w}}}\right)$ menor do que $\mathrm{Q}_{\mathrm{x} 0}$. Como o aquífero utilizado nesse exemplo é extremamente permeável, provavelmente não seria necessário construir uma barreira no local, já que o fluxo de água subterrânea seria desviado naturalmente. Porém, simulou-se a instalação das barreiras de baixa e alta permeabilidade para comparar os seus desempenhos em locais onde a condutividade hidráulica da área encapsulada é menor do que a do aquífero. Com a construção da slurry wall, o fluxo diminui ainda mais e, comparando os valores de $\mathrm{Q}$ antes $\left(Q_{x 0_{w}}\right)$ e depois $\left(Q_{x 0_{w}}{ }^{\prime}\right)$, sua eficiência é de $96 \%$. Com a barreira de alta permeabilidade, o fluxo uniforme através da área encapsulada também é menor do que $Q_{x 0}$, porém, comparando com $Q$ anterior à instalação $\left(Q_{x 0_{w}}\right)$, a redução é de apenas $2 \%$.

Esses exemplos de aplicação das barreiras hidráulicas verticais mostram que nos casos em que a região encapsulada e o aquífero possuem condutividades hidráulicas diferentes, o desempenho da barreira escolhida deve ser avaliado comparando-se o fluxo uniforme através da área contaminada antes e depois da sua instalação. A partir desses resultados, também é possível concluir que nos casos em que o maciço de resíduos possui condutividade hidráulica maior do que o aquífero, a 
barreira de alta permeabilidade é a solução mais eficaz. Já nos problemas em que o aterro possui condutividade hidráulica menor do que o aquífero, a técnica mais indicada é a slurry wall. Em casos reais, deve-se determinar a espessura e o material de preenchimento da barreira de modo que o fluxo através do aterro seja reduzido a um nível aceitável. Então, as características da barreira devem ser analisadas para verificar a viabilidade de construção da estrutura no aquífero em questão.

\subsection{Experimento em escala reduzida}

Foram realizados alguns testes preliminares com diferentes gradientes hidráulicos e concentrações de sal. Dentre eles, o que forneceu os melhores resultados foi o teste no qual a diferença de carga hidráulica entre os reservatórios e a concentração de sal de eram de $0,7 \mathrm{~cm}$ e $700 \mathrm{mg} / \mathrm{l}$ respectivamente. Os resultados obtidos estão detalhados a seguir, desde a simulação matemática até o monitoramento do experimento.

\subsubsection{Simulação do experimento}

Para simular o escoamento através do experimento, foram utilizados os dados da Tabela 6. A Figura 23 apresenta a rede de fluxo gerada a partir do código do Apêndice B. O fator de redução (D - Equação 47) resultante foi de 0,0202, ou seja, no experimento a barreira é capaz de reduzir em $97,98 \%$ o fluxo através da área encapsulada.

Com o objetivo de analisar as cotas piezométricas e as velocidades médias $(v=q / n)$ em cada ponto do experimento, foram gerados os gráficos das Figuras 24, 25, 26, 27 e 28. As Figuras 24 e 25 apresentam os valores da cota piezométrica e da velocidade média em todos os domínios. Devido às diferentes magnitudes da velocidade média nos três domínios, as Figuras 26, 27 e 28 mostram os campos de velocidade do aquífero, da barreira e da área encapsulada separadamente, para possibilitar a visualização dos vetores. 
Tabela 6. Dados utilizados na simulação do experimento

\begin{tabular}{l|l}
\hline Condutividade hidráulica da areia fina & $\mathrm{K}_{\mathrm{w}}=\mathrm{K}_{\mathrm{a}}=1,5 \times 10^{-4} \mathrm{~m} / \mathrm{s}$ \\
\hline Condutividade hidráulica do cascalho & $\mathrm{K}_{\mathrm{b}}=5 \times 10^{-2} \mathrm{~m} / \mathrm{s}$ \\
\hline Raio interno & $0,1225 \mathrm{~m}$ \\
\hline Raio externo & $0,1900 \mathrm{~m}$ \\
\hline Carga piezométrica no reservatório 1 & $\phi_{1}=0,3170 \mathrm{~m}$ \\
\hline Carga piezométrica do reservatório 2 & $\Phi_{2}=0,3100 \mathrm{~m}$ \\
\hline Potencial de descarga no reservatório 1 & $\Phi_{1}=\frac{1}{2} \mathrm{~K}_{1} \phi_{1}{ }^{2}=\frac{1}{2} 1,5 \times 10^{-4} 0,3170^{2}=7,54 \times 10^{-6} \mathrm{~m}^{3} / \mathrm{s}$ \\
\hline Potencial de descarga no reservatório 2 & $\Phi_{2}=\frac{1}{2} \mathrm{~K}_{2} \phi_{2}{ }^{2}=\frac{1}{2} 1,5 \times 10^{-4} 0,3100^{2}=7,21 \times 10^{-6} \mathrm{~m}^{3} / \mathrm{s}$ \\
\hline Potencial de descarga ao longo do eixo y & $\Phi_{0}=\frac{1}{2}\left(\Phi_{1}+\Phi_{2}\right)=7,37 \times 10^{-6} \mathrm{~m}^{3} / \mathrm{s}$ \\
\hline Altura piezométrica ao longo do eixo y & $\phi_{0}=\sqrt{\frac{2 \Phi_{0}}{\mathrm{~K}_{0}}=\sqrt{\frac{9,83 \times 10^{-6}}{10^{-4}}=0,3135 \mathrm{~m}}}$ \\
\hline Vetor dearga & $Q_{\mathrm{x} 0}=\frac{\Phi_{1}-\Phi_{2}}{\mathrm{~L}}=\frac{7,54 \times 10^{-6}-7,21 \times 10^{-6}}{0,90}=3,66 \times 10^{-7} \mathrm{~m}^{2} / \mathrm{s}$ \\
\hline
\end{tabular}

Figura 23. Rede de fluxo do experimento $(D=0,0202)$

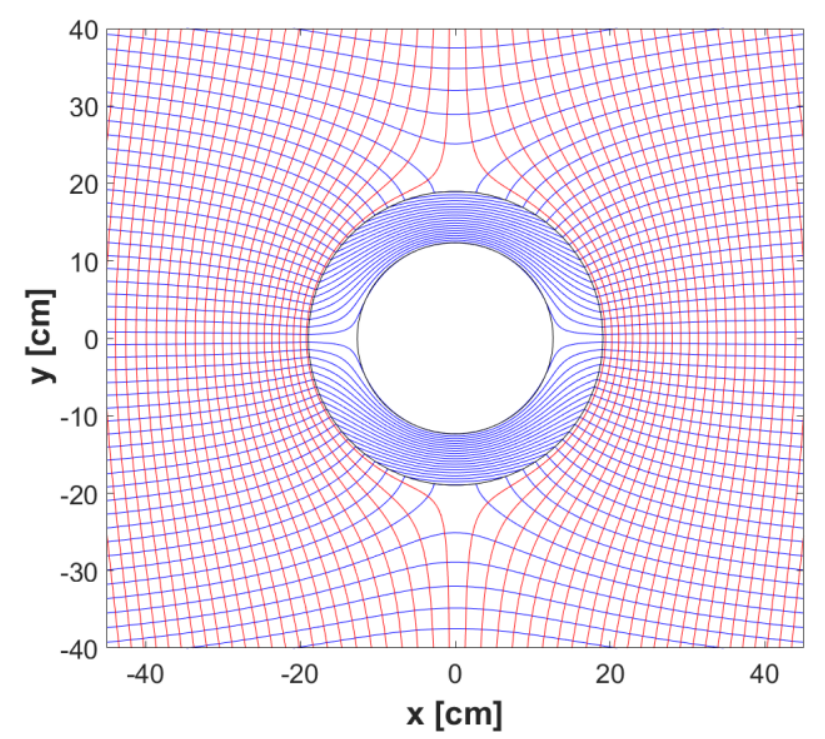

Fonte: Autor. 
Figura 24. Superfície indicando as cotas piezométricas do experimento

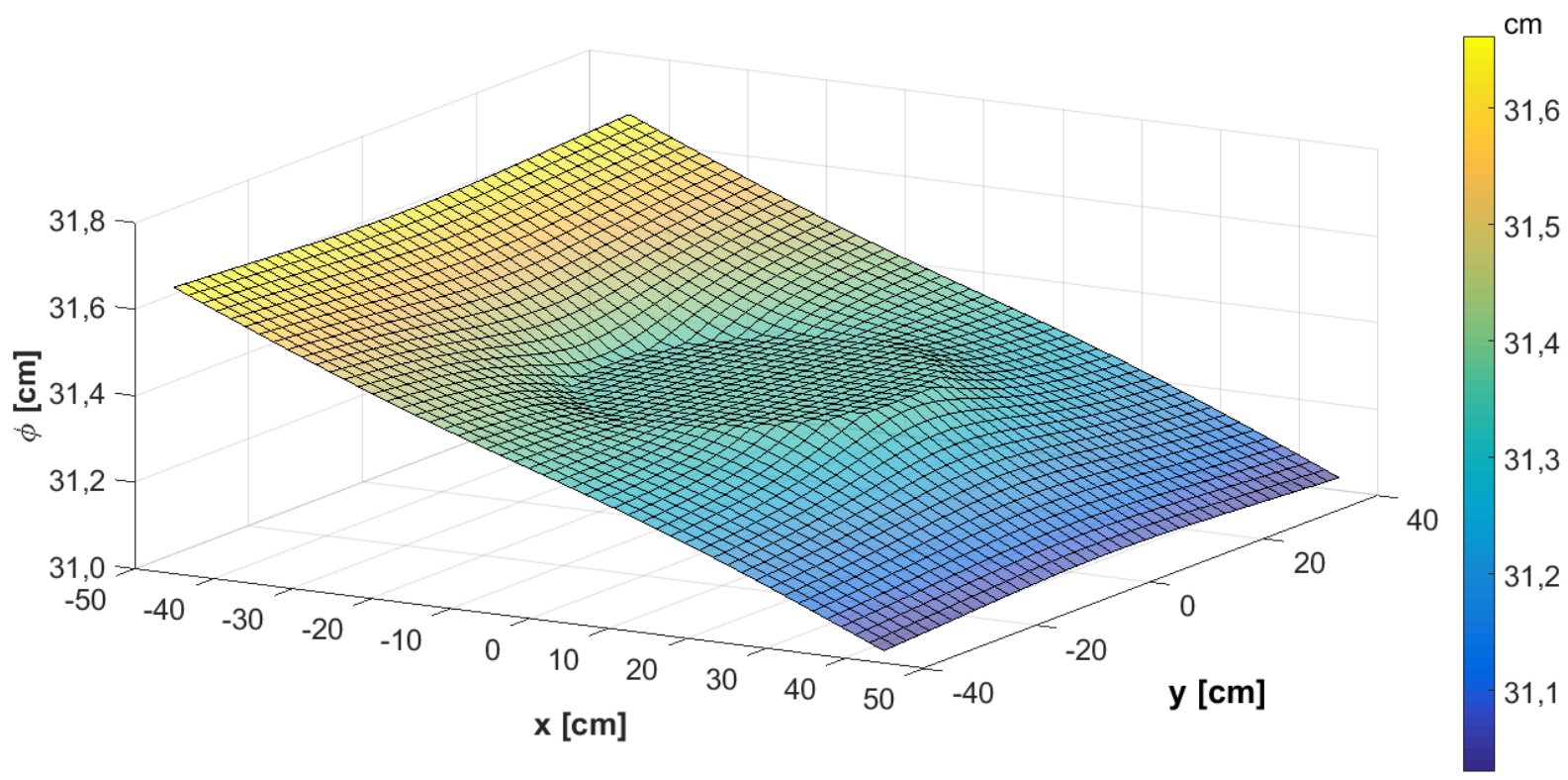

Fonte: Autor.

Figura 25. Campo da velocidade média

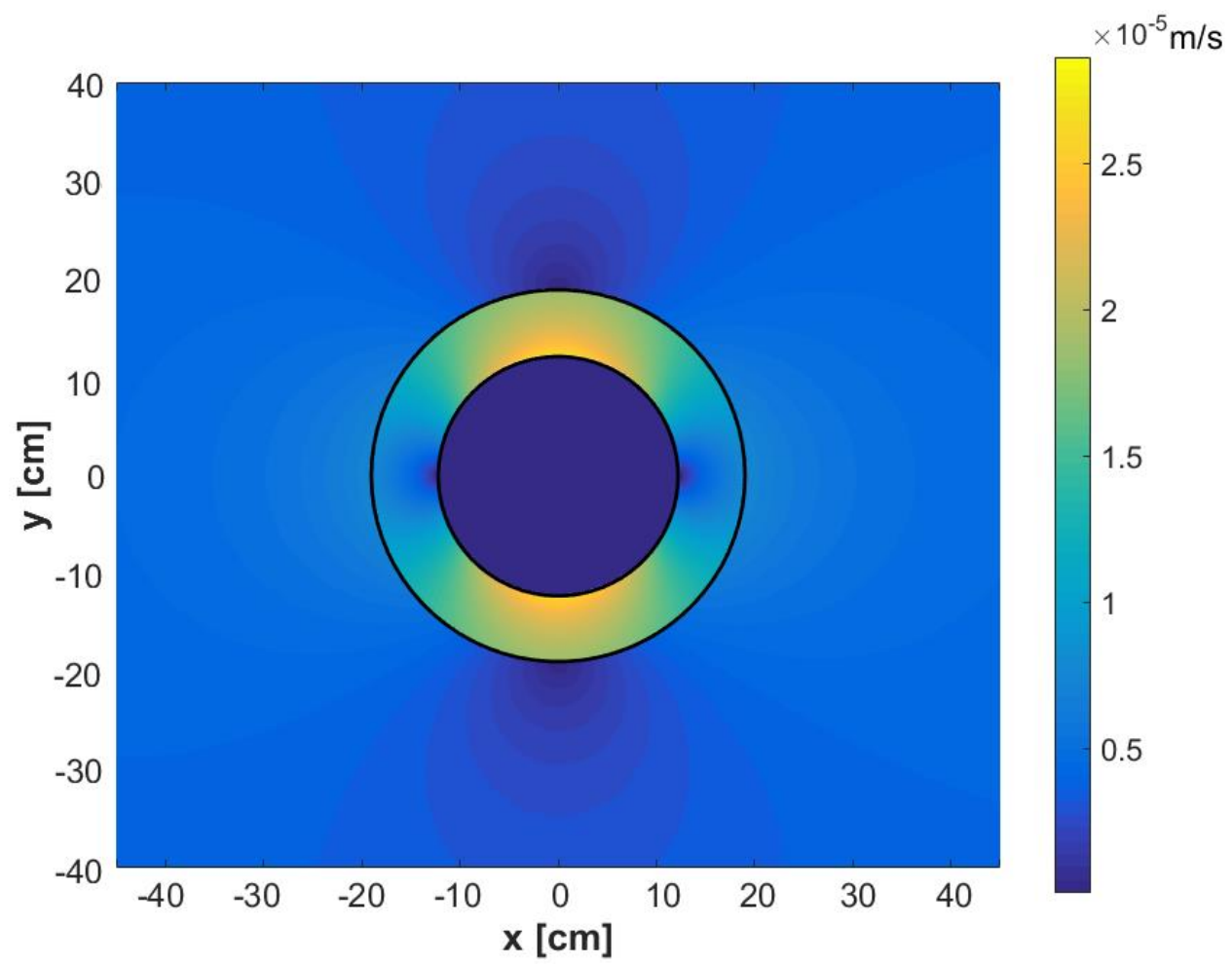

Fonte: Autor. 
Figura 26. Campo da velocidade média no domínio do aquífero

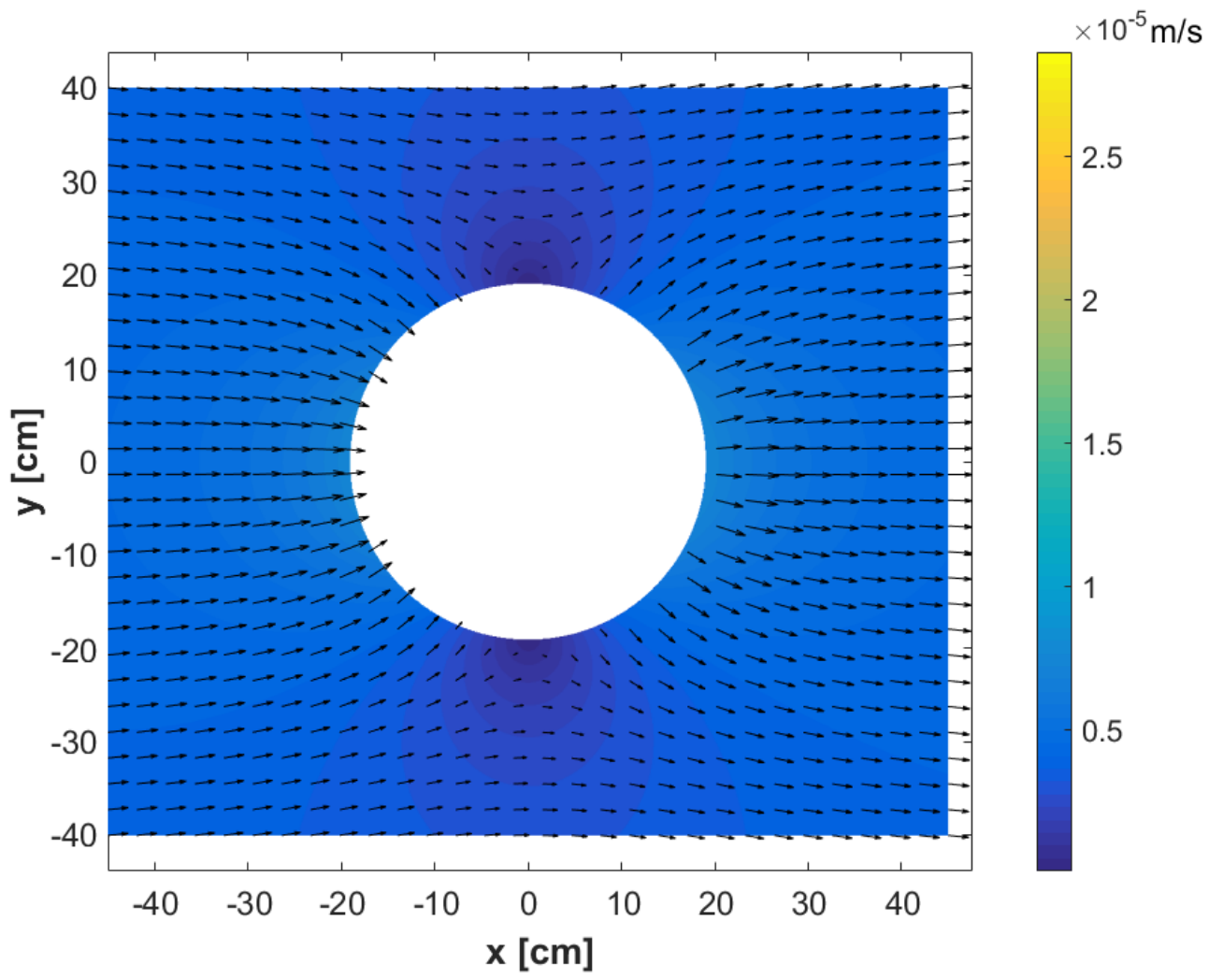

Fonte: Autor.

Figura 27. Campo da velocidade média no domínio da barreira

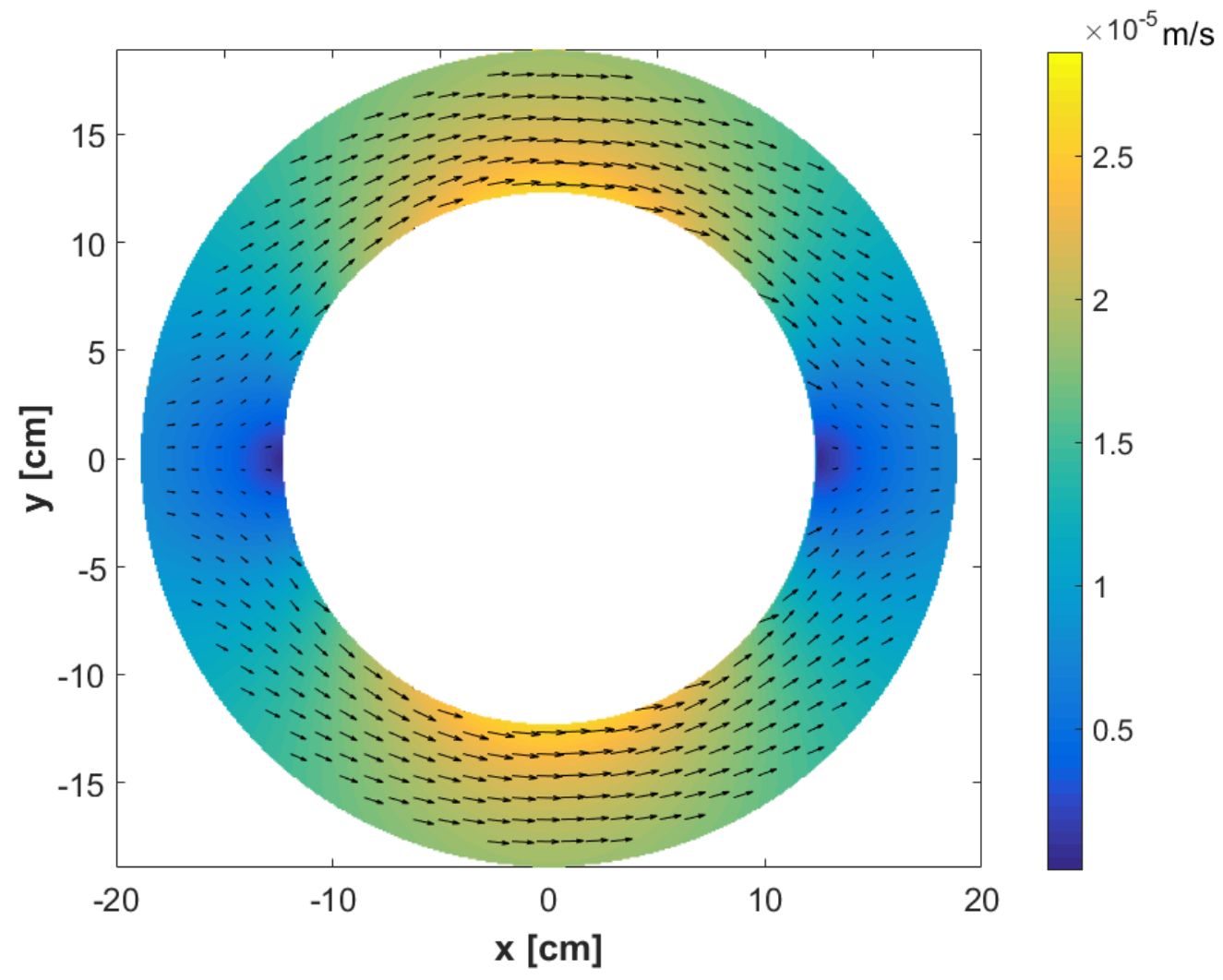

Fonte: Autor. 
Figura 28. Campo da velocidade média no domínio da área encapsulada

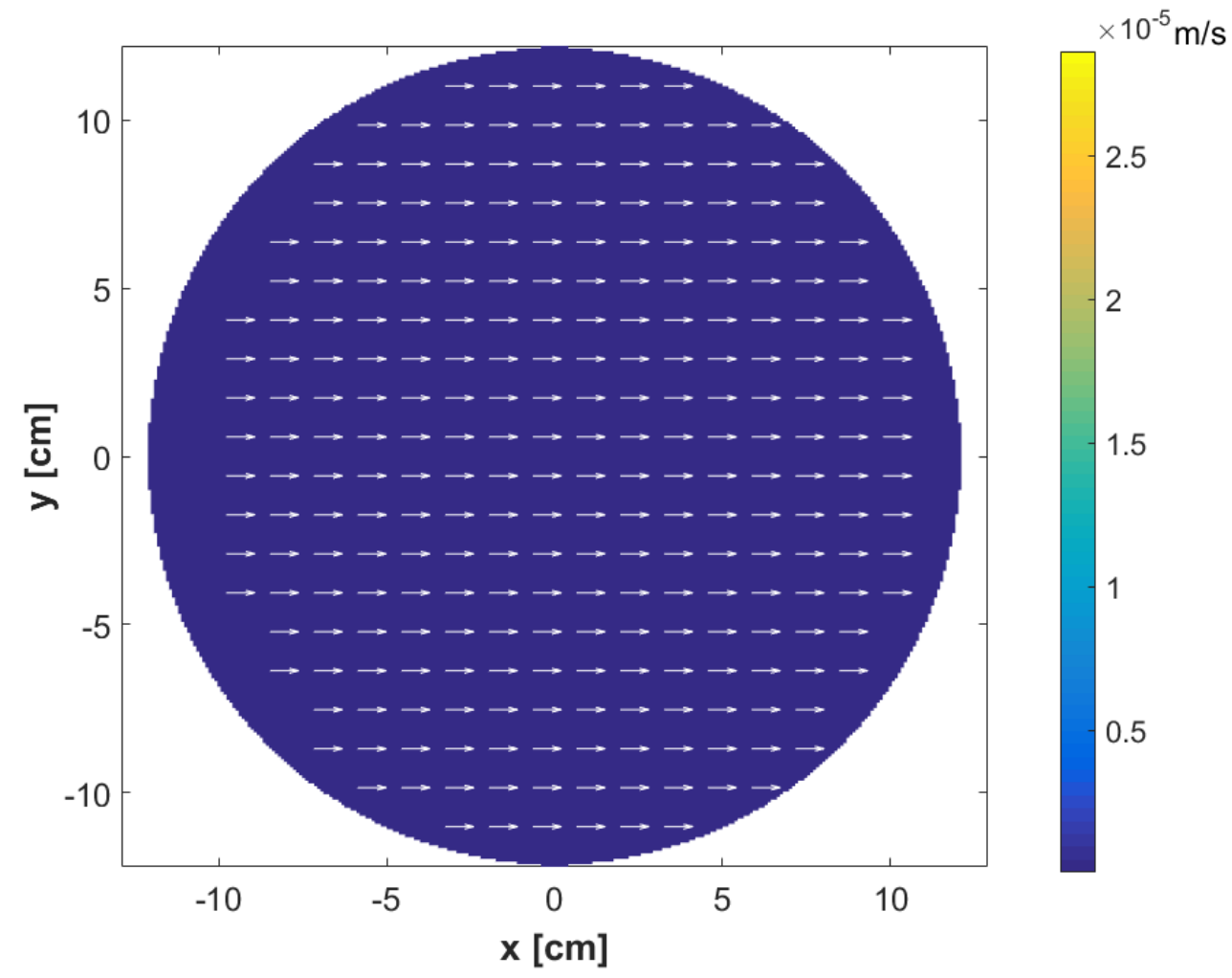

Fonte: Autor.

A partir desses resultados, conclui-se que uma das simplificações adotadas foi assumir que nas extremidades verticais da caixa $(x=-45 \mathrm{~cm} \mathrm{e} x=45 \mathrm{~cm}$ ) o fluxo é uniforme, pois como pode ser visto na Figura 23, o comprimento do experimento não é grande o suficiente para que o fluxo uniforme seja estabelecido. No entanto, essa simplificação não possui influência considerável nos resultados finais, já que como mostra a Figura 24, as cotas piezométricas nas extremidades são aproximadamente iguais às dos reservatórios $(0,3170$ e 0,3100 m). Outra simplificação adotada foi desprezar nos cálculos os efeitos de parede do experimento. Porém, a partir da Figura 26, é possível observar que nas extremidades horizontais ( $\mathrm{y}=-40 \mathrm{~cm}$ e $\mathrm{y}=40 \mathrm{~cm}$ ) os vetores da velocidade média são praticamente paralelos às bordas do experimento, ou seja, os efeitos de parede não são significativos.

A Figura 26 mostra que a velocidade média aumenta conforme as partículas do fluido se aproximam da interface entre a areia e o cascalho, com exceção das regiões próximas às coordenadas $(0,20)$ e $(0,-20)$, onde as velocidades são menores devido ao ponto de estagnação. Na Figura 27, observa-se que a velocidade média atinge o seu valor máximo no interior da barreira em $x=0$. Já na área encapsulada (Figura 28), - fluxo é uniforme e as partículas se movimentam com baixa velocidade $\left(\mathrm{v}=7,9 \times 10^{-8} \mathrm{~m} / \mathrm{s}\right)$. Utilizando as informações das Figuras 25, 26, 27 e 28, calculou-se 
o tempo que as partículas do fluido levam para se deslocar entre determinados pontos localizados na reta $\mathrm{y}=0$ (Tabela 7). As trajetórias descritas na primeira coluna da Tabela 7 (Partida - Chegada) estão indicadas na Figura 29. A vazão calculada para 0 experimento foi de $3,2 \times 10^{-7} \mathrm{~m}^{3} / \mathrm{s}$ ou $0,322 \mathrm{ml} / \mathrm{s}$.

Tabela 7. Tempo de deslocamento entre os pontos localizados em y=0

\begin{tabular}{ccccc}
\hline Partida - Chegada & Distância $(\mathbf{m})$ & $\begin{array}{c}\text { Velocidade média } \\
(\mathbf{m} / \mathbf{s})\end{array}$ & Tempo (h) & Tempo (dia) \\
\hline Reservatório 1 - S01 & 0,1250 & $4,82 \times 10^{-6}$ & 7,2 & 0,3 \\
\hline Reservatório 1 - S03 & 0,2500 & $5,43 \times 10^{-6}$ & 12,8 & 0,5 \\
\hline $\begin{array}{c}\text { Interface da barreira com } \\
\text { a área contaminada - S04 }\end{array}$ & 0,0575 & $7,31 \times 10^{-8}$ & 218,6 & 9,1 \\
\hline $\begin{array}{l}\text { Interface da barreira com } \\
\text { a área contaminada - S08 }\end{array}$ & 0,1250 & $7,64 \times 10^{-8}$ & 454,5 & 18,9 \\
\hline $\begin{array}{c}\text { Interface da barreira com } \\
\text { a área contaminada - S12 }\end{array}$ & 0,1925 & $7,73 \times 10^{-8}$ & 692 & 28,8 \\
\hline $\begin{array}{c}\text { Interface da barreira com } \\
\text { o aquífero - S14 }\end{array}$ & 0,1250 & $6,03 \times 10^{-6}$ & 5,8 & 0,2 \\
\hline
\end{tabular}

Figura 29. Trajetórias do fluido

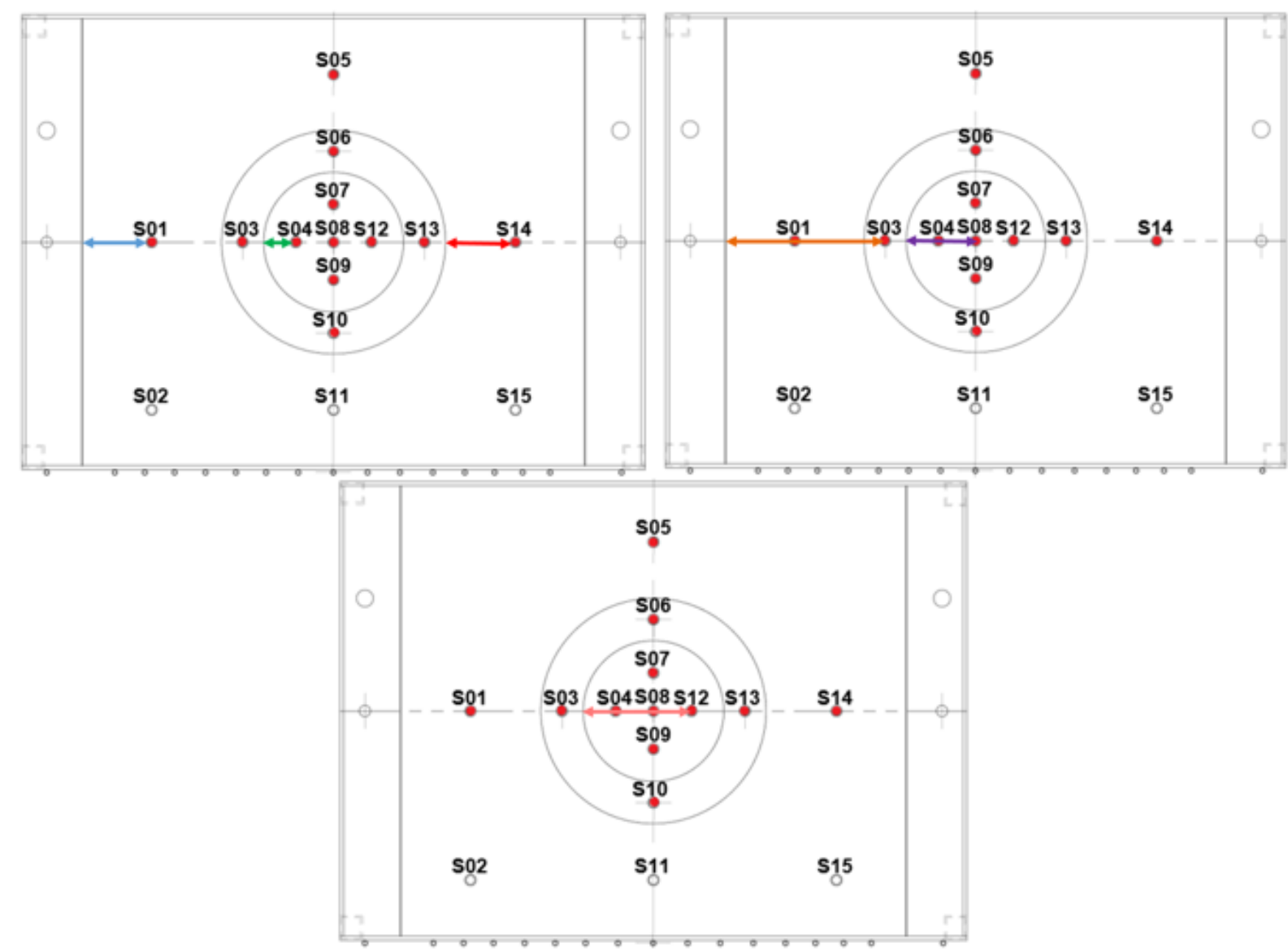

Fonte: Autor. 
5.2.2. Sensores de condutividade elétrica

Os valores medidos pelos dataloggers (Resistência ${ }_{\text {sensor }} /$ Resistência $_{\text {resistor }}$ ) durante o experimento e as respectivas condutividades elétricas obtidas através do condutivímetro da Vernier foram correlacionados para calibrar os sensores. A regressão não linear que melhor se ajustou aos dados foi do tipo potência $\left(a \cdot x^{b}\right)$. A Tabela 8 apresenta os coeficientes "a" e "b", o coeficiente de determinação e o intervalo de confiança de $95 \%$ da média do erro para cada um dos sensores. Os gráficos resultantes estão apresentados no Apêndice C.

Para transformar os valores de condutividade elétrica em concentração de sal, foram preparadas onze amostras de água da torneira contendo de 0 a 0,850 $\mathrm{g} / \mathrm{l}$ de sal de cozinha e o condutivímetro da Vernier foi utilizado para medir as condutividades. A reta resultante é apresentada na Figura 30. 
Tabela 8. Coeficientes " $a$ " e "b" da regressão não linear, $\mathbf{R}^{2}$ e intervalo de confiança de $95 \%$ da média do erro dos sensores de condutividade elétrica

\begin{tabular}{ccccc}
\hline Sensor & $\mathbf{a}$ & $\mathbf{b}$ & $\mathbf{R}^{\mathbf{2}}$ & Intervalo de confiança do erro \\
\hline S01 & 262504 & $-1,56$ & 0,999 & {$[-18,34 ; 8,50]$} \\
\hline S03 & 661850 & $-1,73$ & 0,992 & {$[-14,59 ; 7,90]$} \\
\hline S04 & 198313 & $-1,55$ & 0,998 & {$[-4,74 ; 2,97]$} \\
\hline$S 05$ & 193271 & $-1,43$ & 0,991 & {$[-24,00 ; 5,56]$} \\
\hline$S 06$ & 545815 & $-1,76$ & 0,995 & {$[-23,82 ; 1,17]$} \\
\hline$S 07$ & 125458 & $-1,46$ & 0,997 & {$[-7,56 ; 7,00]$} \\
\hline$S 08$ & 161776 & $-1,45$ & 0,992 & {$[-18,95 ; 2,96]$} \\
\hline$S 09$ & 145601 & $-1,36$ & 0,998 & {$[-12,64 ; 3,03]$} \\
\hline$S 10$ & 600378 & $-1,82$ & 0,998 & {$[-11,60 ; 7,33]$} \\
\hline$S 12$ & 105758 & $-1,36$ & 0,998 & {$[-4,22 ; 5,15]$} \\
\hline$S 13$ & 211386 & $-1,53$ & 0,994 & {$[-4,49 ; 6,96]$} \\
\hline$S 14$ & 94060 & $-1,27$ & 0,992 & {$[-21,16 ; 4,59]$}
\end{tabular}

Figura 30. Correlação da condutividade elétrica com a concentração de sal

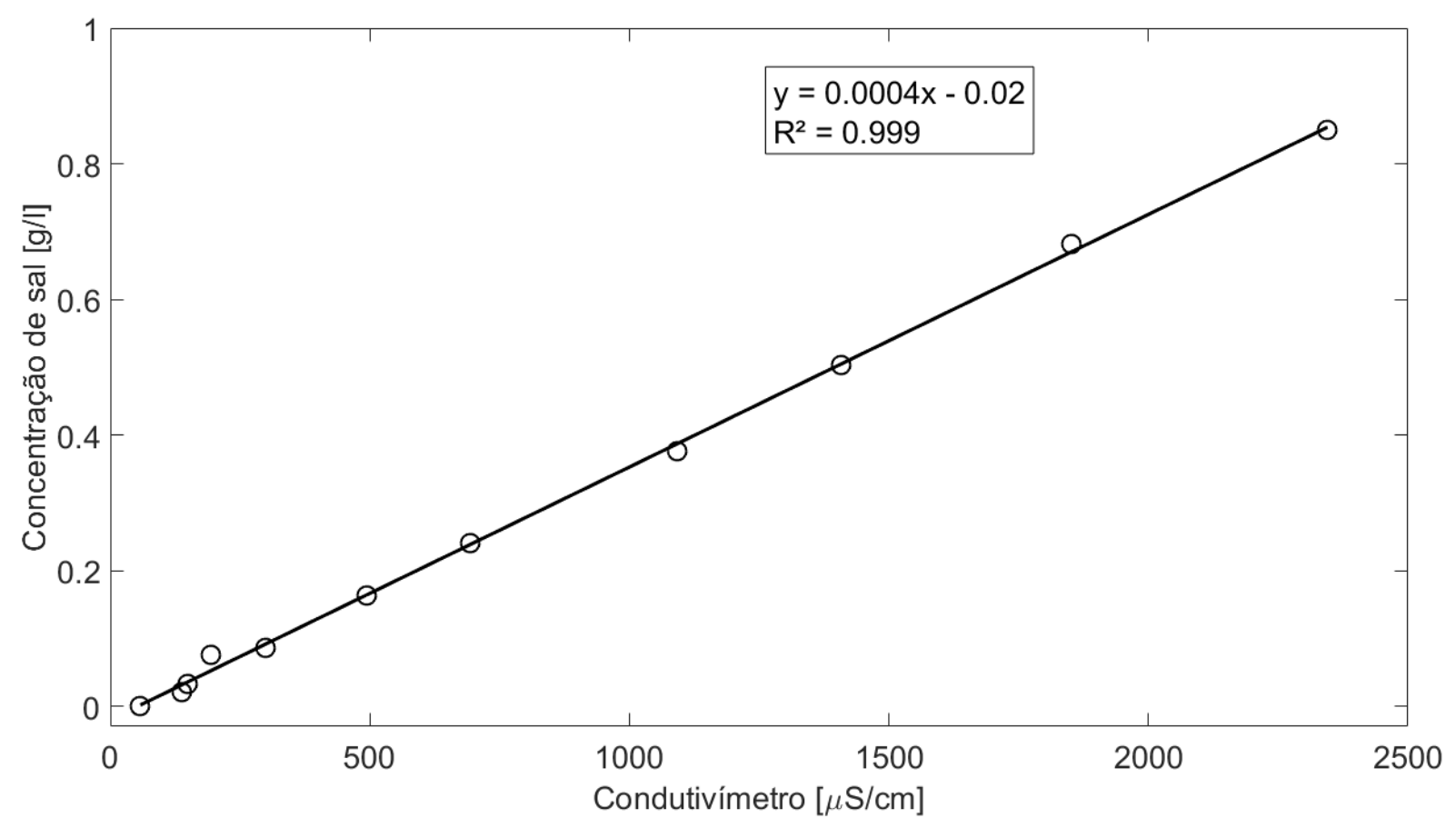

Fonte: Autor. 


\subsubsection{Monitoramento}

O experimento foi monitorado por aproximadamente seis dias (140 horas). A vazão medida no extravasor do reservatório de saída foi de 0,322 $\mathrm{ml} / \mathrm{s}$, sendo exatamente igual à estimada no item 5.2.1. A Figura 31 mostra o resultado do monitoramento feito a cada dez minutos pelos sensores de condutividade elétrica nos doze pontos indicados na Figura 22, e a Figura 32 apresenta as medições diárias utilizando o condutivímetro da Vernier nos outros três pontos e nos dois reservatórios laterais. Para facilitar a visualização do monitoramento, os gráficos de cada ponto estão apresentados separadamente no Apêndice D, os quais mostram tanto as medições realizadas pelos sensores de condutividade elétrica quanto os respectivos valores obtidos pelo condutivímetro. A partir da análise dos gráficos do Apêndice $D$, conclui-se que os resultados dos sensores de condutividade elétrica são satisfatórios, já que são bem próximos dos medidos com o condutivímetro.

\section{Figura 31. Resultado do monitoramento utilizando os sensores de condutividade elétrica}

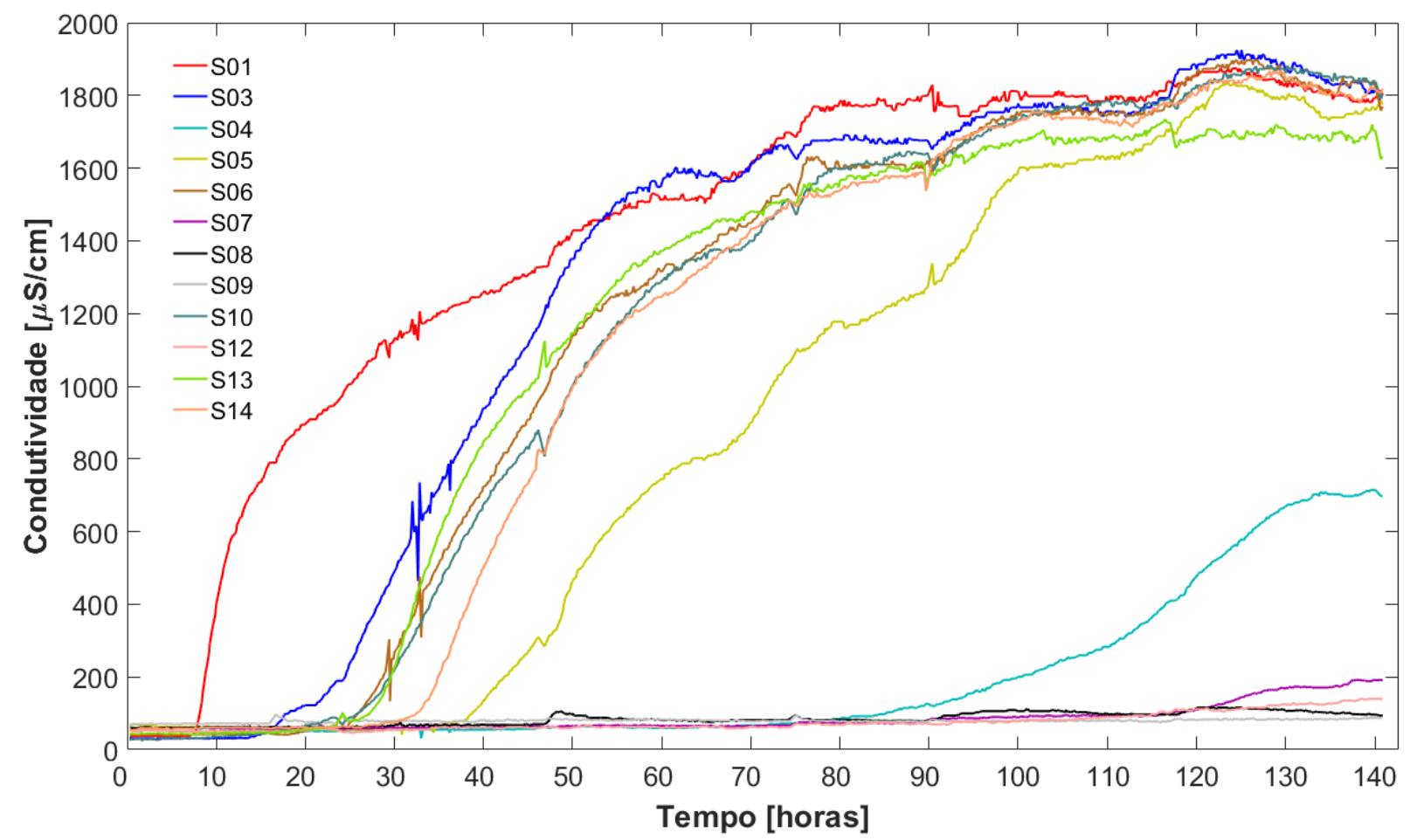

Fonte: Autor. 
Figura 32. Resultado do monitoramento utilizando o condutivímetro

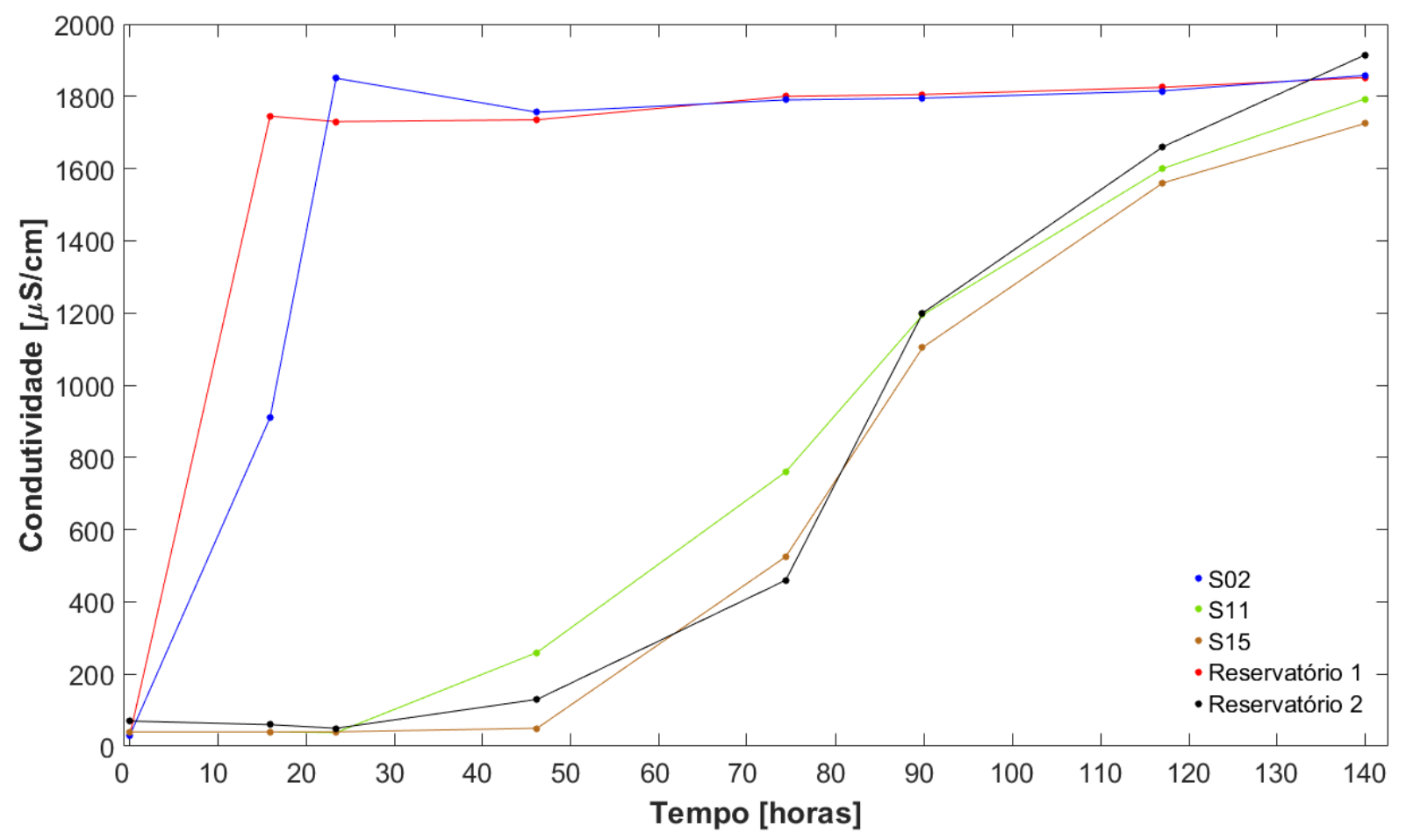

Fonte: Autor.

A partir da Figura 31, observa-se, que como esperado, a água com sal chega em todos os sensores do aquífero e da barreira, mas atinge minimamente os pontos da área encapsulada, com exceção do S04, que dentre os cinco sensores foi o que apresentou a maior condutividade elétrica por ser o ponto mais próximo da interface barreira-área encapsulada. A Tabela 9 apresenta os sensores de condutividade elétrica por ordem de chegada da água com sal e as respectivas condutividades elétricas e concentrações de sal no final do experimento. É possível constatar que em todos os pontos do aquífero e da barreira, a condutividade elétrica alcança o valor máximo, que é de aproximadamente $1800 \mu \mathrm{S} / \mathrm{cm}$ ou $700 \mathrm{mg} / \mathrm{l}$. A condutividade elétrica no S04 teve um aumento considerável $(737 \mu \mathrm{S} / \mathrm{cm})$ e os valores nos pontos S07, S09 e $S 12$ são relativamente baixos. No ponto $S 08$, a condutividade final atingiu $76 \mu \mathrm{S} / \mathrm{cm}$, que é semelhante à da água pura $(50 \mu \mathrm{S} / \mathrm{cm})$. Nota-se que apesar do ponto $\mathrm{S} 08$ apresentar alguns picos na condutividade elétrica antes do que o S07, S09 e S12, seu valor de condutividade no final do experimento é inferior. 
Tabela 9. Ordem de chegada da água com sal em cada sensor e respectivos valores de condutividade elétrica e concentração de sal após 140 horas.

\begin{tabular}{cccc}
\hline Ordem & Sensor & Condutividade elétrica $(\boldsymbol{\mu S} / \mathbf{c m})$ & Concentração de sal $(\mathbf{m g} / \mathbf{l})$ \\
\hline $1^{\circ}$ & $\mathrm{S} 01$ & 1838 & 715 \\
\hline $2^{0}$ & $\mathrm{~S} 03$ & 1838 & 715 \\
\hline $3^{\circ}$ & $\mathrm{S} 06$ & 1827 & 711 \\
\hline $4^{\circ}$ & $\mathrm{S} 10$ & 1838 & 715 \\
\hline $5^{\circ}$ & $\mathrm{S} 13$ & 1802 & 701 \\
\hline $6^{\circ}$ & $\mathrm{S} 14$ & 1815 & 706 \\
\hline $7^{\circ}$ & $\mathrm{S} 05$ & 1759 & 684 \\
\hline $8^{\circ}$ & $\mathrm{S} 04$ & 737 & 275 \\
\hline $9^{\circ}$ & $\mathrm{S} 07$ & 194 & 58 \\
\hline $10^{\circ}$ & $\mathrm{S} 12$ & 139 & 36 \\
\hline $11^{\circ}$ & $\mathrm{S} 08$ & 76 & 10 \\
\hline $12^{\circ}$ & $\mathrm{S} 09$ & 106 & 22 \\
\hline
\end{tabular}

Verifica-se que, devido à presença da barreira, o transporte mais rápido ocorre em $\mathrm{y}=0$, onde as partículas saem do ponto $\mathrm{S} 01$, contornam a área encapsulada e chegam no ponto S14. Mesmo estando mais próximo do reservatório, o ponto S05 é atingido somente algumas horas depois que o ponto $\mathrm{S} 14$. $\mathrm{Na}$ área encapsulada, a água com sal chega primeiro no S04, depois no S07, praticamente ao mesmo tempo no S12 e no S08, e então no S09. Porém, era esperado que o escoamento fosse simétrico em relação ao eixo $\mathrm{x}$, ou seja, a água com sal deveria atingir os pontos $\mathrm{S} 07$, S08 e S09 ao mesmo tempo e só então o ponto S12. Além disso, segundo a Tabela 7 (Item 5.2.1), a água com sal deveria demorar aproximadamente 9, 19 e 29 dias para se deslocar da barreira até os pontos S04, S08 e S12 respectivamente. Como apresentado na Tabela 10, o tempo de deslocamento entre os pontos localizados no aquífero (S01, S03 e S14) são semelhantes aos calculados na Tabela 7. Porém, entre os pontos da área encapsulada (S04, S08 e S12) o tempo foi significantemente menor, resultando em aproximadamente 3 dias. Essas divergências provavelmente ocorreram devido às irregularidades no formato da barreira e aos processos de difusão, que serão discutidos no item a seguir. 
Tabela 10. Tempo levado pelas partículas do fluido para se deslocar entre os pontos localizados em $y=0$

\begin{tabular}{ccc}
\hline Partida - Chegada & Tempo (h) & Tempo (dia) \\
\hline Reservatório 1 - S01 & 7 & 0,3 \\
\hline Reservatório 1 - S03 & 13 & 0,5 \\
\hline Interface da barreira com a área contaminada - S04 & 65 & 2,7 \\
\hline Interface da barreira com a área contaminada - S08 & 80 & 3,3 \\
\hline Interface da barreira com a área contaminada - S12 & 80 & 3,3 \\
\hline Interface da barreira com o aquífero - S14 & 4 & 0,2 \\
\hline
\end{tabular}

\subsubsection{Irregularidades da barreira}

Após os testes, o material de preenchimento da barreira foi retirado para verificar se as partículas de areia tinham infiltrado na estrutura e preenchido os espaços vazios do cascalho. Como houve penetração da areia na barreira (Figura 33), a condutividade hidráulica do material de preenchimento foi determinada novamente através do permeâmetro de carga constante. A partir dos resultados, concluiu-se que as partículas de areia não causaram diminuição significativa na condutividade hidráulica da barreira, pois anteriormente à instalação a condutividade hidráulica era de $5,38 \times 10^{-2} \mathrm{~m} / \mathrm{s}$, e depois da instalação o valor obtido foi de $5,15 \times 10^{-2} \mathrm{~m} / \mathrm{s}$.

Figura 33. Material de preenchimento após os testes

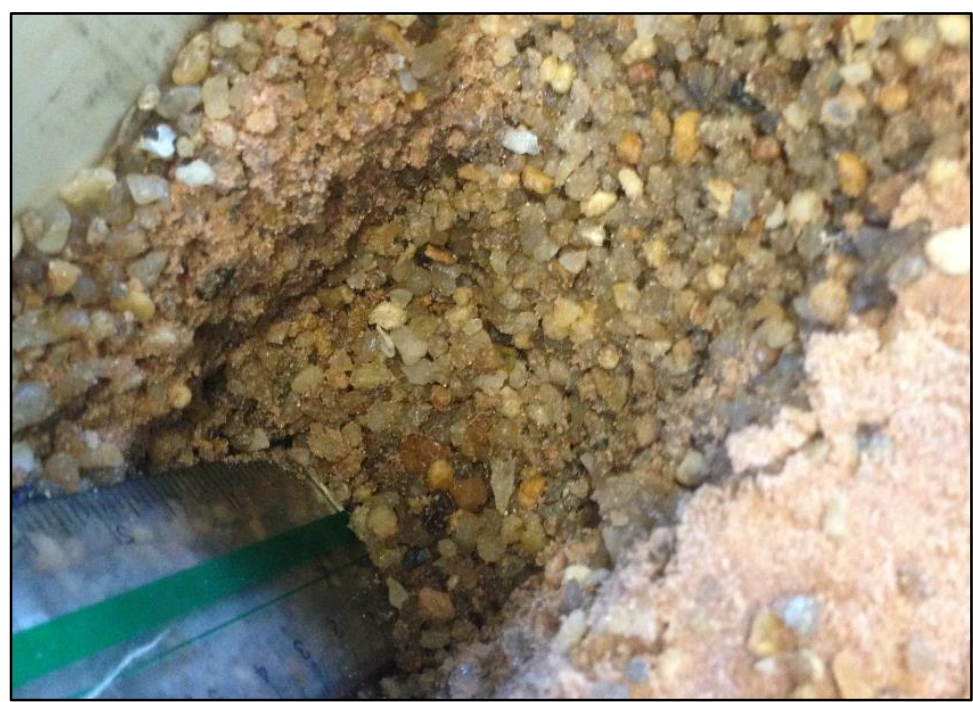

Fonte: Autor.

Após a retirada no material de preenchimento, observou-se que o formato da barreira não ficou perfeitamente cilíndrico (Figura 34) como indicado no projeto do Apêndice A. Como pode ser verificado na Figura 35, a espessura da barreira não é a mesma em todos os pontos. Na imagem da esquerda, a espessura é de aproximadamente $7 \mathrm{~cm}$, e na imagem da direita, a espessura é de aproximadamente 
$4 \mathrm{~cm}$. Essas irregularidades na simetria da barreira afetam o fluxo através da área encapsulada e, por esse motivo, os resultados obtidos durante o experimento podem ser ligeiramente diferentes dos calculados.

Figura 34. Aquífero e área encapsulada após a retirada do material de preenchimento da barreira

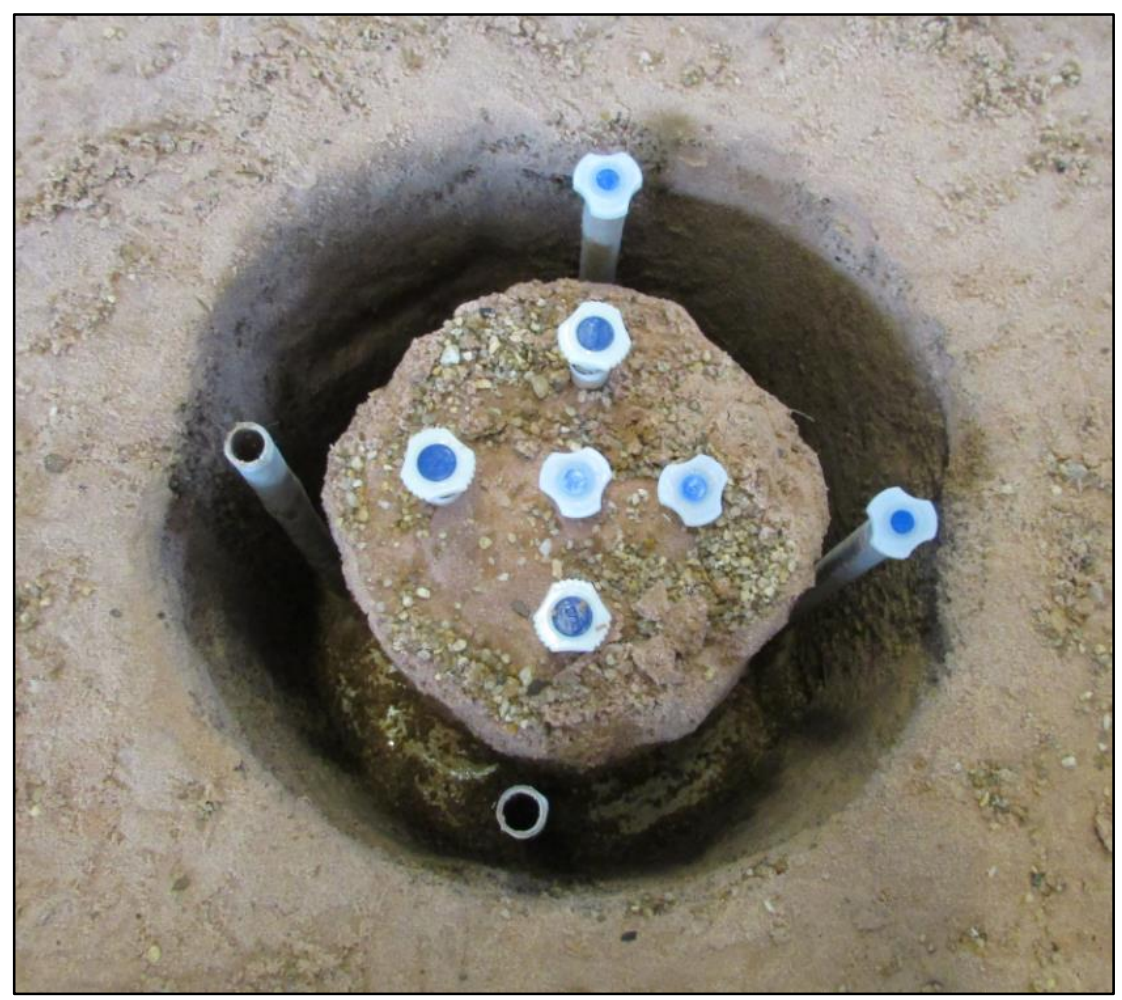

Fonte: Autor.

Figura 35. Espessuras da barreira
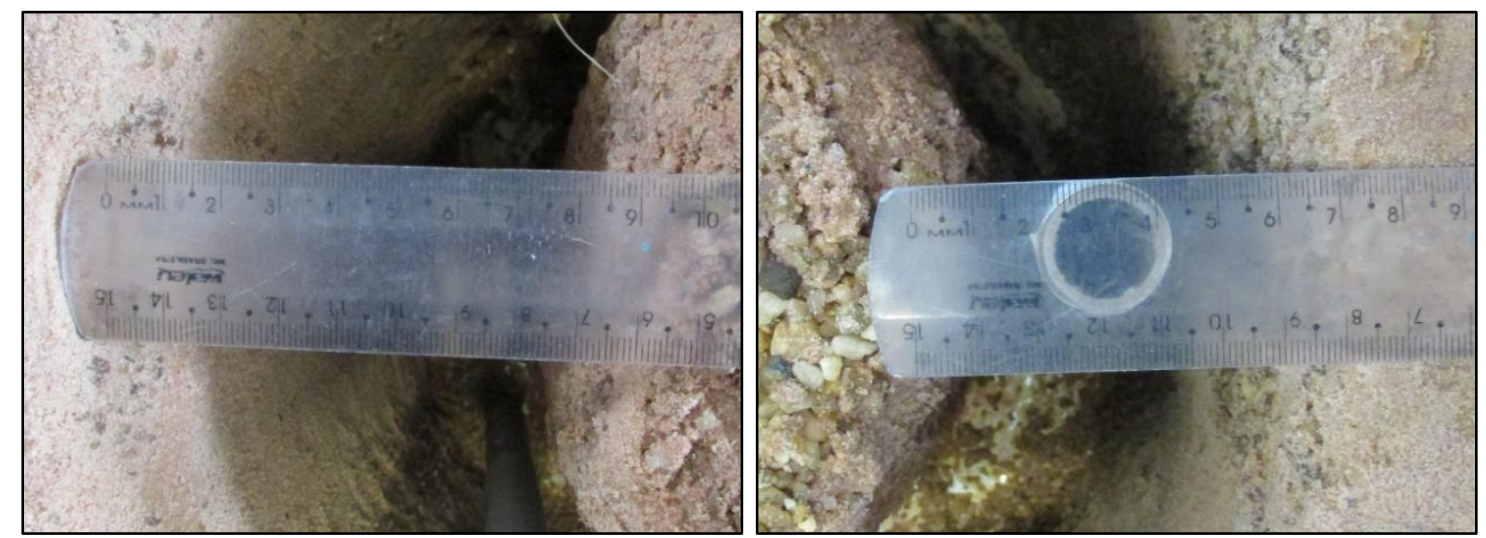

Fonte: Autor.

\subsubsection{Transporte por difusão}

Como a velocidade média na área encapsulada é consideravelmente baixa, o transporte por difusão também deve ser levado em consideração. A partir da Equação 81 , foi calculado o número de Peclet da difusão molecular $\left(\mathrm{Pe}_{\mathrm{d}}\right)$ para essa região. 


$$
P e=\frac{V d_{s}}{D_{d}}
$$

na qual:

$\mathrm{V}(\mathrm{m} / \mathrm{s})$ é a velocidade média $(\mathrm{q} / \mathrm{n})$;

$\mathrm{d}_{\mathrm{s}}(\mathrm{m})$ é o tamanho médio das partículas de solo; e

$D_{d}(m)$ é o coeficiente de difusão molecular.

A velocidade utilizada foi de $7,9 \times 10^{-8} \mathrm{~m} / \mathrm{s}$ (Figura 28), considerou-se que o tamanho médio das partículas de areia está entre 0,05 e 0,3 mm e o coeficiente de difusão da solução de água com cloreto de sódio utilizado foi de $1,612 \times 10^{-9} \mathrm{~m}^{2} / \mathrm{s}$. Assim, o número de Peclet mínimo $\left(\mathrm{d}_{\mathrm{s}}=0,05 \mathrm{~mm}\right)$ é de 0,002 e o máximo $\left(\mathrm{d}_{\mathrm{s}}=0,3 \mathrm{~mm}\right)$ é de 0,015. De acordo com Bear (1972), para valores baixos de $\mathrm{Pe}_{\mathrm{d}}$ (menores que aproximadamente 0,4), a difusão molecular é predominante.

Para simular a difusão na área encapsulada, foi utilizado o programa Comsol 5.1 para o transporte de espécies diluídas no meio poroso. Os mecanismos de transporte adicionais selecionados foram a convecção e a dispersão em meio poroso. A partir da inserção dos dados abaixo, o programa gerou o gráfico apresentado na Figura 36.

- Campo de velocidade (velocidade de Darcy): $2,4 \times 10^{-8} \mathrm{~m} / \mathrm{s}$

- Porosidade: 0,3 (Item 4.2.1)

- Coeficiente de difusão molecular: $1,612 \times 10^{-9} \mathrm{~m}^{2} / \mathrm{s}$

- Coeficiente de dispersividade longitudinal e transversal horizontal:

$\alpha_{L}(m)=\frac{1}{100}$ escala do experimento $=\frac{1}{100} 0,90=9 \times 10^{-3} \mathrm{~m}$ $\alpha_{T H}(m)=\frac{1}{10} \alpha_{L}=9 \times 10^{-4} \mathrm{~m}$ 
- Condições de contorno:

Valores iniciais de concentração dentro da área circular: $0 \mathrm{~g} / \mathrm{m}^{3}$

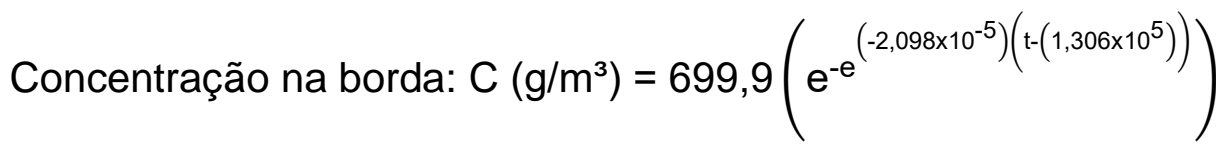

A expressão da concentração na borda da área circular em função do tempo foi obtida a partir dos dados de condutividade elétrica do sensor S03 durante o experimento.

Figura 36. Gráfico do transporte da água com sal na área encapsulada

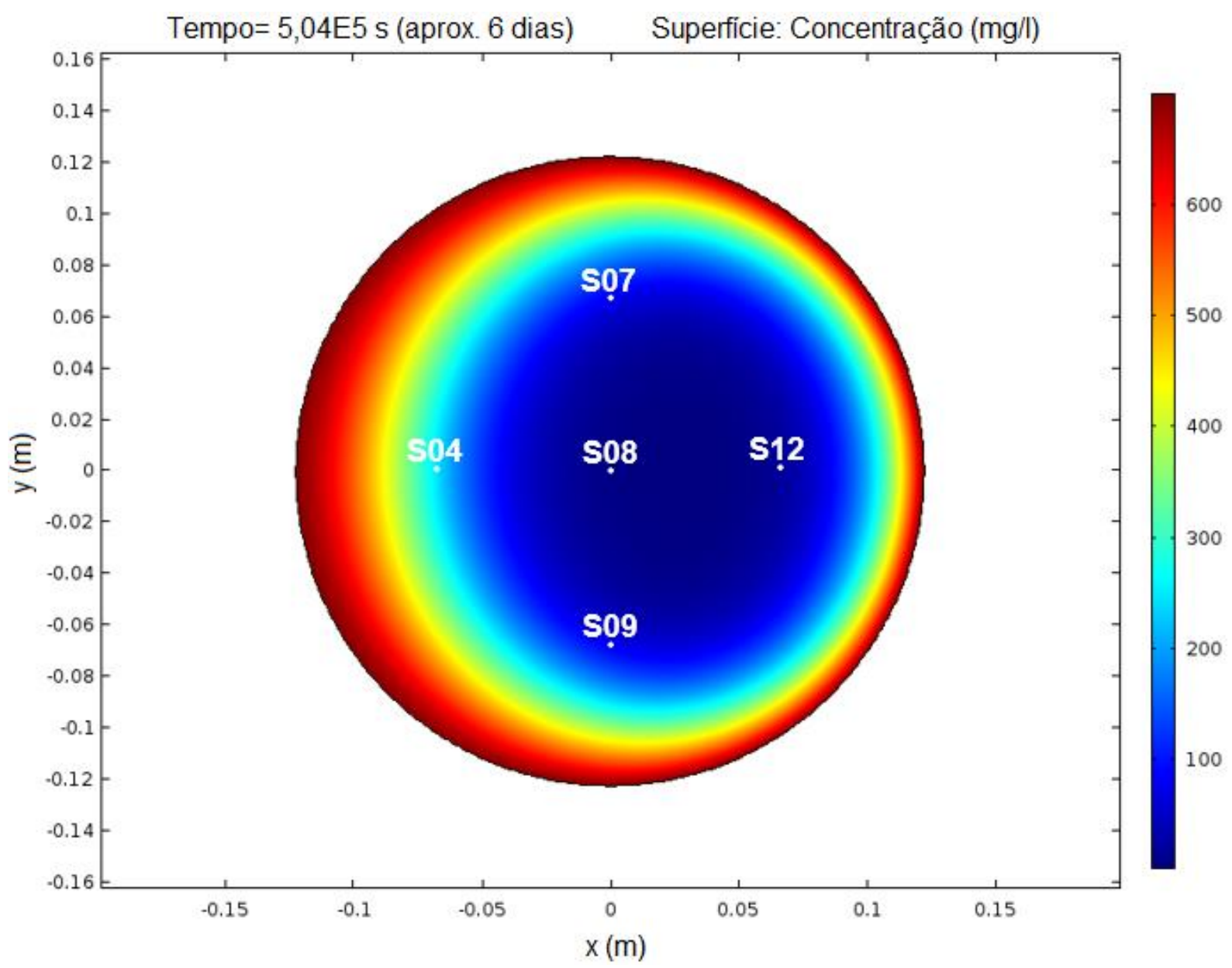

Fonte: Autor.

A Tabela 11 apresenta a comparação entre as concentrações de sal no final do experimento e as calculadas pelo programa. Nota-se que os valores são semelhantes, comprovando que na área contaminada o transporte por difusão é significativo. Por essa razão, a água com sal atinge os pontos S04, S07, S08, S09 e S12 nos tempos apresentados na Tabela 10, que são menores do que os apresentados na Tabela 7. Logo, é possível concluir que a água com sal atinge os pontos da área encapsulada mais rapidamente do que o calculado pela solução analítica devido ao transporte 
difusivo, o qual não foi considerado no desenvolvimento matemático. Além disso, se houvesse apenas o transporte advectivo, a água com sal chegaria primeiro no ponto S04, então no S07, S08 e S09 e por último no S12. Mas como a difusão ocorre da borda da área circular em direção ao centro, os pontos S07, S09 e S12 atingem concentrações maiores que o S08.

A partir desses resultados, conclui-se que a barreira de alta permeabilidade é uma técnica de encapsulamento adequada para os casos em que o objetivo seja impedir o transporte advectivo através de determinada região. Porém, a barreira não é indicada para as situações em que seja necessário reduzir o transporte difusivo, já que os materiais de preenchimento permeáveis, como a brita e o cascalho, não são capazes de conter a difusão. Assim, em casos reais, deve-se verificar o coeficiente de difusão molecular dos contaminantes presentes na área a ser encapsulada, calcular o número de Peclet, analisar se o transporte difusivo na região é significativo e, assim, decidir se a barreira de alta permeabilidade é uma solução adequada para o problema.

Tabela 11. Comparação entre as concentrações finais experimentais e calculadas

\begin{tabular}{ccc}
\hline Sensor & Concentração experimento (mg/l) & Concentração COMSOL (mg/l) \\
\hline S04 & 275 & 230 \\
\hline S07 & 58 & 70 \\
\hline S08 & 10 & 7 \\
\hline S09 & 22 & 70 \\
\hline S12 & 36 & 20 \\
\hline
\end{tabular}




\section{CONCLUSÕES E RECOMENDAÇÕES}

Nesse trabalho, a solução analítica para barreiras hidráulicas verticais cilíndricas, desenvolvida por Strack (2017), foi expandida para os casos em que a região encapsulada e o aquífero possuem condutividades hidráulicas diferentes, como nos casos em que os resíduos sólidos são dispostos abaixo do nível d'água. A partir dos resultados apresentados, foi possível concluir que nos casos em que a região encapsulada possui condutividade hidráulica maior do que o aquífero, a barreira de alta permeabilidade é a solução mais eficaz. Já nos problemas em que a região encapsulada possui condutividade hidráulica menor do que o aquífero, a técnica mais indicada é a slurry wall.

No experimento em escala reduzida, observou-se que a água com sal chega em todos os sensores localizados no aquífero e na barreira antes de atingir os pontos da área encapsulada. A partir dos resultados do monitoramento, conclui-se que a vazão e os tempos de deslocamento das partículas entre os pontos localizados no aquífero foram semelhantes aos calculados. Porém, os resultados do experimento e da solução analítica foram consideravelmente diferentes para os pontos na região encapsulada, pois o transporte difusivo não havia sido levado em consideração no desenvolvimento matemático. Já os valores fornecidos pela simulação do transporte de espécies diluídas em meio poroso, a qual abrange tanto a advecção quanto a difusão, foram bem próximos dos resultados obtidos no final do experimento, comprovando que na região encapsulada o transporte por difusão é significativo. As demais diferenças entre os resultados experimentais e simulados ocorreram devido a diferentes fatores, tais como as irregularidades da barreira, as incertezas dos sensores de condutividade elétrica e as diferenças entre a condutividade hidráulica vertical, que foi medida no permeâmetro e utilizada nas simulações, e a condutividade hidráulica horizontal, que é a que realmente interfere no experimento.

A partir desses resultados, conclui-se que a barreira de alta permeabilidade é uma técnica de encapsulamento adequada para os casos em que o objetivo seja impedir o transporte advectivo através de determinada região. Porém, a barreira não é indicada para as situações em que seja necessário reduzir o transporte difusivo, já que os materiais de preenchimento de alta permeabilidade, como a brita e o cascalho, não são capazes de conter a difusão. 
Para a continuidade das pesquisas no tema proposto por esta dissertação, recomenda-se que seja desenvolvido o elemento analítico da barreira vertical cilíndrica, para que ela possa ser superposta com outros elementos hidrogeológicos e, assim, compor soluções para problemas mais específicos. Baseando-se na solução analítica da barreira vertical cilíndrica apresentada neste trabalho, também é possível estender o desenvolvimento matemático para as barreiras elípticas. Dessa maneira, a simulação da barreira vertical seria mais abrangente em relação ao formato da área a ser encapsulada. Além disso, em experimentos futuros, recomenda-se trocar 0 material da área contaminada por outros que apresentem condutividades hidráulicas diferentes da condutividade hidráulica do aquífero, para analisar o desempenho da barreira em diferentes situações. 


\section{REFERÊNCIAS}

ABRELPE. Panorama dos resíduos sólidos no Brasil. Associação Brasileira Empresas de Limpeza Pública e Resíduos Especiais, 2017.

ALBAIGES, J.; CASADO, F.; VENTURA, F. Organic indicators of groundwater pollution by a sanitary landfill. Water Research, v. 20, n. 9, p. $1153-1159,1986$.

ÁLVARES, C. M. B. Contribuição ao conhecimento do meio físico da região do lixão de São Carlos - SP, através de estudos geológicos, geofísicos, topográficos e químicos. 2000. 158 p. Dissertação (Mestrado). Escola de Engenharia de São Carlos, Universidade de São Paulo, São Carlos.

ARNETH, J. D.; MILDE, G.; KERNDORFF, H.; SCHLEYER, R. Waste deposit influences on groundwater quality as a tool for waste type and site selection for final storage quality. In: BACCINI, P. (Ed.). The Landfill. Springer Berlin Heidelberg, v.20, 1989. cap. 22, p. 399-415. (Lecture Notes in Earth Sciences).

ASSOCIAÇÃO BRASILEIRA DE NORMAS TÉCNICAS. NBR 10.004: Resíduos Sólidos - Classificação. Rio de Janeiro, 2004. 71 p.

ASTM. D7100-11: Standard Test Method for Hydraulic Conductivity Compatibility Testing of Soils with Aqueous Solutions. ASTM International, West Conshohocken, PA, 2011. $17 \mathrm{p}$.

BEAR, J. Dynamics of fluids in porous media. USA: American Elsevier Environmental Science, 1972. 764 p.

BESERRA, L. B. S.; SOUZA, I. M. F., BARBOSA, D. G.; ATHAÍDE JÚNIOR, G. B.; NÓBREGA, C. C.; GADELHA, C. L. M.; RIBEIRO, W. L. B; MOURA, A. H. M. Estudo da qualidade das águas subterrâneas na região próxima ao antigo lixão do Roger em João Pessoa - PB. Anais do Simpósio Brasileiro de Recursos Hídricos. São Paulo: ABRH, 2007. 10 p.

BIDONE, F. R. A.; POVINELLI, J. Conceitos básicos de resíduos sólidos. São Carlos: EESC/USP, 1999. 120 p.

BRASIL. Lei no 12.305, de 02 de agosto de 2010. Institui a Política Nacional de Resíduos Sólidos; altera a Lei 9.605, de 12 de fevereiro de 1998; e dá outras providências. Diário Oficial da União, Brasília, DF, 3 ago. 2010.

CHRISTENSEN, T. H.; KJELDSEN, P.; ALBRECHTSEN, H. J. R.; HERON, G.; NIELSEN, P. H.; BJERG, P. L.; HOLM, P. E. Attenuation of landfill leachate pollutants in aquifers. Critical Reviews in Environmental Science and Technology, v. 24, n. 2, p. $119-202,1994$.

COELHO, M. G.; LIMA, S. C.; MARAGNO, A. N. F.; ALBUQUERQUE, Y. T.; LEMOS, J. C.; SANTOS, C. L.; BRANDÃO, S. L. Contaminação das águas do lençol freático por disposição inadequada de resíduos sólidos urbanos em Uberlândia-MG/Brasil. Anais do Congresso Interamericano de Ingenieria Sanitaria y Ambiental, 2002, Cancum. 
COZZARELLI, I. M.; BÖHLKE, J. K.; MASONER, J.; BREIT, G. N.; LORAH, M. M.; TUTTLE, M. L. W.; JAESCHKE, J. B. Biogeochemical evolution of a landfill leachate plume, Norman, Oklahoma. Groundwater, v. 49, n. 5, p. 663 - 687, 2011.

D'APPOLONIA, D. J. Soil-Bentonite Slurry Trench Cutoffs. Journal of the Geotechnical Engineering Division, ASCE, v. 106, n. 4, p. 399 - 417. 1980.

DEEGAN, Jr, J. Looking Back At Love Canal. Environmental science \& technology, v. 21, n. 4, p. 328-331, 1987.

DU, Y. J.; FAN, R. D.; REDDY, K. R.; LIU, S. Y.; YANG, Y. L. Impacts of presence of lead contamination in clayey soil-calcium bentonite cutoff wall backfills. Applied Clay Science, v. 108, p.111-122, 2015.

ELLERT, N.; ROSS, S.; MENDES, J. M. B.; MARTIM, E. Mapeamento geofísico do lixão de São Carlos. Anais do 6 Congresso Brasileiro de Águas Subterrâneas. Porto Alegre: Associação Brasileira de Águas Subterrâneas, 1990. p. 82-88.

EL-SALAM, M.M.A; ABU-ZUID, G.I. Impact of landfill leachate on the groundwater quality: A case study in Egypt. Journal of advanced research, v. 6, n. 4, p.579-586, 2015.

EPA (United States Environmental Protection Agency). Advancing Sustainable Materials Management: 2014 Fact Sheet. Publicado em novembro de 2016. https://www.epa.gov/sites/production/files/2016-

11/documents/2014_smmfactsheet_508.pdf.

EUROPEAN COMMISSION (Eurostat Statistics Explained). Waste statistics. Dados extraídos em Maio de 2017. Atualização do artigo planejada para: outubro de 2018. http://ec.europa.eu/eurostat/statistics-

explained/index.php/Waste_statistics\#Total_waste_generation.

EVANS, J. C. Vertical cutoff walls. In: D. E. DANIEL. Geotechnical Practice for Waste Disposal. London: Chapman \& Hall, 1993. cap. 17. p. 430-454.

EVANS, J. C.; FANG, H. Y.; KUGELMAN, I. J. Organic fluid effects on the permeability of soil-bentonite slurry walls. Proceedings of the National Conference on Environmental Emergencies, 1985, Cincinnati - OH, p. $267-271$.

FATTA, D.; PAPADOPOULOS, A.; LOIZIDOU, M. A study on the landfill leachate and its impact on the groundwater quality of the greater area. Environmental Geochemistry and Health, vol. 21, n. 2, p.175-190, 1999.

FERNANDEZ, F.; QUIGLEY, R. M. Hydraulic conductivity of natural clays permeated with simple liquid hydrocarbons. Canadian Geotechnical Journal, vol. 22, n. 2, p. 205 $-214,1985$.

FETTER, C. W.Applied hydrogeology. USA: Prentice-Hall, 1994. 691 p.

FITTS, C. R. Groundwater science. USA: Academic press, 2002. 450 p. 
FOSTER, S.; HIRATA, R.; GOMES, D.; D'ELIA, M.; PARIS, M. Groundwater quality protection. Washington, DC: The World Bank, 2002. 103 p.

FREEMAN, H. M.; HARRIS, E. F. Hazardous waste remediation: innovative treatment technologies. USA: Technomic Publishing, 1995.

FREITAS, A, L, S. Caracterização do aqüifero Botucatu na região do lixão de São Carlos. 1996. 113 p. Dissertação (Mestrado). Escola de Engenharia de São Carlos, Universidade de São Paulo, São Carlos.

GADOTTI, R. F. Avaliação da contaminação das águas superficiais e subterrâneas adjacentes ao lixão da cidade de São Carlos. 1997. 150 p. Dissertação (Mestrado). Escola de Engenharia de São Carlos, Universidade de São Paulo, São Carlos.

GARVIN, S. L.; HAYLES, C.S. The chemical compatibility of cement-bentonite cut-off wall material. Construction and Building Materials, v. 13, n. 6, p.329-341, 1999.

GAUTAM, A.; PATHAK, G.; SAHNI, A. Assessment of ground water quality at municipal solid waste dumping site - Sewapura, Jaipur. Current World Environment, v. 6, n. 2, p. 279-282, 2011.

GLEASON, M. H.; DANIEL, D. E.; EYKHOLT, G.R. Calcium and sodium bentonite for hydraulic containment applications. Journal of Geotechnical and Geoenvironmental Engineering, v. 123, n. 5, p.438-445, 1997.

GONÇALVES, A. R. L.; BOSSOLAN, N. R. S.; ORLANDO, M. J. G. Determinação de fluxo defreativo no aterro sanitário de São Carlos. Anais do $7^{\circ}$ Congresso de Águas Subterrâneas. Belo Horizonte: Associação Brasileira de Águas Subterrâneas, 1992. p 114-118.

HADLEY, P. W.; NEWELL, C. J. Groundwater remediation: The next 30 years. Groundwater, v. 50, n. 5, p. 669 - 678, 2012.

HAITJEMA, H. M. Modeling Regional Ground-Water Flow in Fulton County, Indiana: Using the Analytic Element Method. Groundwater, v. 30, n. 5, p. 660 - 666, 1992.

HAITJEMA, H. M. Analytic element modeling of groundwater flow. Academic Press. 1995.

HAN, Z.; MA, H.; SHI, G.; HE, L.; WEI, L.; SHI, Q. A review of groundwater contamination near municipal solid waste landfill sites in China. Science of the Total Environment, 10 p., 2016.

HAUSER, T. R.; BROMBERG, S. M. EPA's monitoring program at Love Canal 1980. Environmental monitoring and assessment, v. 2, n. 3, p. 249-271, 1982.

HAVERKAMP, B.; BIURRUN, E. Closure of the Richard underground repository for low and intermediate level radioactive waste-application of the hydraulic cage concept. Atw. Internationale Zeitschrift fuer Kernenergie, v. 51, n. 12, p. 797-802, 2006. 
HOORNWEG, D.; P. BHADA-TATA. What a waste: a global review of solid waste management. Urban Development Series Knowledge Papers, The World Bank. Publicado em março de 2012, no 15.

https://siteresources.worldbank.org/INTURBANDEVELOPMENT/Resources/3363871334852610766/What_a_Waste2012_Final.pdf.

HOORNWEG, D.; P. BHADA-TATA; C. KENNEDY. Environment: Waste production must peak this century. Nature, v. 502, n. 7473, p. 615-617, 2013.

KATSUMI, T.; ISHIMORI, H.; ONIKATA, M.; FUKAGAWA, R. Long-term barrier performance of modified bentonite materials against sodium and calcium permeant solutions. Geotextiles and Geomembranes, v. 26, n. 1, p.14-30, 2008.

KIMMEL, G. E.; BRAIDS, O. C. Leachate plumes in a highly permeable aquifer. Ground Water, v. 12, n. 6, p. 388-393, 1974.

LOIZIDOU, M.; KAPETANIOS, E.G. Effect of leachate from landfills on underground water quality. Science of the Total Environment, vol. 128, n. 1, p.69-81, 1993.

LOPES, A. A. Estudo da gestão integrada dos resíduos sólidos urbanos na bacia Tietê- Jacaré (UGRHI-13). 2007. 370 p. Tese (Doutorado) Escola de Engenharia de São Carlos Universidade de São Paulo, São Carlos.

MADSEN, F. T.; MITCHELL, J. K. Chemical effects on clay fabric and hydraulic conductivity. In: BACCINI, P. (editor). The Landfill. Berlin, Heidelberg: Springer, 1989. p. 201-251.

MALUSIS, M. A; MCKEEHAN, M. D. Chemical compatibility of model soil-bentonite backfill containing multiswellable bentonite. Journal of Geotechnical and Geoenvironmental Engineering, v. 139, n. 2, p.189-198, 2013.

MANOEL FILHO, J. Contaminação das águas subterrâneas. In: FEITOSA, F. A. C.; MANOEL FILHO, J.; FEITOSA, E. C.; DEMETRIO, J. G. A. (organizadores). Hidrogeologia: Conceitos e Aplicações. Rio de Janeiro: CPRM: LABHID, 2008. p. 381-404.

MATHIAZHAGAN, M.; SELVAKUMAR, T.; GANESAN, M. Detection of solid waste dumpsite-induced groundwater contamination leachate using electrical resistivity method. In: (Ed.). Groundwater Modeling and Management under Uncertainty: CRC Press, 2012. p. 307-312.

MCDOUGALL, W. J.; FUSCO, R. A; O'BRIEN, R. P. Containment and treatment of the Love Canal landfill leachate. Journal (Water Pollution Control Federation), v. 52, n. 12, p. $2914-2924,1980$.

MENEZES, D. B. Diagnóstico dos impactos do depósito de resíduos sólidos de São Carlos-SP, no meio físico. 1994. 103 p. Dissertação (Mestrado). Escola de Engenharia de São Carlos, Universidade de São Paulo, São Carlos.

MITCHELL, J. K.; MITCHELL, R. A. Environmental geotechnics: Two case histories. Proceedings of the Fifth International Conference on Case Histories in Geotechnical Engineering, New York, NY, April 13-14, 2004. 
MOR, S.; RAVINDRA, K.; DAHIYA, R.P; CHANDRA, A. Leachate characterization and assessment of groundwater pollution near municipal solid waste landfill site. Environmental monitoring and assessment, vol. 118, n. 1, p. 435-456, 2006.

MULLIGAN, C.N.; YONG, R.N.; GIBBS, B.F. Remediation technologies for metalcontaminated soils and groundwater: an evaluation. Engineering geology, v. 60, n. 1, p.193-207, 2001.

NATIONAL RESEARCH COUNCIL. Assessment of the performance of engineered waste containment barriers. Washington, D. C.: National Academies Press, 2007. 134 p.

NOYES, R. Nuclear waste cleanup technology and opportunities. Noyes Publications, 1995.

OLIVEIRA, S.; PASQUAL, A. Avaliação de parâmetros indicadores de poluição por efluente líquidos de um aterro sanitário. Eng. sanit. ambient., vol. 9, n. 3, p. 240-249, 2004.

PEJON, O. J.; RODRIGUES, V. G. S.; ZUQUETTE, L. V. Impactos ambientais sobre o solo. In: CALIJURI, M. C.; CUNHA, D. G. F. (organizadores). Engenharia Ambiental: Conceitos, Tecnologia e Gestão. Rio de Janeiro: Elselvier, 2013. p. 317-343.

PIAI, K. A.; FERREIRA, P. C.; TREVILATO, T. M. B.; SEGURA-MUÑOZ, S. I. Análise dos níveis de metais em água subterrânea coletada a montante e jusante do aterro sanitário de Ribeirão Preto, Brasil. Águas Subterrâneas, v. 20, n. 1, p. 131-138, 2006.

REBOUÇAS, A. C. Água doce no mundo e no Brasil. In: REBOUÇAS, A. C.; BRAGA, B.; TUNDISI, J.G. (organizadores). Águas doces no Brasil: capital ecológico, uso e conservação. São Paulo: Escrituras, 2006. p. 1-35.

REBOUÇAS, A. C. Importância da água subterrânea. In: FEITOSA, F. A. C.; MANOEL FILHO, J.; FEITOSA, E. C.; DEMETRIO, J. G. A. (organizadores). Hidrogeologia: Conceitos e Aplicações. Rio de Janeiro: CPRM: LABHID, 2008. p. 13-29.

REDDY, K. R.; HETTIARACHCHI, H.; PARAKALLA, N.; GANGATHULASI, J.; BOGNER, J.; LAGIER, T. Hydraulic conductivity of MSW in landfills. Journal of Environmental Engineering, v. 135, n. 8, p. 677 - 683, 2009.

REINHARD, M.; BARKER, J. F.; GOODMAN, N. L. Occurrence and distribution of organic chemicals in two landfill leachate plumes. Environmental Science \& Technology, v. 18, n. 12, p. $953-961,1984$.

REINIUS, E. Method to reduce the groundwater flow around a subsurface storge of nuclear waste. Subsurface space: environmental protection, low cost storage, energy savings: proceedings of the international symposium (Rockstore '80), Stockholm, Sweden, June 23-27, 1980, p. 977-982.

ROCHA, L. C. R.; HORBE, A. M. C. Contaminação provocada por um depósito de lixo no aqüífero Alter do Chão em Manaus - AM. ACTA AMAZONICA. v. 36, n. 3, p. 307312, 2006. 
SAMADDER, S. R.; PRABHAKAR, R.; KHAN, D.; KISHAN, D.; CHAUHAN, M. S. Analysis of the contaminants released from municipal solid waste landfill site: A case study. Science of the Total Environment, v. 580, p. 593-601, 2017.

SHACKELFORD, C. D. Waste-soil interactions that alter hydraulic conductivity. In Hydraulic conductivity and waste contaminant transport in soil. ASTM International. 1994.

SHARMA, H. D.; LEWIS, S. P. Waste containment systems, waste stabilization, and landfills: design and evaluation. John Wiley \& Sons, 1994. 608 p.

SHINZATO, M. P. B. Mobilização de poluentes no maciço de resíduos de lixão desativado. 2014. 196 p. Tese de Doutorado Hidráulica e Saneamento - Escola de Engenharia de São Carlos, Universidade de São Paulo.

SHINZATO, M. P.; WENDLAND, E. C. Estudos qualitativos em lixão desativado instalado em área de afloramento do Sistema Aquífero Guarani. Anais do XVII CONGRESSO BRASILEIRO DE ÁGUAS SUBTERRÂNEAS; VII FENÁGUA - Feira Nacional da Água; XVIII Encontro Nacional de Perfuradores de Poços, 2012, Bonito - MS.

SINGH, U.K.; KUMAR, M.; CHAUHAN, R.; JHA, P.K.; RAMANATHAN, A.L.; SUBRAMANIAN, V. Assessment of the impact of landfill on groundwater quality: A case study of the Pirana site in western India. Environmental monitoring and assessment, v. 141, n. 1-3, p.309-321, 2008.

SOUTO, G. D. B.; POVINELLI, J. Resíduos sólidos. In: CALIJURI, M. C.; CUNHA, D. G. F. (organizadores). Engenharia Ambiental: Conceitos, Tecnologia e Gestão. Rio de Janeiro: Elselvier, 2013. p. 565-588.

STRACK, O. D. L. Groundwater Mechanics. North Oaks: SC Inc, 1989. 732 p.

STRACK, O. D. L. Theory and applications of the analytic element method. Reviews of Geophysics, v. 41(2), 2003.

STRACK, O. D. L. Analytical Groundwater Mechanics. Cambridge University Press, 2017.

THOMAS, R .W; KOERNER, R. M. Advances in HDPE barrier walls. Geotextiles and Geomembranes, v. 14, n. 7 - 8, p. $393-408,1996$.

UMEKI, H. Repository design. In: ALEXANDER, W. R.; MCKINLEY, L. (editores). Deep geological disposal of radioactive waste. Elsevier, 2007. v. 9, $1^{\text {a }}$ Edição, 300 p.

VELOZO, R. Caracterização geológico-geotécnica do lixão desativado de São Carlos - SP, com auxílio da geofísica. 2006. 177 p. Dissertação (Mestrado) Escola de Engenharia de São Carlos, Universidade de São Paulo, São Carlos.

WILLIAMS, P. T. Waste treatment and disposal. John Wiley \& Sons, 2005. 392 p. 


\section{APÊNDICE A}

Planta do experimento com medidas verticais em milímetros

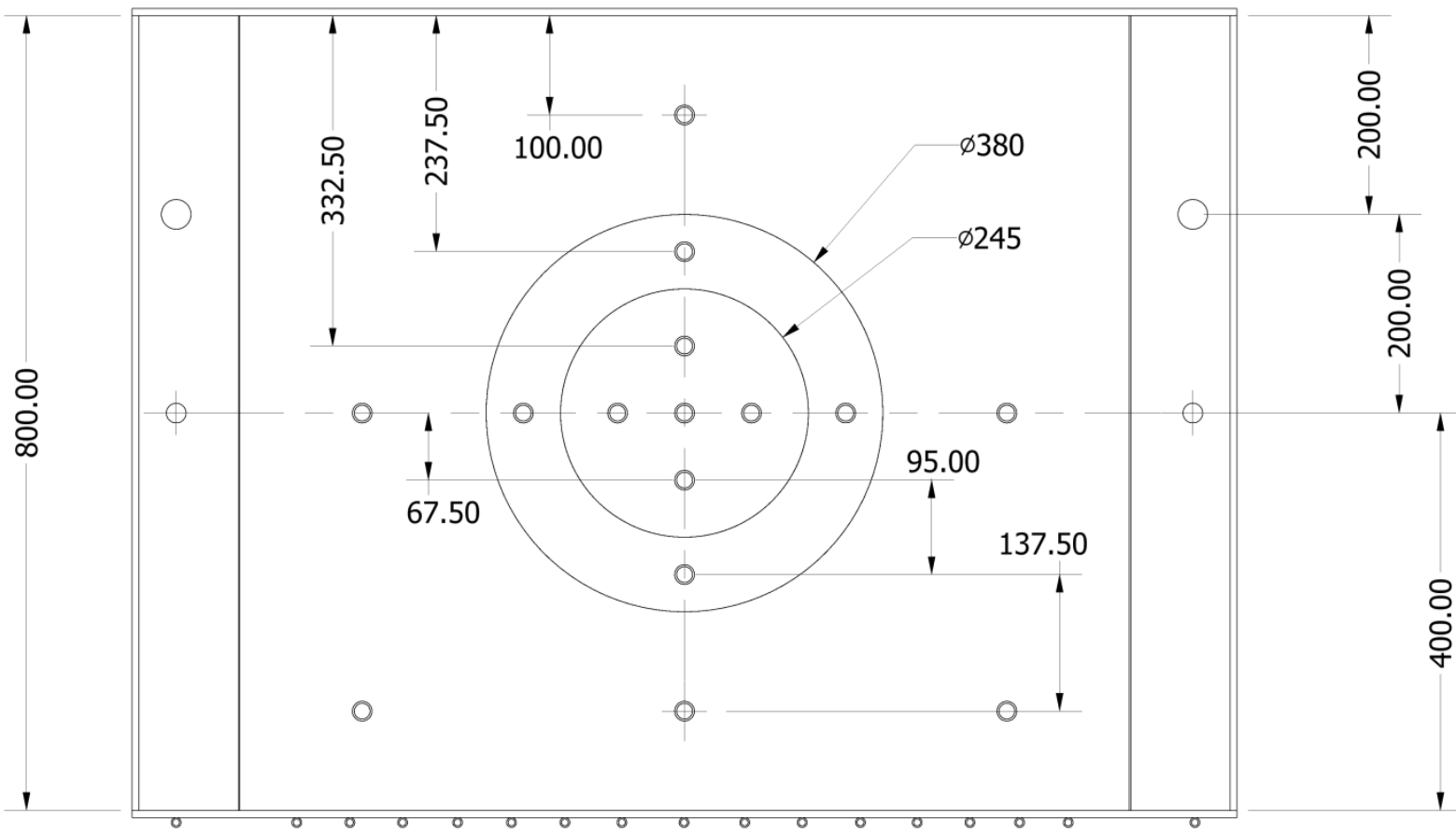

Planta do experimento com medidas horizontais em milímetros

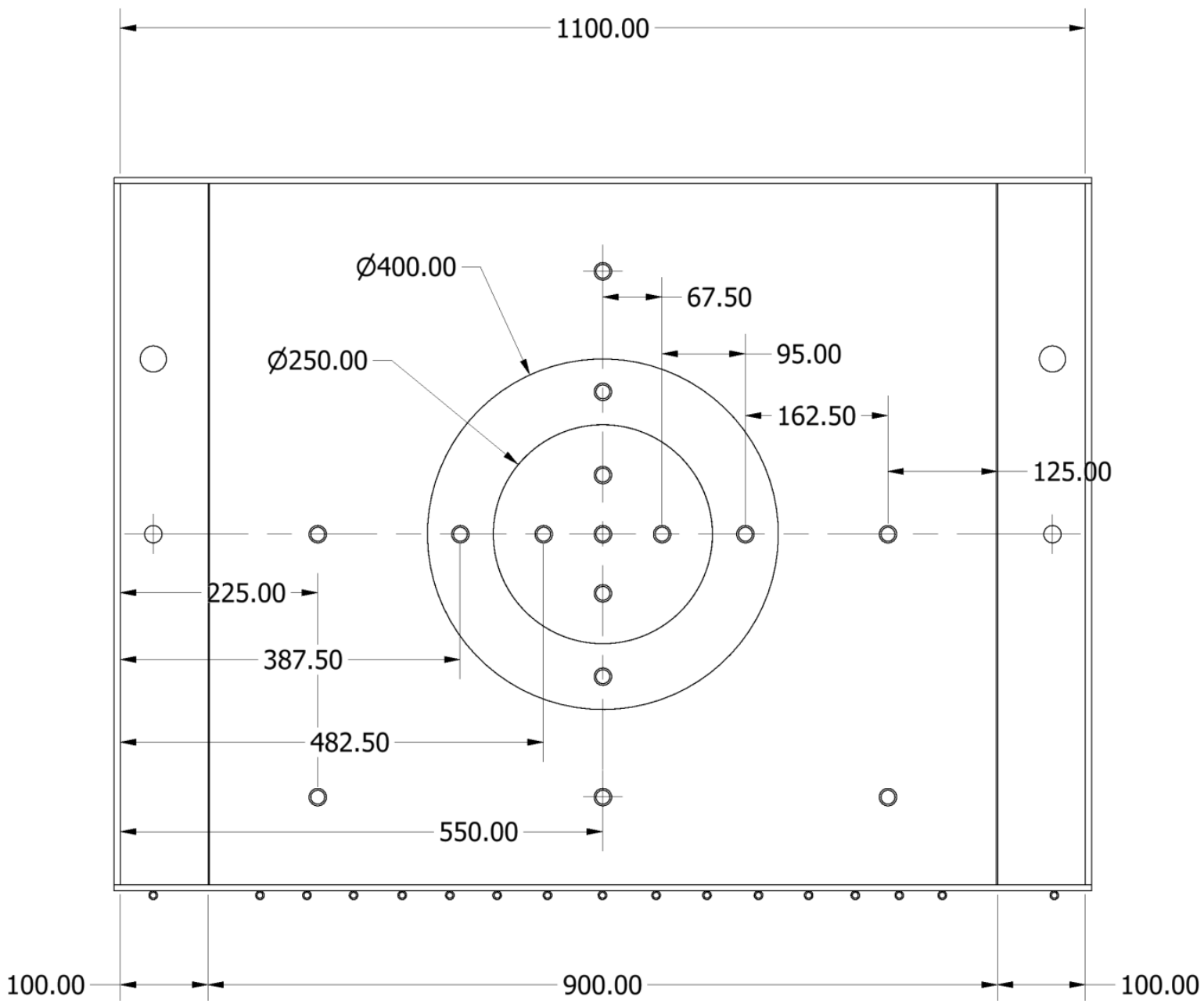


86

Corte AA do experimento com medidas em milímetros
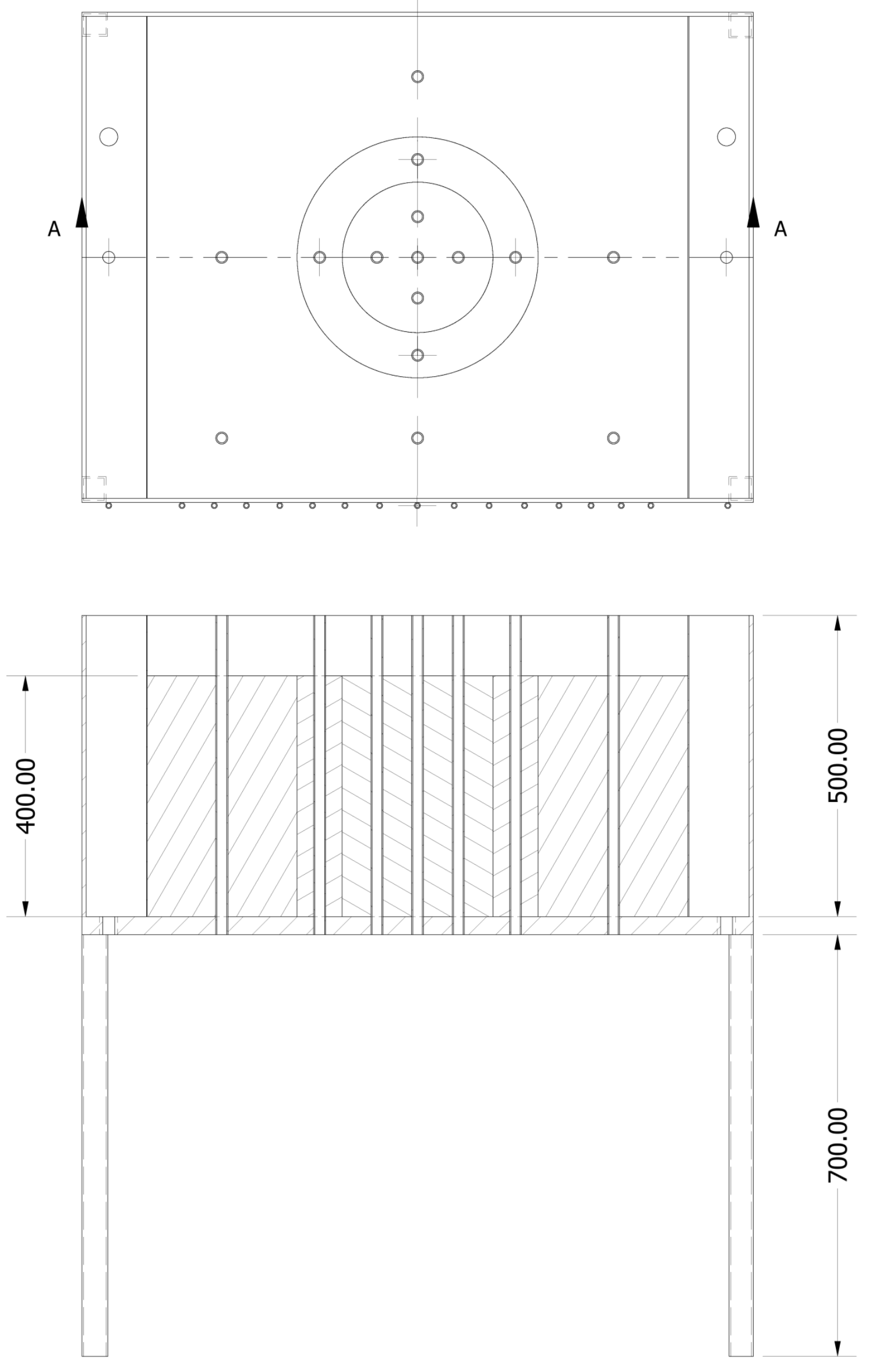


\section{APÊNDICE B}

function [flownet barreira] = barreira(xfrom, xto, Nx, yfrom, yto, Ny, kw, kb, ka, R, Rw, Qx0, Phio)

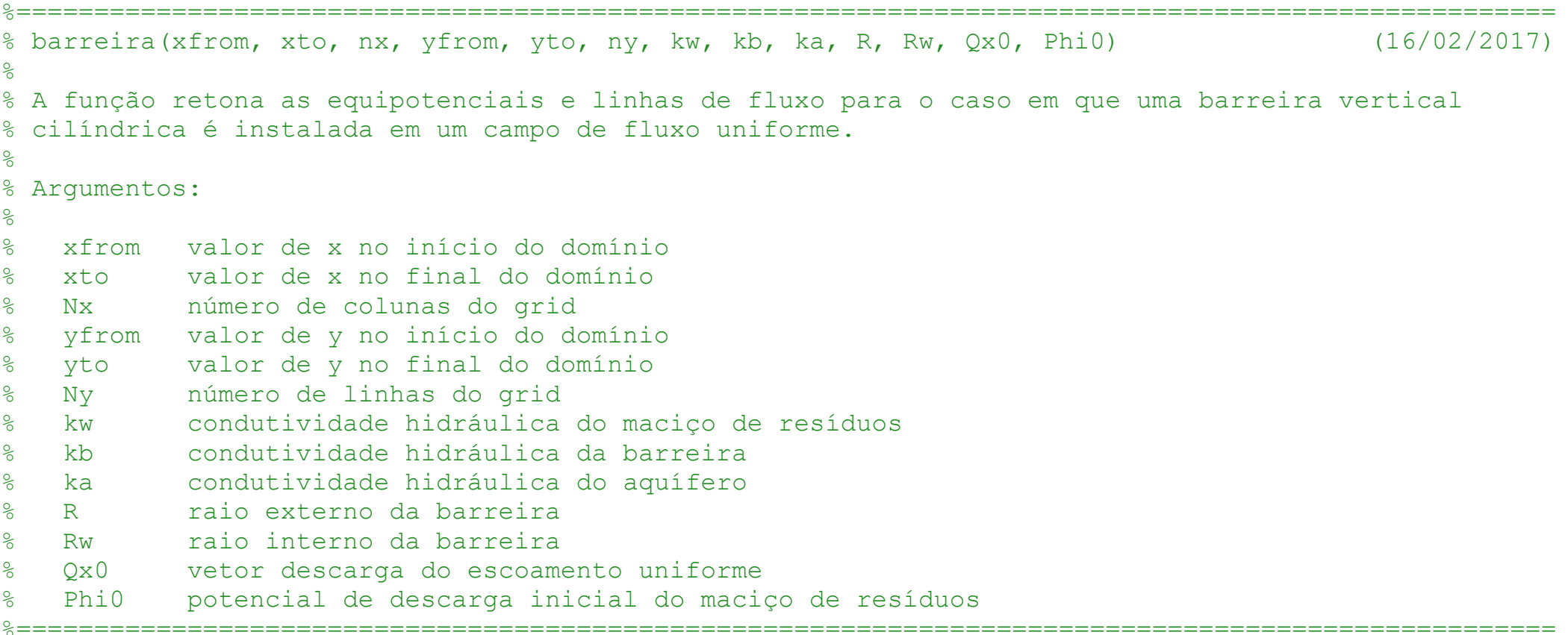

$X=$ linspace (xfrom, xto, Nx);

$\mathrm{Y}=$ linspace (yfrom, yto, Ny) :

oCalculando os coeficientes:

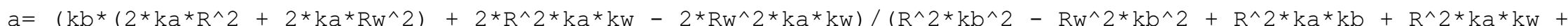
$\left.\mathrm{Rw}^{\wedge} 2 * \mathrm{ka} \mathrm{k}^{*} \mathrm{~kb}+\mathrm{R}^{\wedge} 2 * \mathrm{~kb} \mathrm{k}^{\star} \mathrm{kw}-\mathrm{Rw}^{\wedge} 2 * \mathrm{ka} \mathrm{kw}^{*}+\mathrm{Rw}^{\wedge} 2 * \mathrm{~kb} \mathrm{k}^{*} \mathrm{kw}\right)-1$;

$\mathrm{b}=(2 * \mathrm{~kb} *(\mathrm{~kb}+\mathrm{kw})) /\left((\mathrm{ka}+\mathrm{kb}) *(\mathrm{~kb}-\mathrm{kw}) *\left((\mathrm{~kb}+\mathrm{kw}) /(\mathrm{kb}-\mathrm{kw})+\left(\mathrm{Rw}^{\wedge} 2 *(\mathrm{ka}-\mathrm{kb})\right) /\left(\mathrm{R}^{\wedge} 2 *(\mathrm{ka}+\mathrm{kb})\right)\right)\right) ;$

$c=\left(2^{*} \mathrm{~kb}\right) /\left((\mathrm{ka}+\mathrm{kb}) *\left((\mathrm{~kb}+\mathrm{kw}) /(\mathrm{kb}-\mathrm{kw})+\left(\mathrm{Rw}^{\wedge} 2^{*}(\mathrm{ka}-\mathrm{kb})\right) /\left(\mathrm{R}^{\wedge} 2^{*}(\mathrm{ka}+\mathrm{kb})\right)\right)\right) ;$

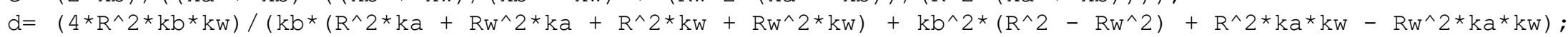

Equações do potencial complexo:

omegal $=@(x, y)-Q x 0 *\left((x+1 i * y)+a *\left(\left(R^{\wedge} 2\right) /(x+1 i * y)\right)\right)+(k a / k w) * P h i 0 ;$ 
omega $2=@(x, y)-Q x 0 *\left(b *(x+1 i * y)+c *\left(\left(R^{\wedge} 2\right) /(x+1 i * y)\right)\right)+(k b / k w) * P h i 0 ;$ omega $=Q(x, y)-Q x 0 * d *(x+1 i * y)+P h i 0 ;$

OPreenchendo a matriz:

Grid_phi $=\operatorname{zeros}(\mathrm{Ny}, \mathrm{Nx})$;

Grid Psi $=\operatorname{zeros}(\mathrm{Ny}, \mathrm{Nx})$.

for row $=1: \mathrm{Ny}$

for $\operatorname{col}=1: \mathrm{Nx}$

if $\operatorname{sqrt}\left(\left(\mathrm{X}(\mathrm{col})^{\wedge} 2\right)+\left(\mathrm{Y}(\mathrm{row})^{\wedge} 2\right)\right)<=\mathrm{RW}$

Grid_phi(row, col) = head_conversion(real(omega3 (X (col), Y(row))), kw, 0);

Grid_Psi (row, col) $=\operatorname{imag}($ omega3 $(X(c o l), Y(r o w)))$;

elseif $\left(\operatorname{sqrt}\left(\left(\mathrm{X}(\operatorname{col})^{\wedge} 2\right)+\left(\mathrm{Y}(\mathrm{row})^{\wedge} 2\right)\right)>\mathrm{RW}\right) \& \&\left(\operatorname{sqrt}\left(\left(\mathrm{X}(\operatorname{col})^{\wedge} 2\right)+\left(\mathrm{Y}(\operatorname{row})^{\wedge} 2\right)\right)<\mathrm{R}\right)$

Grid_phi(row,col)= head_conversion(real(omega2(X(col), Y(row))), kb, 0);

Grid_Psi $($ row, $\mathrm{col})=\operatorname{imag}(\mathrm{omega} 2(\mathrm{X}(\mathrm{col}), \mathrm{Y}(\mathrm{row})))$;

elseif $\operatorname{sqrt}\left(\left(\mathrm{X}(\operatorname{col})^{\wedge} 2\right)+\left(\mathrm{Y}(\mathrm{row})^{\wedge} 2\right)\right)>=\mathrm{R}$

Grid phi (row, col) = head_conversion (real(omegal (X(col), Y(row))), ka, 0) Grid_Psi $(r o w, c o l)=i m a g(\operatorname{omegal}(X(\mathrm{col}), \mathrm{Y}(\mathrm{row})))$; end

end

oPlotando a rede de fluxo:

\section{figure;}

contour(X, Y, Grid Psi, 50, 'b'):

hold on

contour(X, Y, Grid_phi, 30, 'r', 'ShowText', 'off');

axis equal;

hold off 


\section{APÊNDICE C}

Calibração do sensor de condutividade elétrica S01

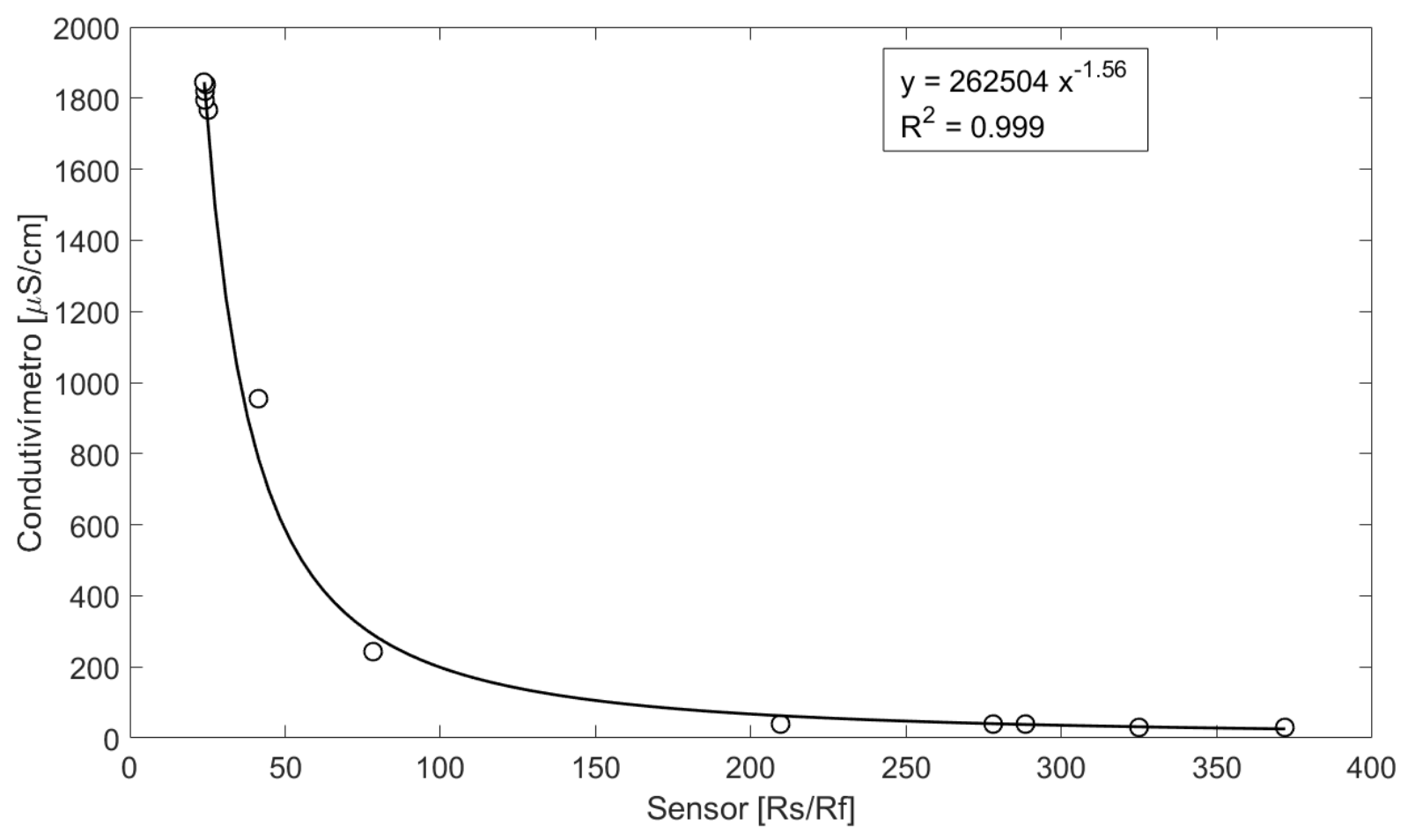

Calibração do sensor de condutividade $\mathrm{S03}$

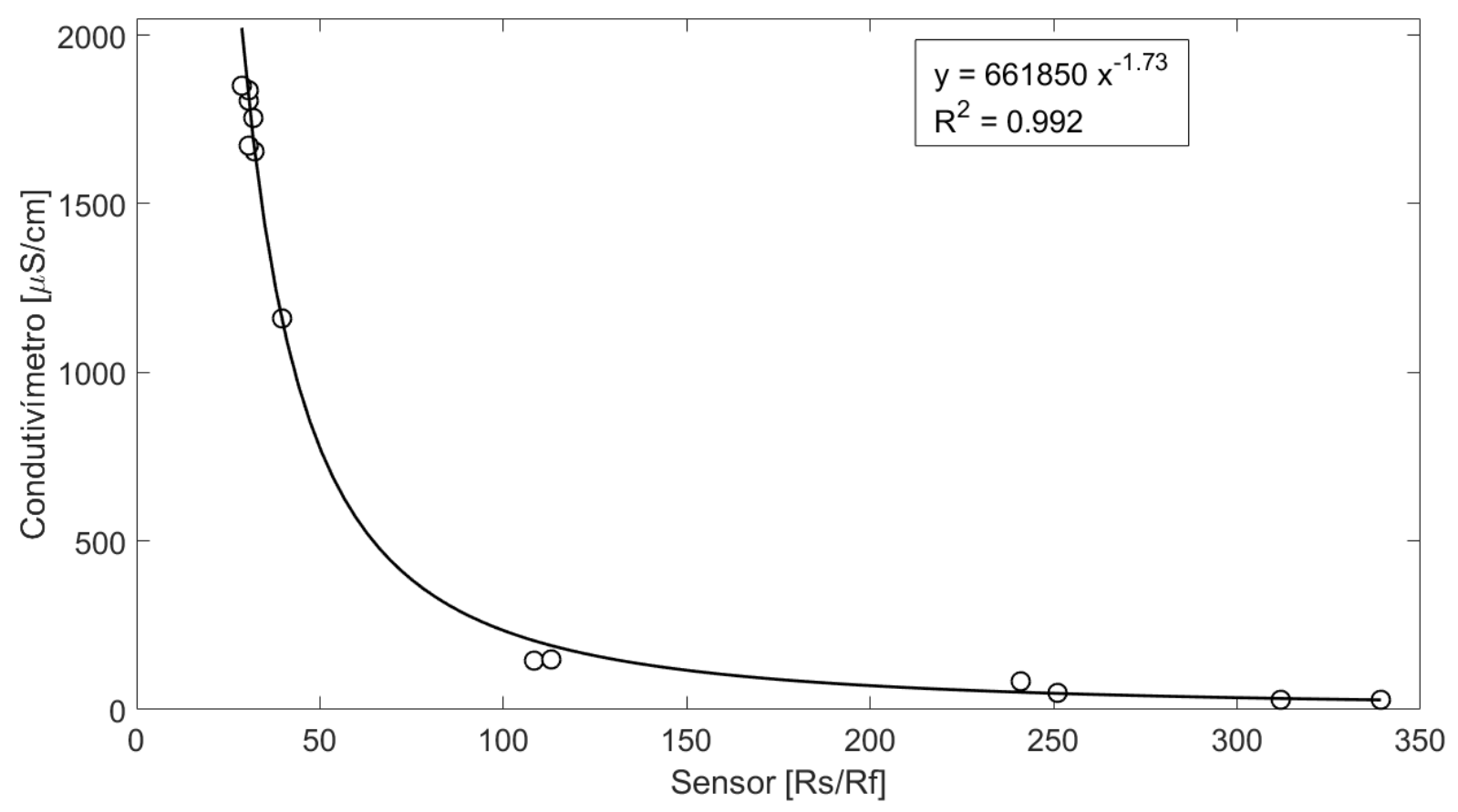


Calibração do sensor de condutividade S04

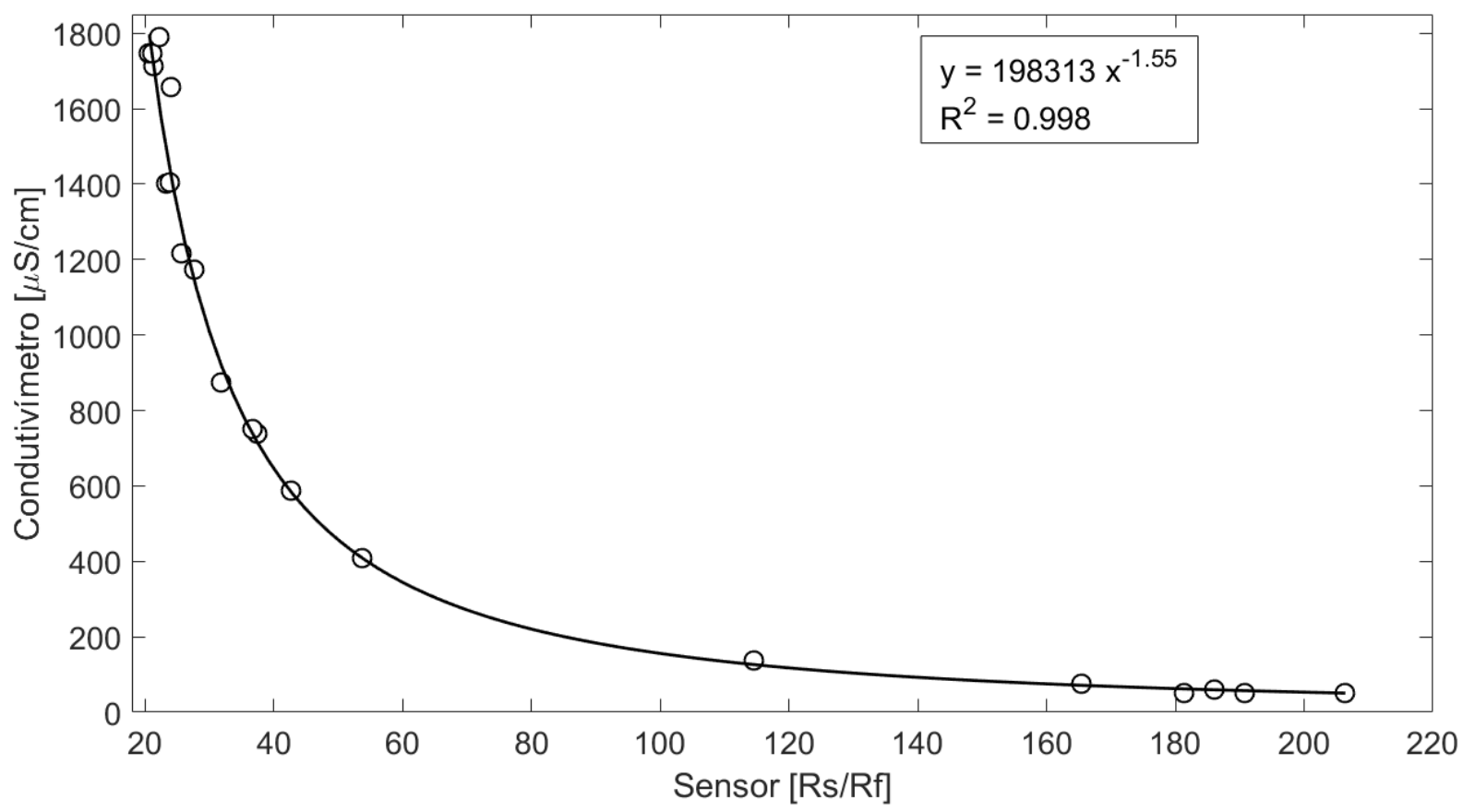

Calibração do sensor de condutividade S05

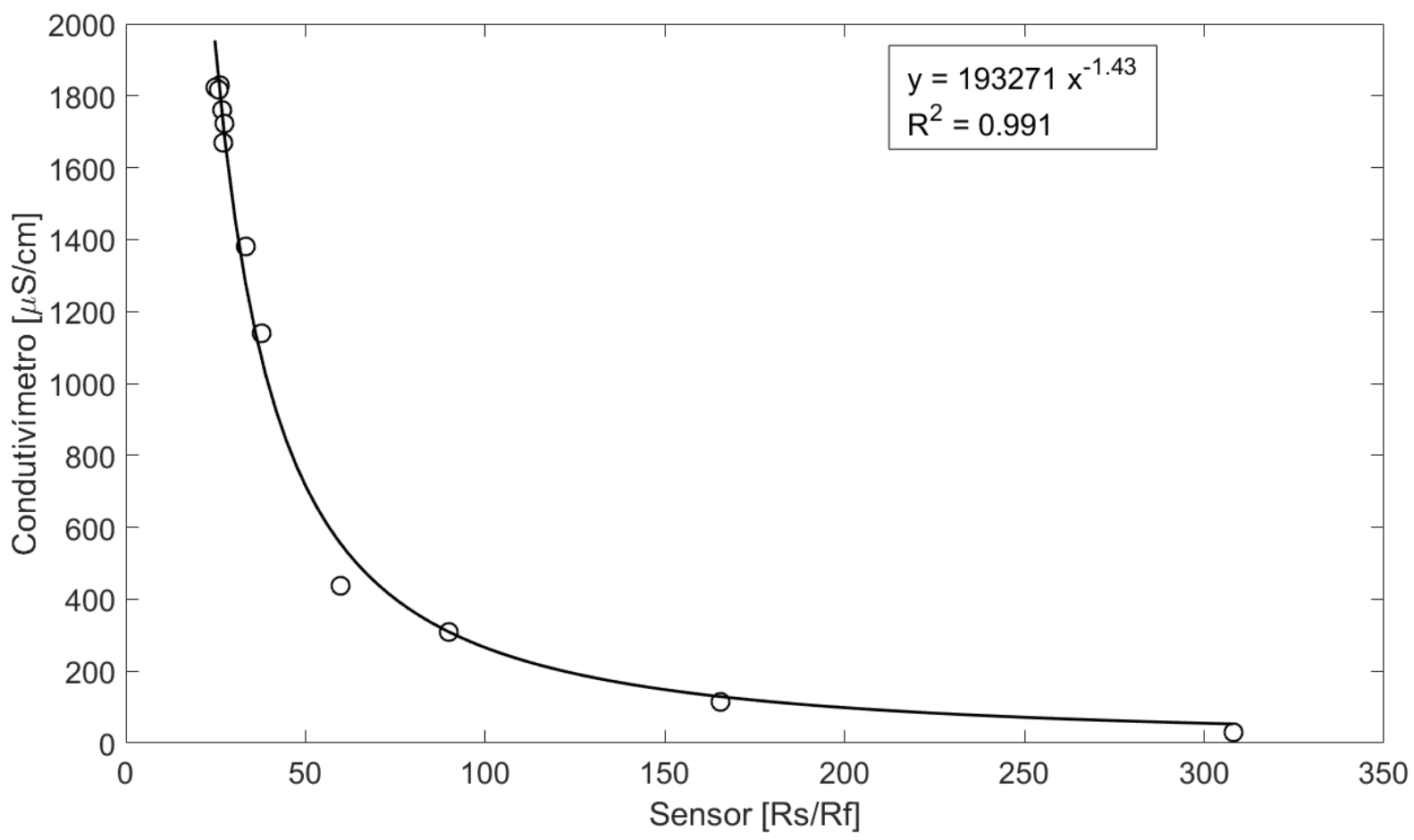


Calibração do sensor de condutividade S06

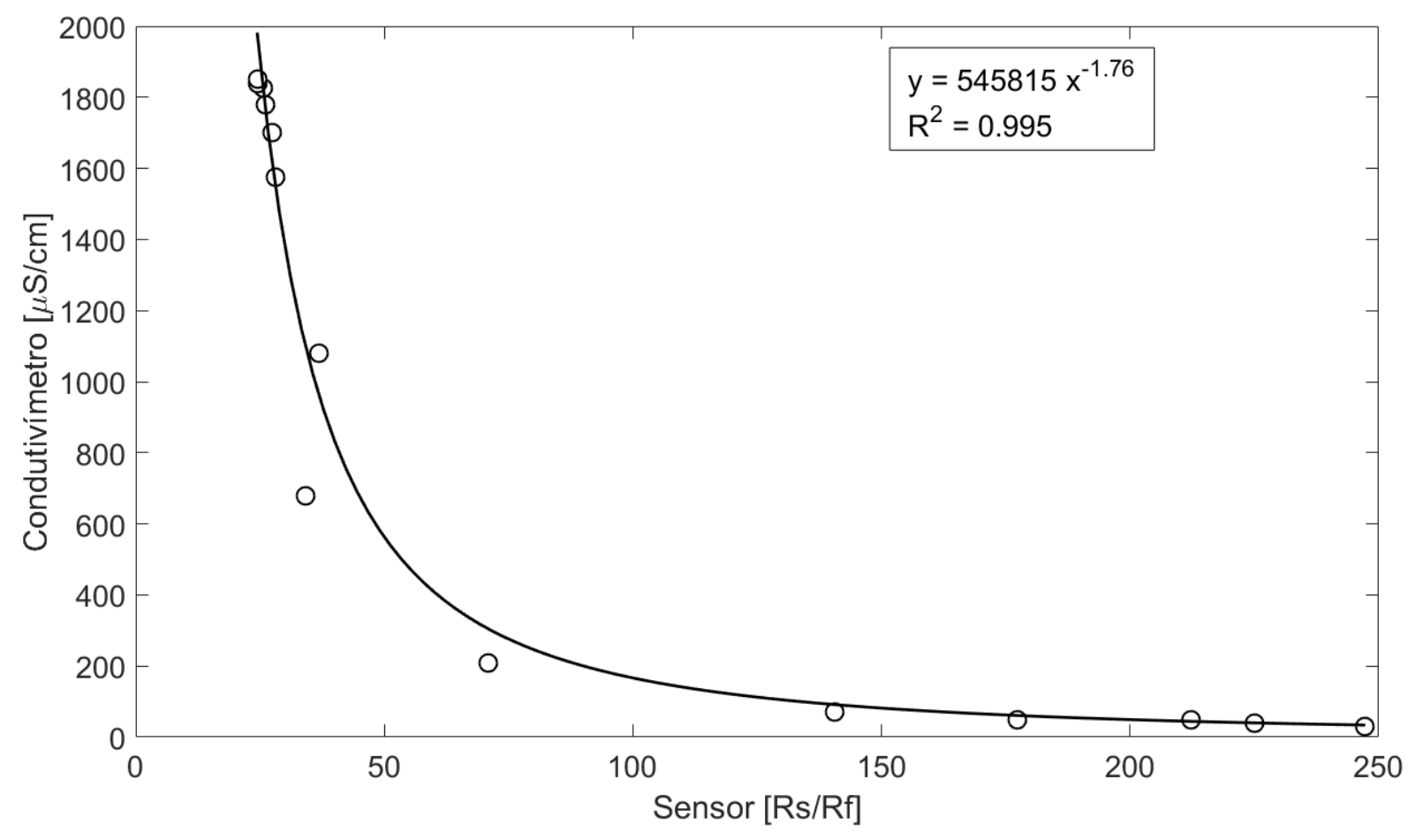

Calibração do sensor de condutividade S07

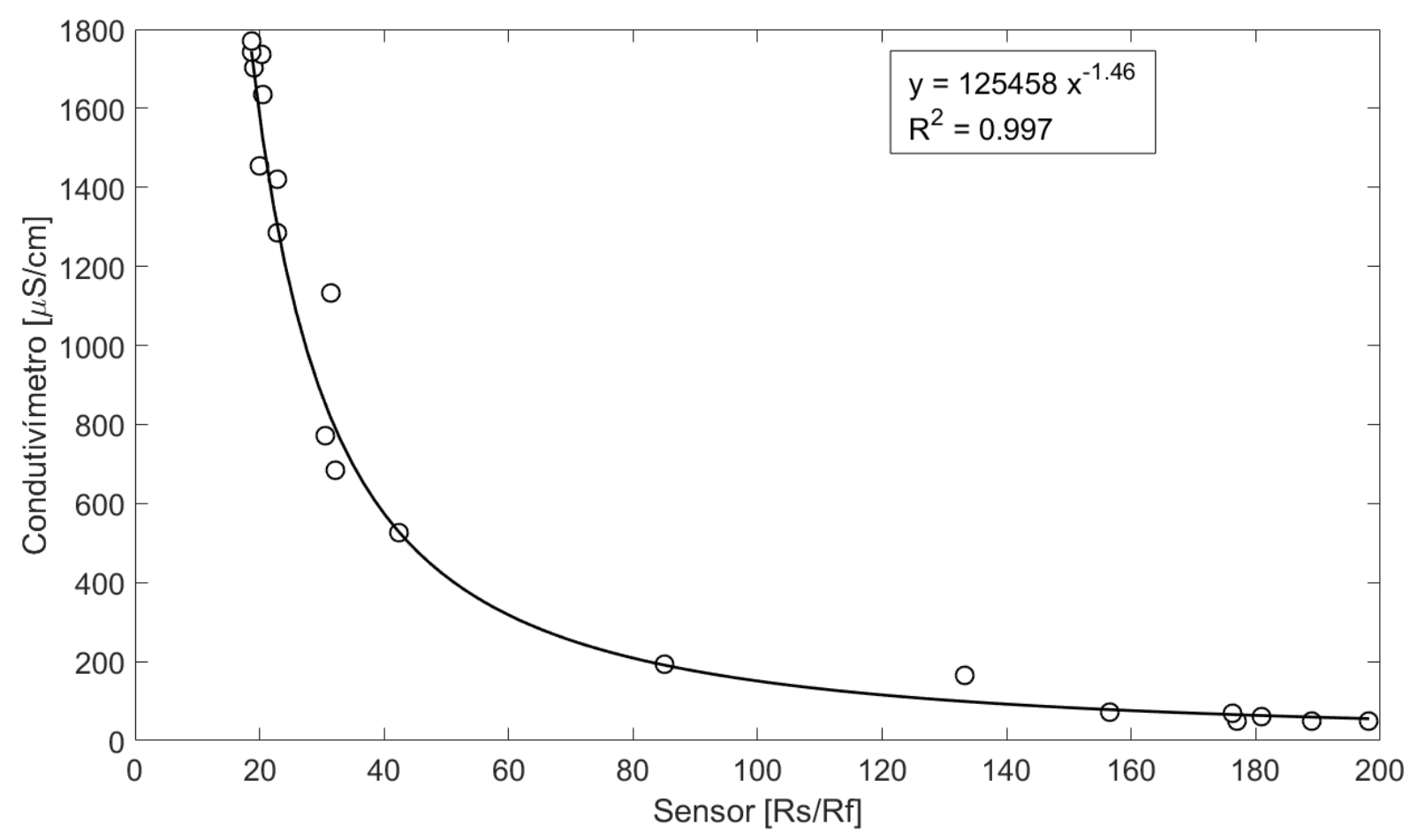


Calibração do sensor de condutividade $\mathbf{S 0 8}$

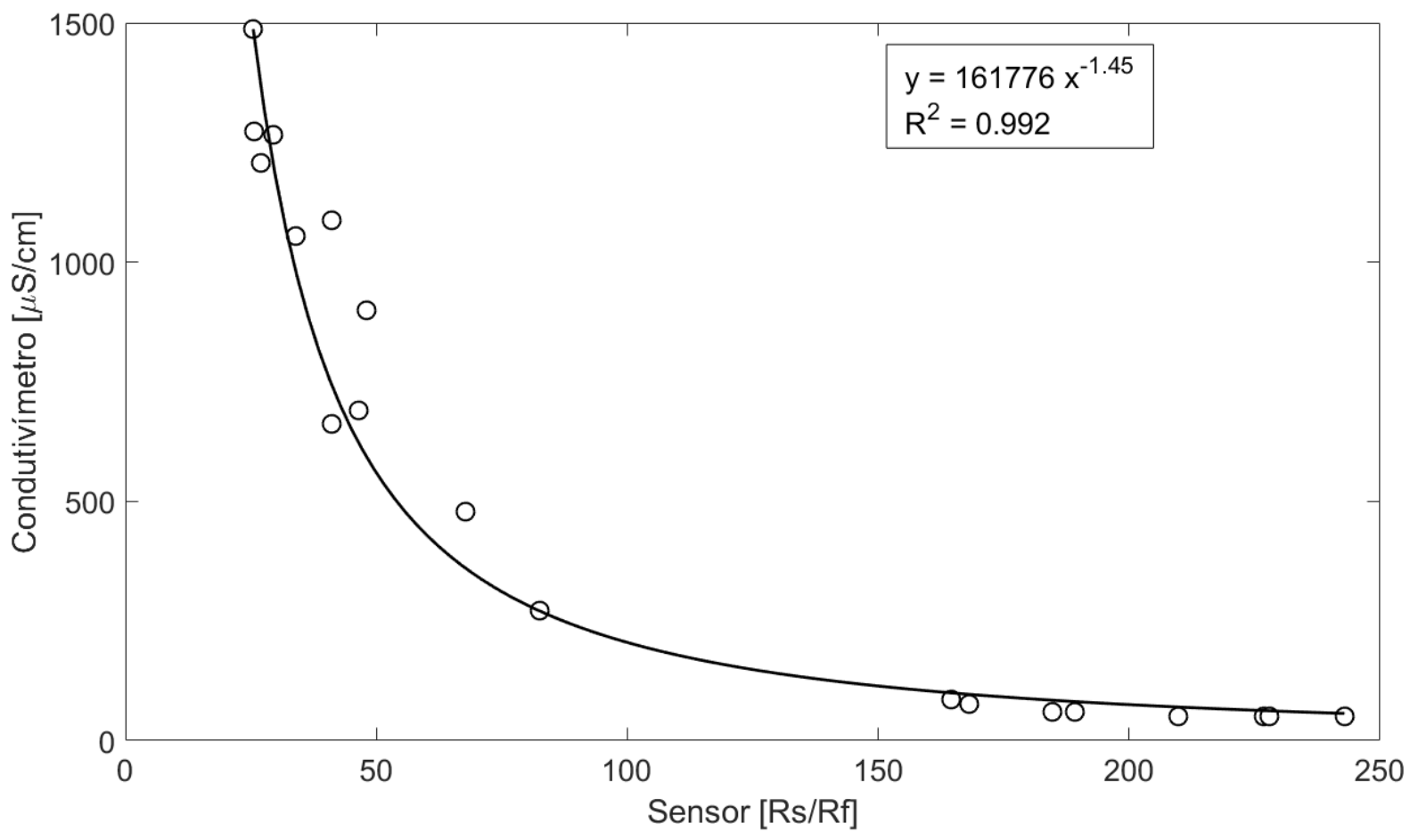

Calibração do sensor de condutividade S09

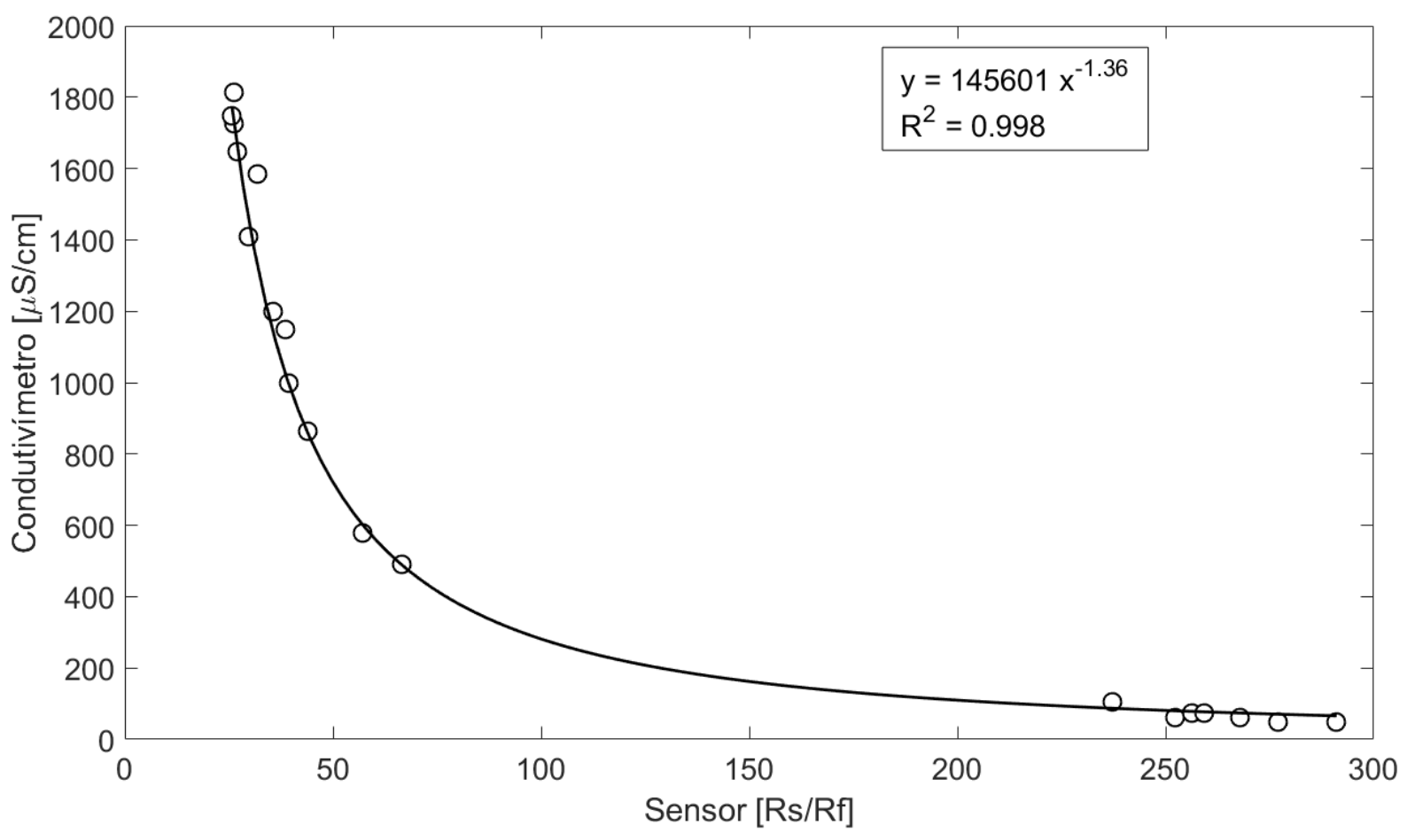


Calibração do sensor de condutividade $\mathbf{S 1 0}$

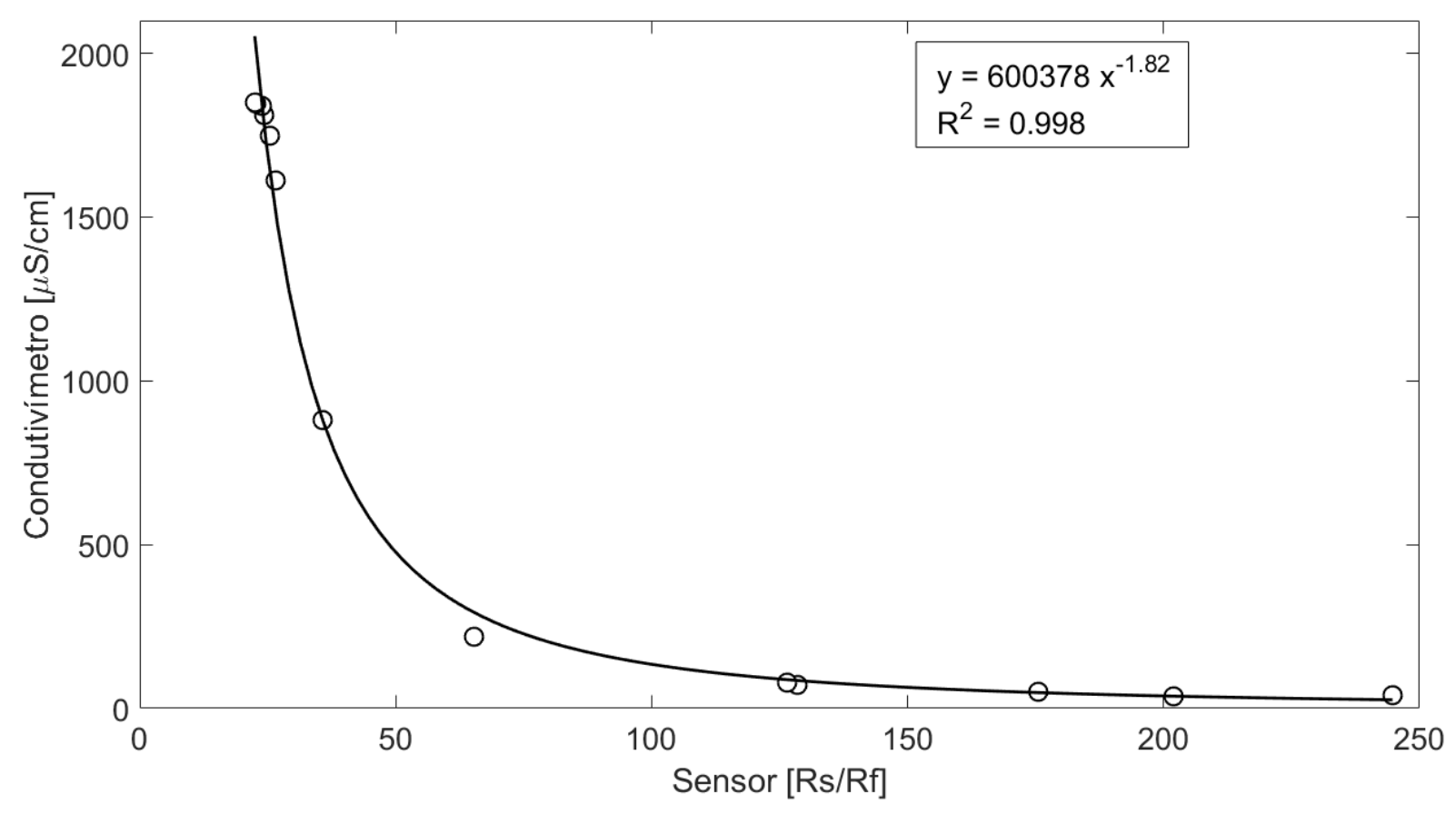

Calibração do sensor de condutividade S12

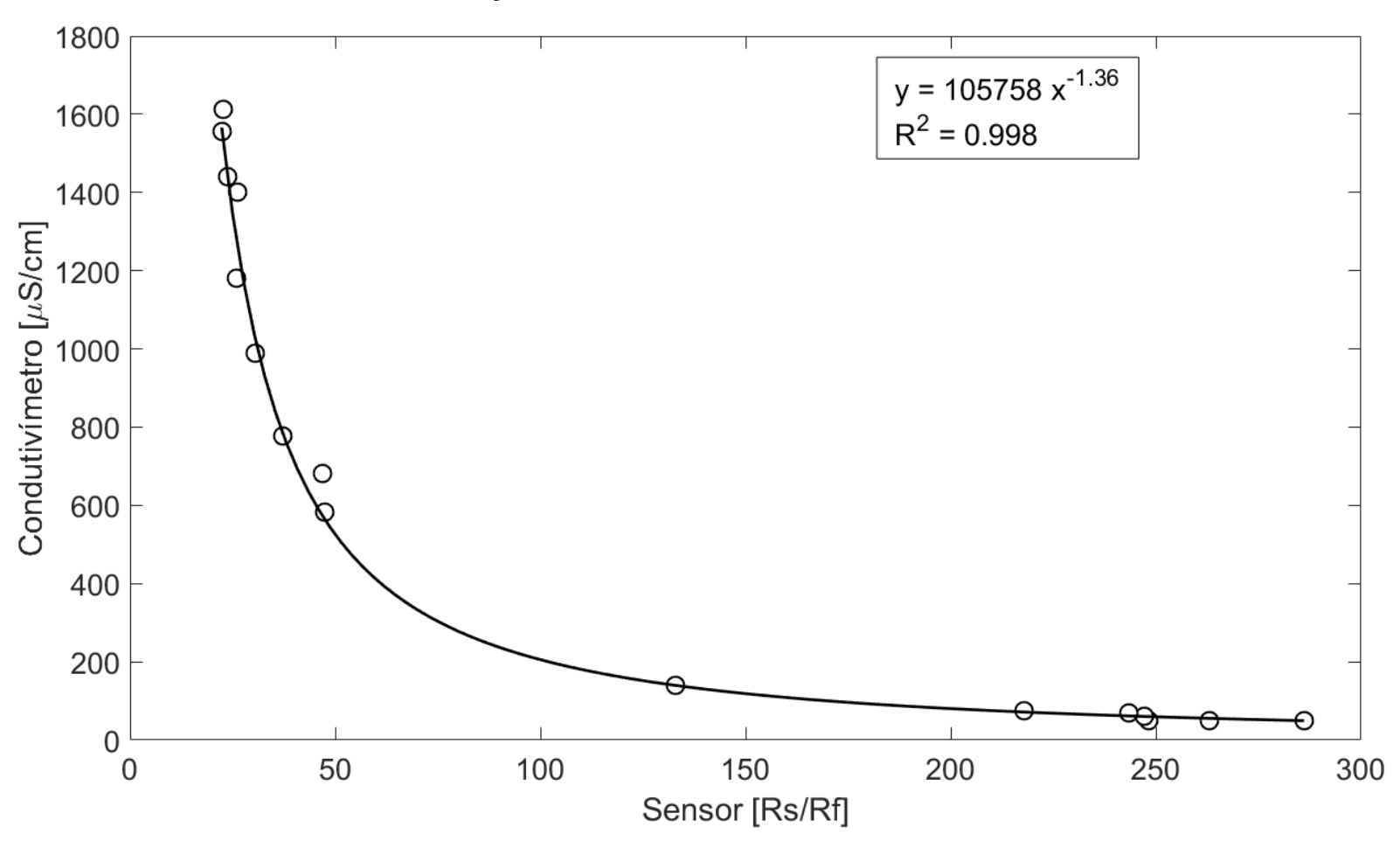


Calibração do sensor de condutividade S13

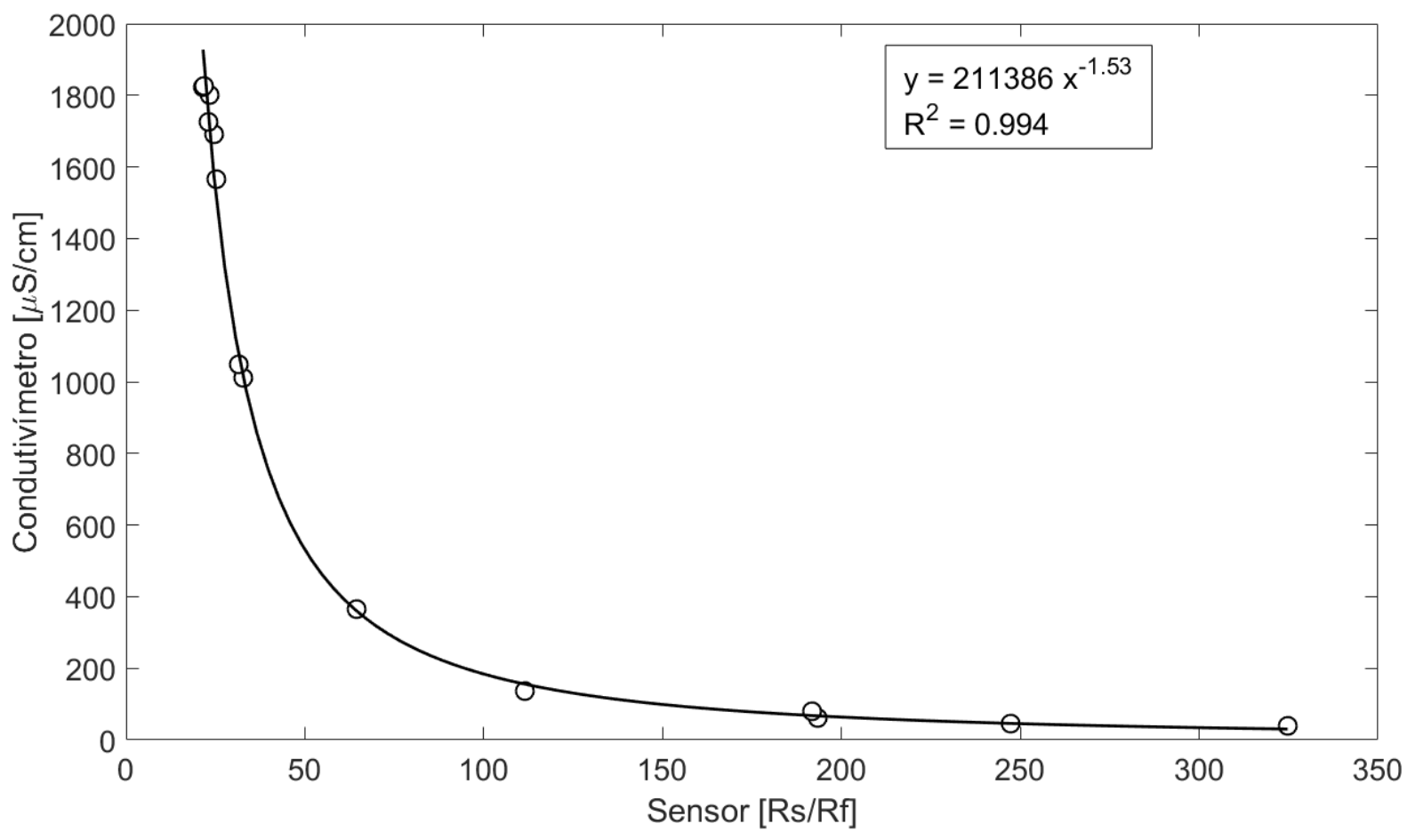

Calibração do sensor de condutividade S14

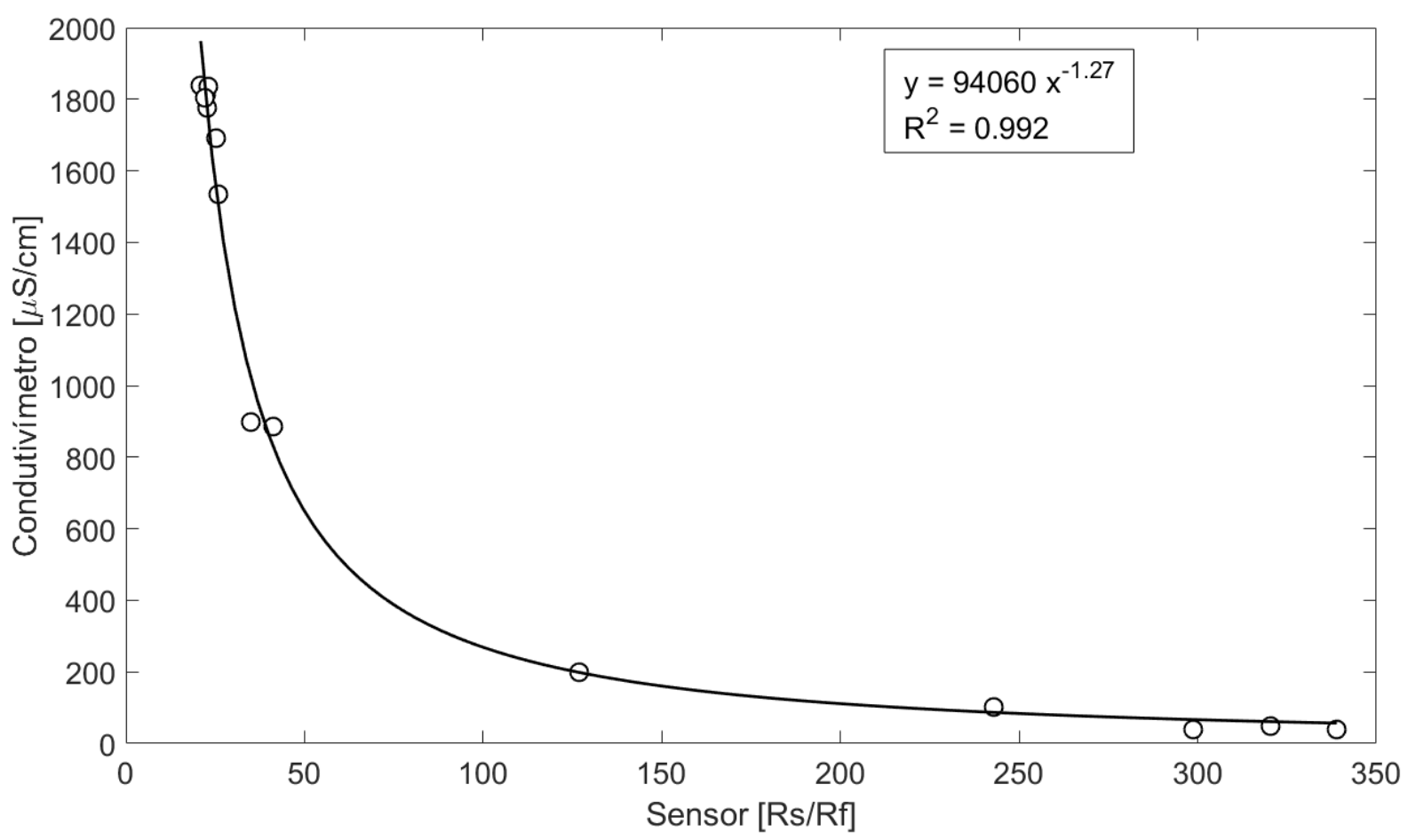




\section{APÊNDICE D}

Monitoramento do ponto S01

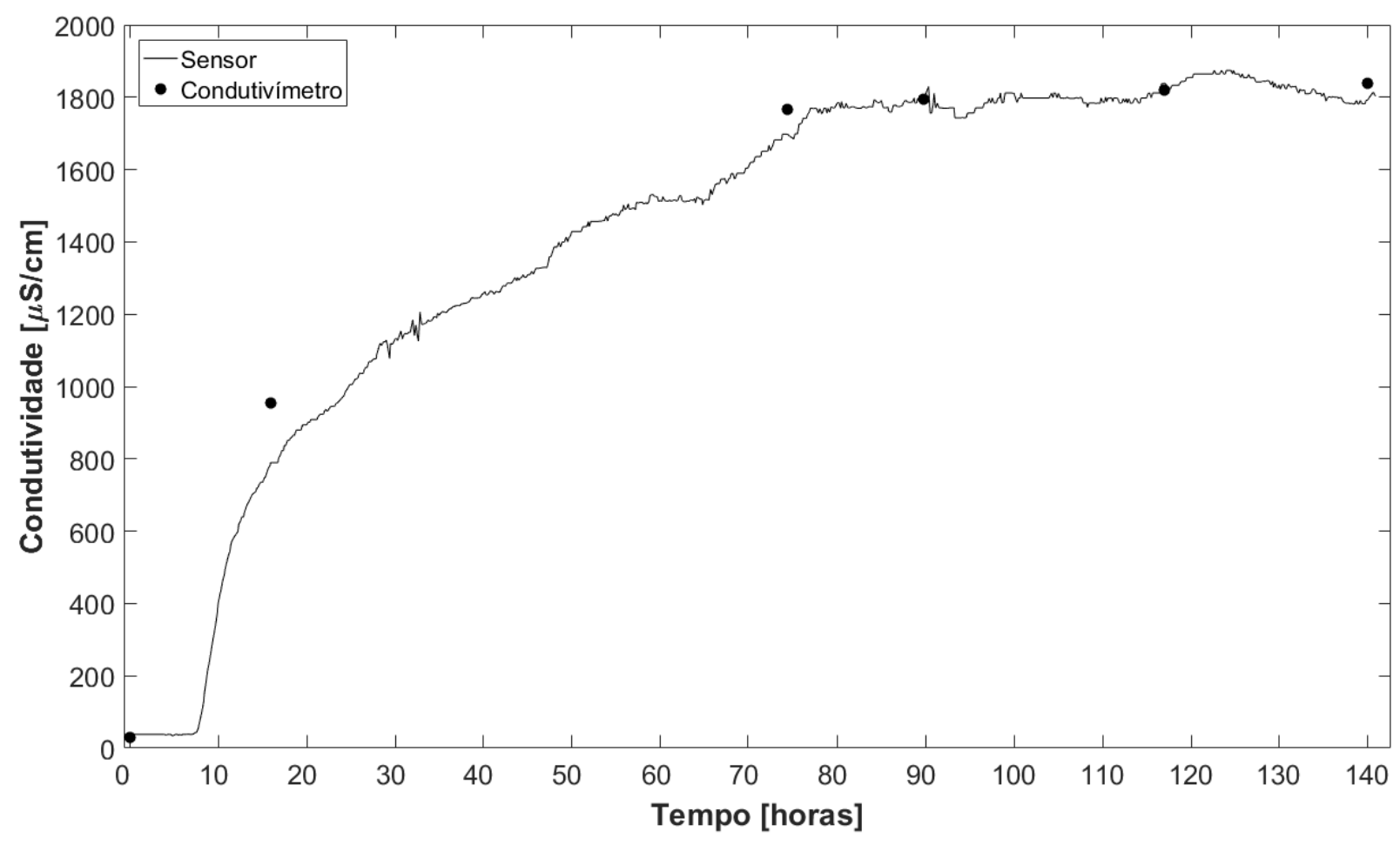

Monitoramento do ponto $\mathrm{S03}$

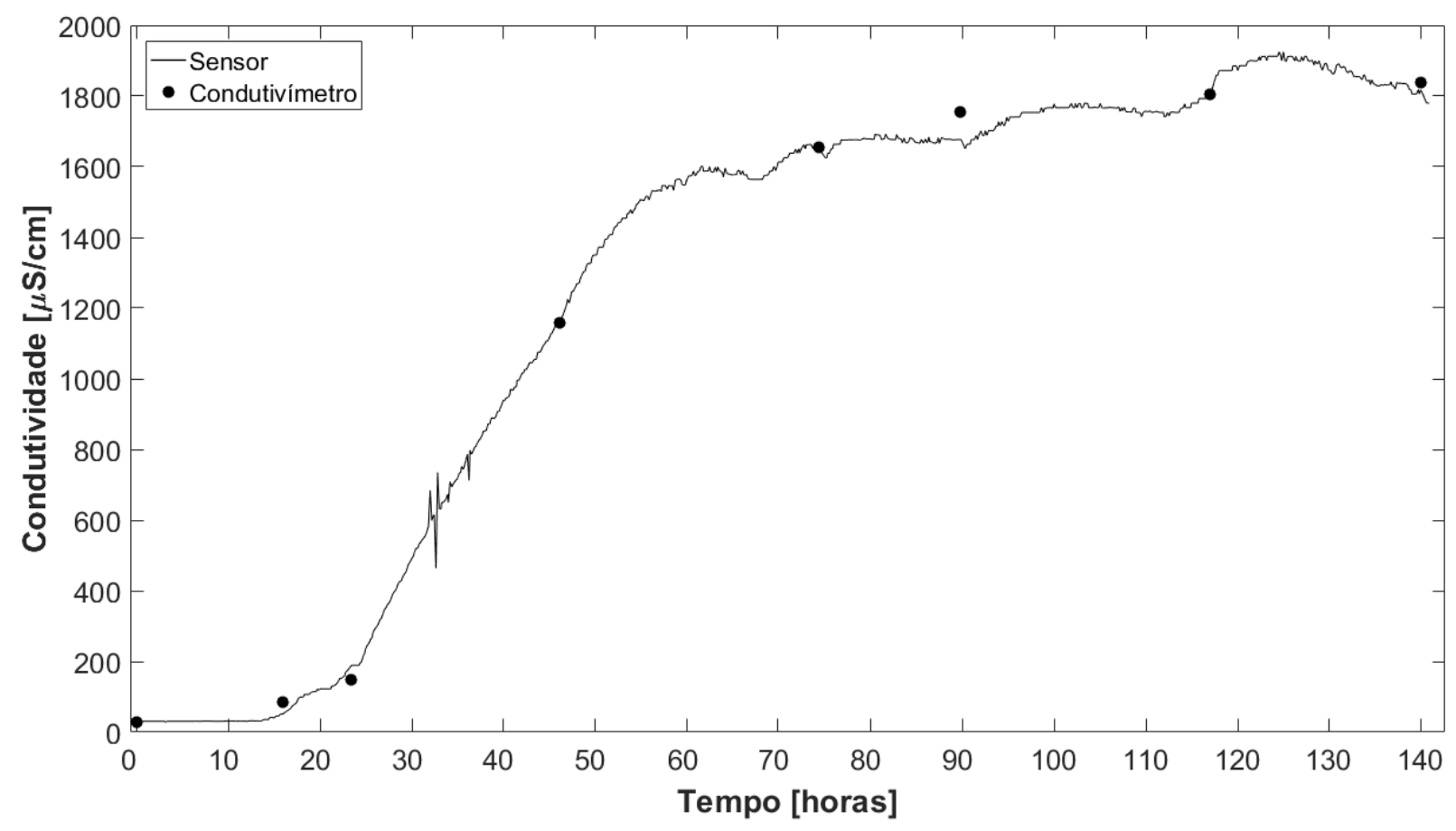


Monitoramento do ponto S04

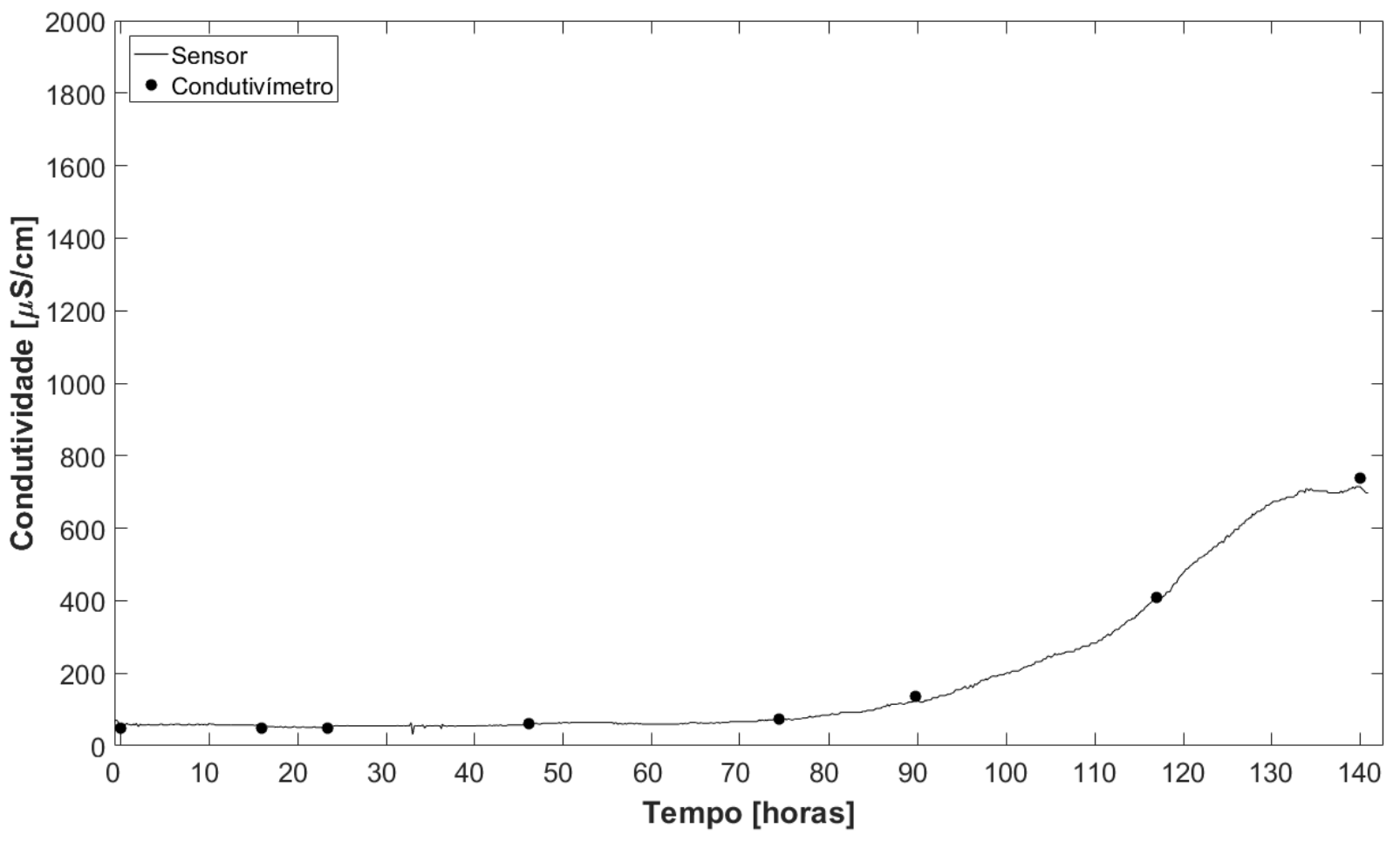

Monitoramento do ponto S05

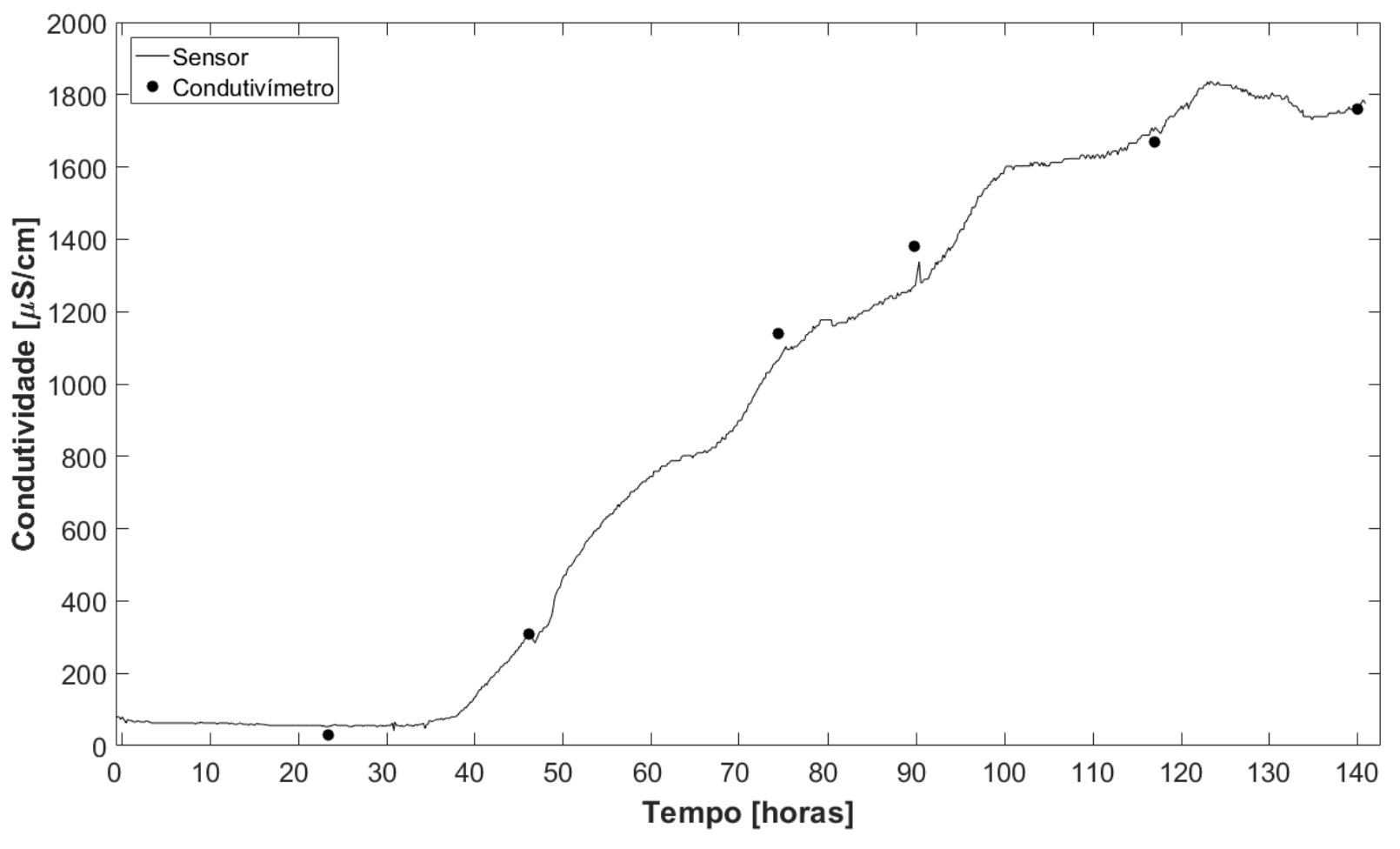




\section{Monitoramento do ponto S06}

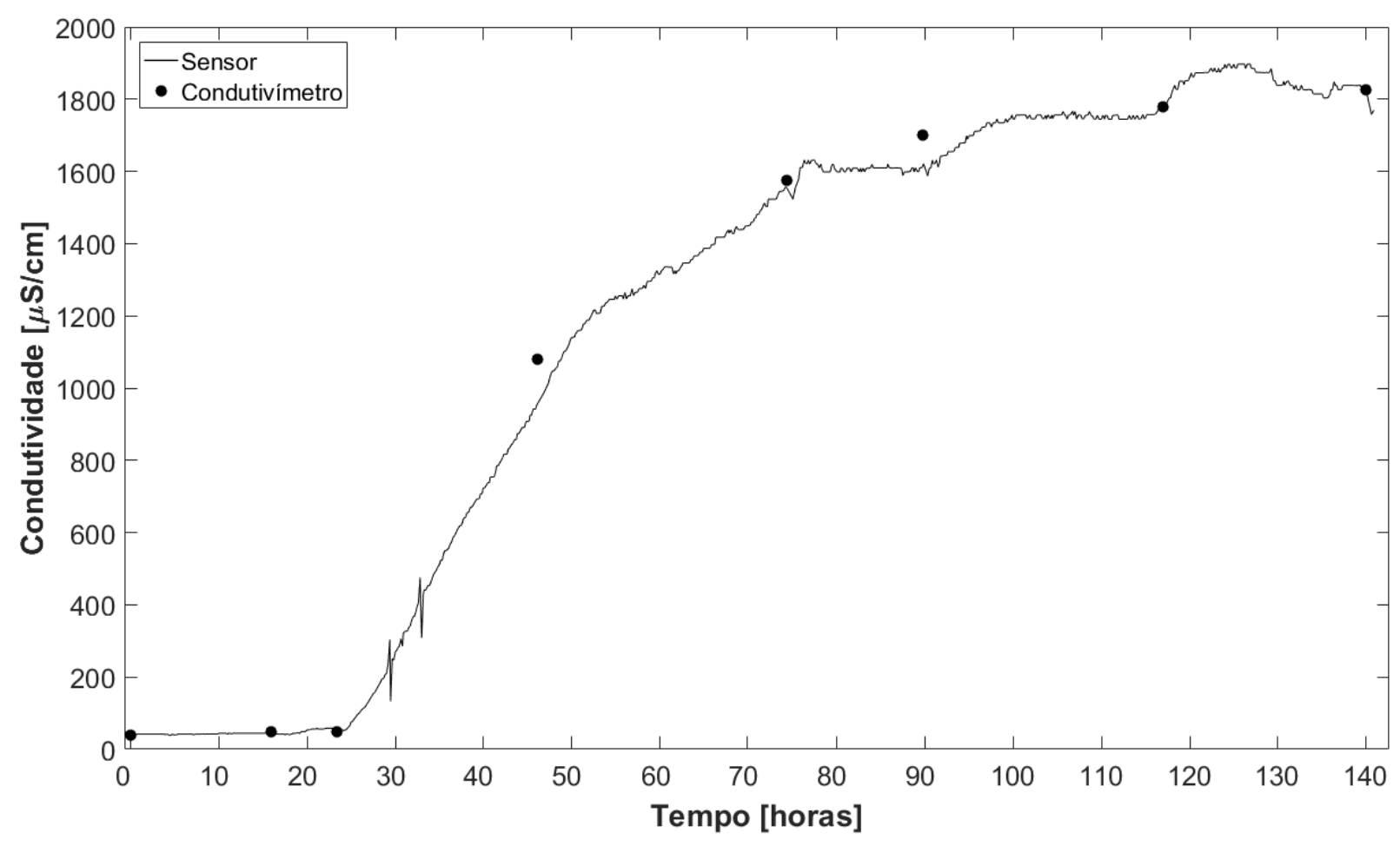

Monitoramento do ponto S07

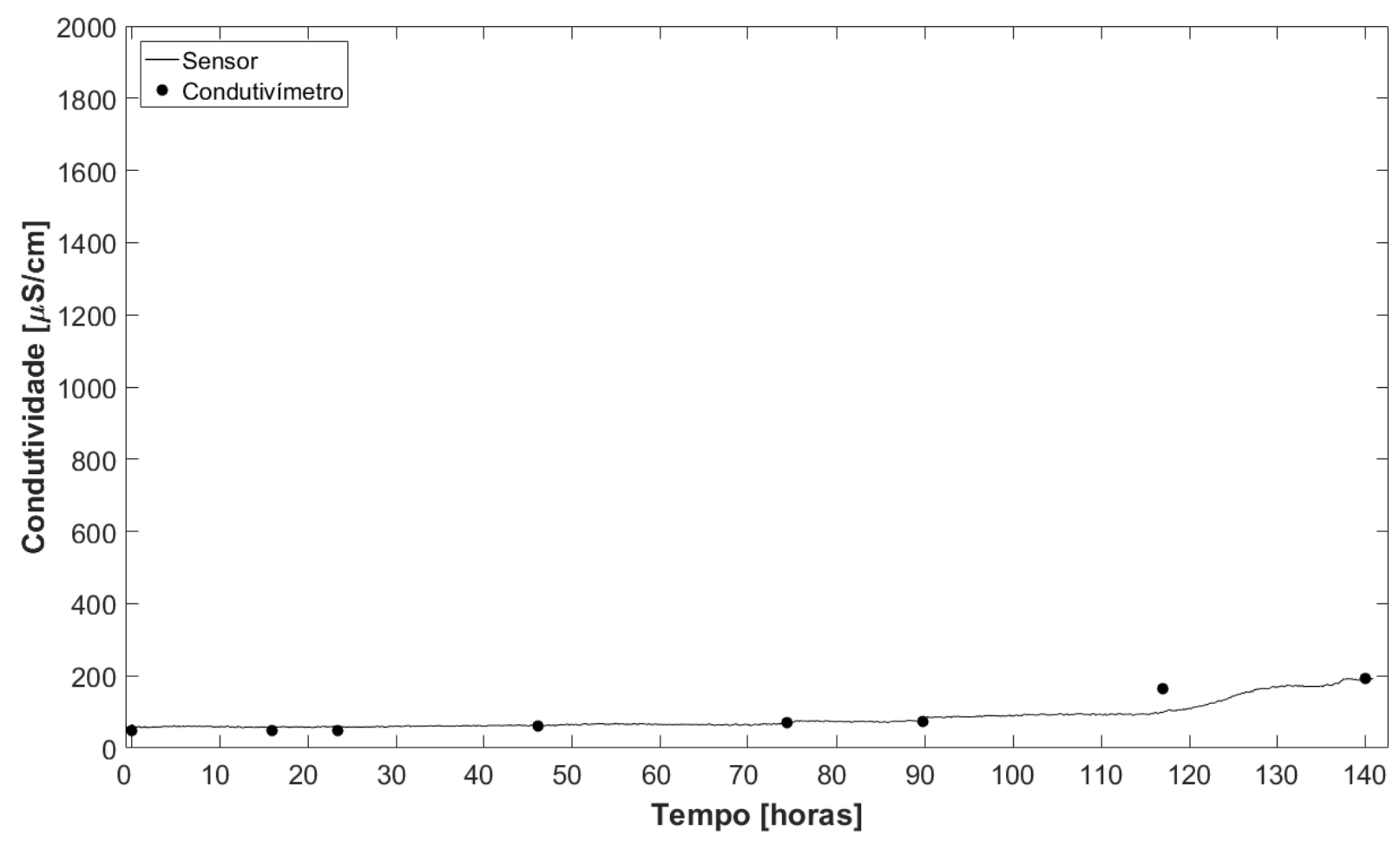


Monitoramento do ponto S08

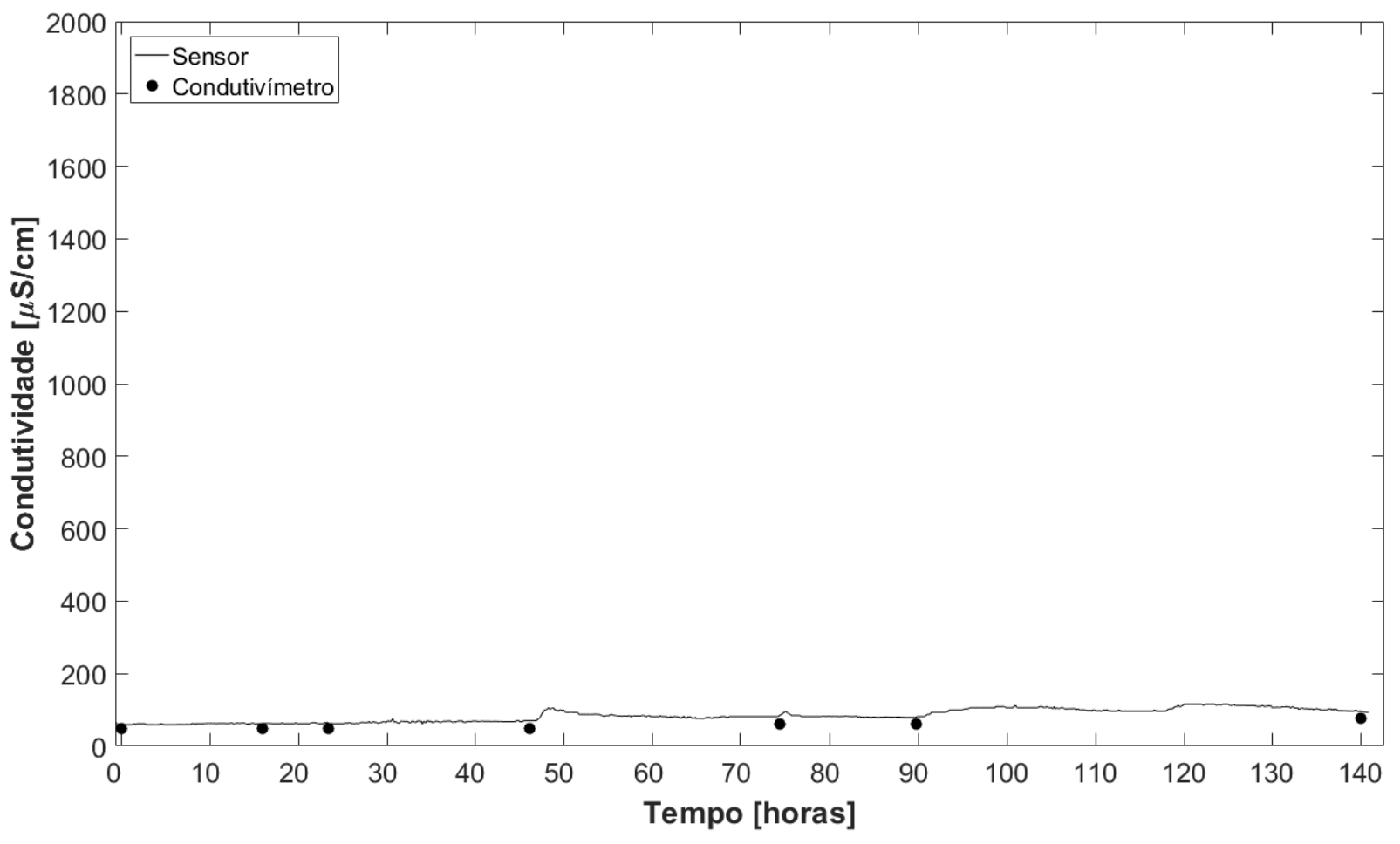

Monitoramento do ponto S09

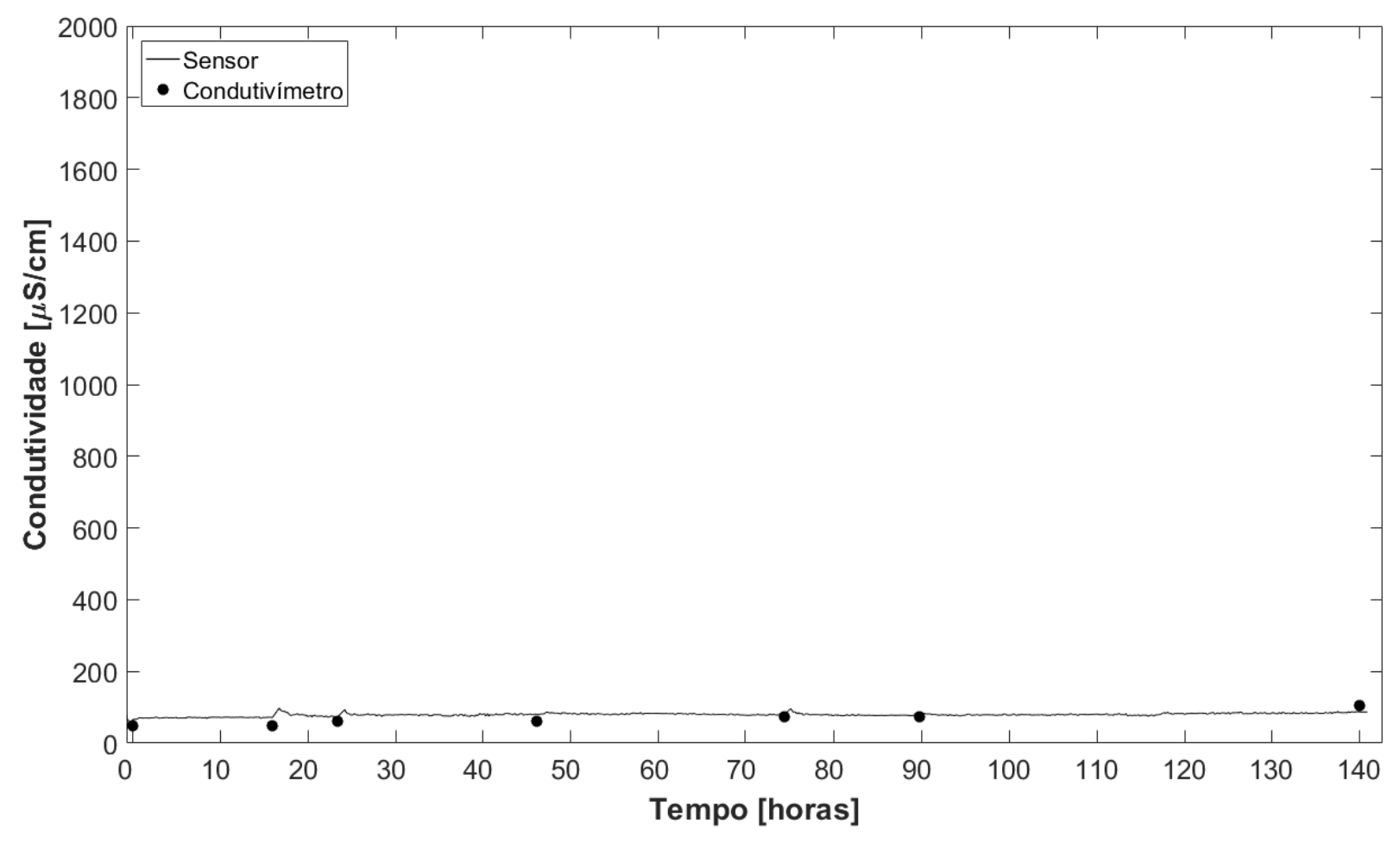


Monitoramento do ponto S10

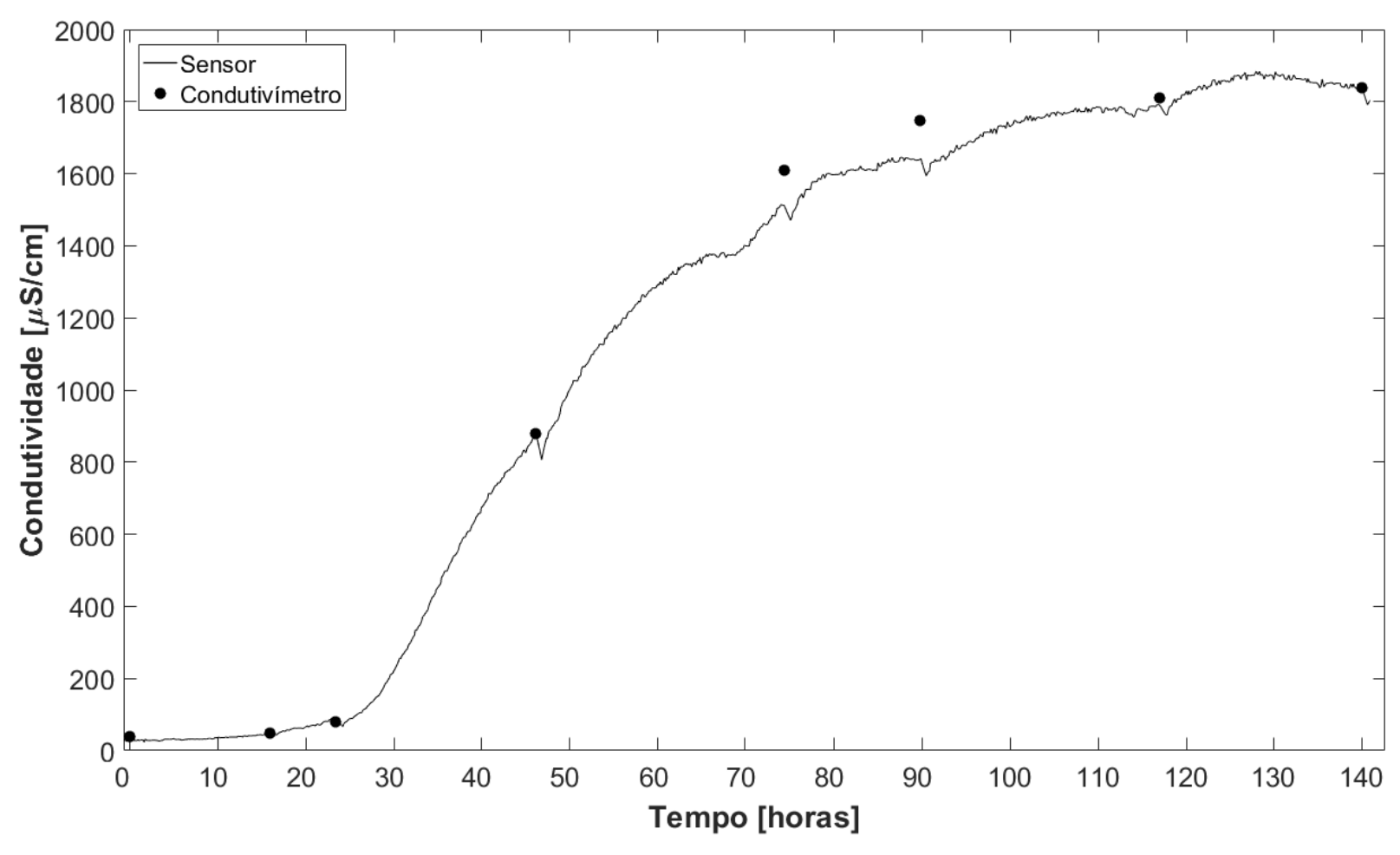

Monitoramento do ponto S12

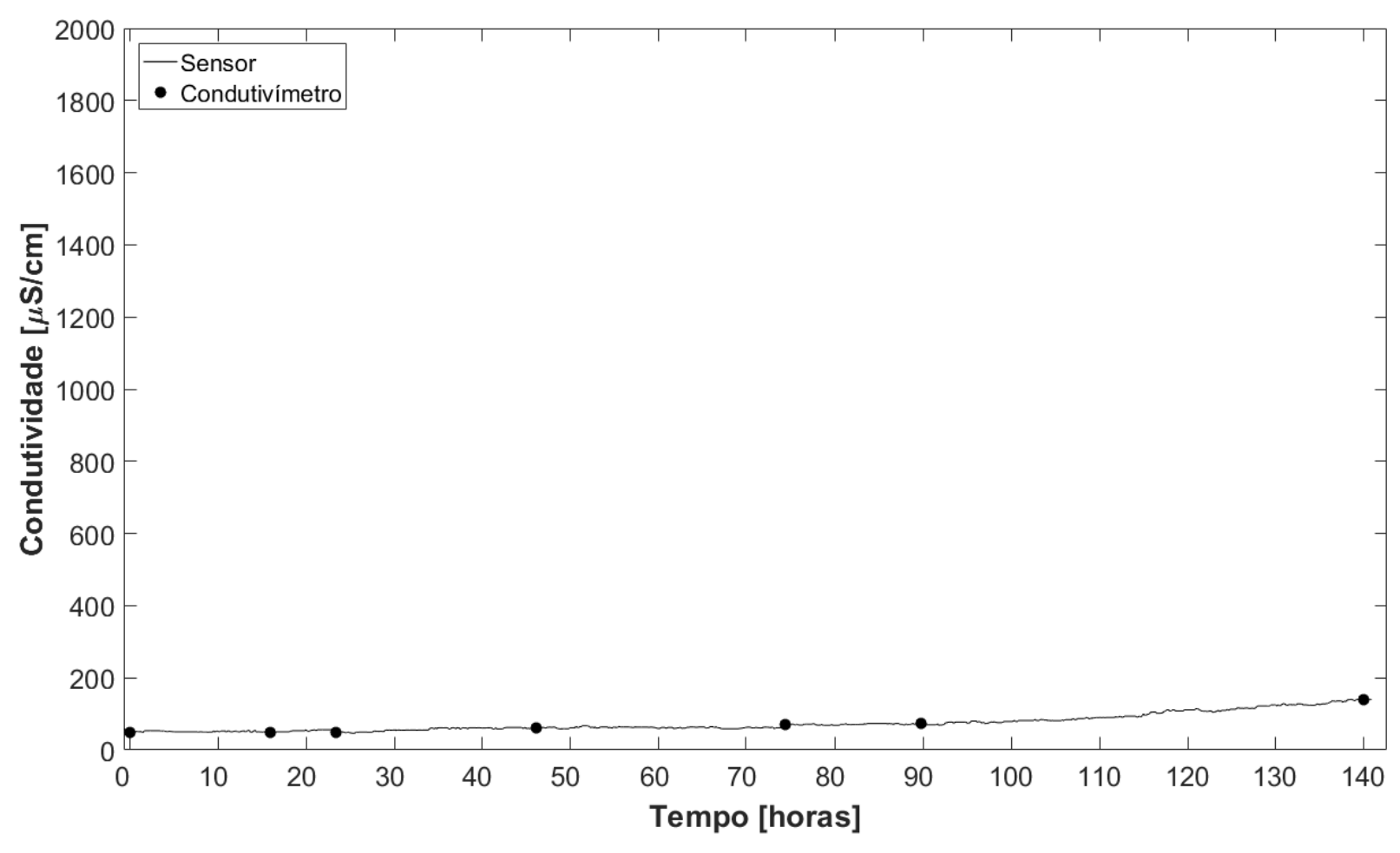


Monitoramento do ponto S13

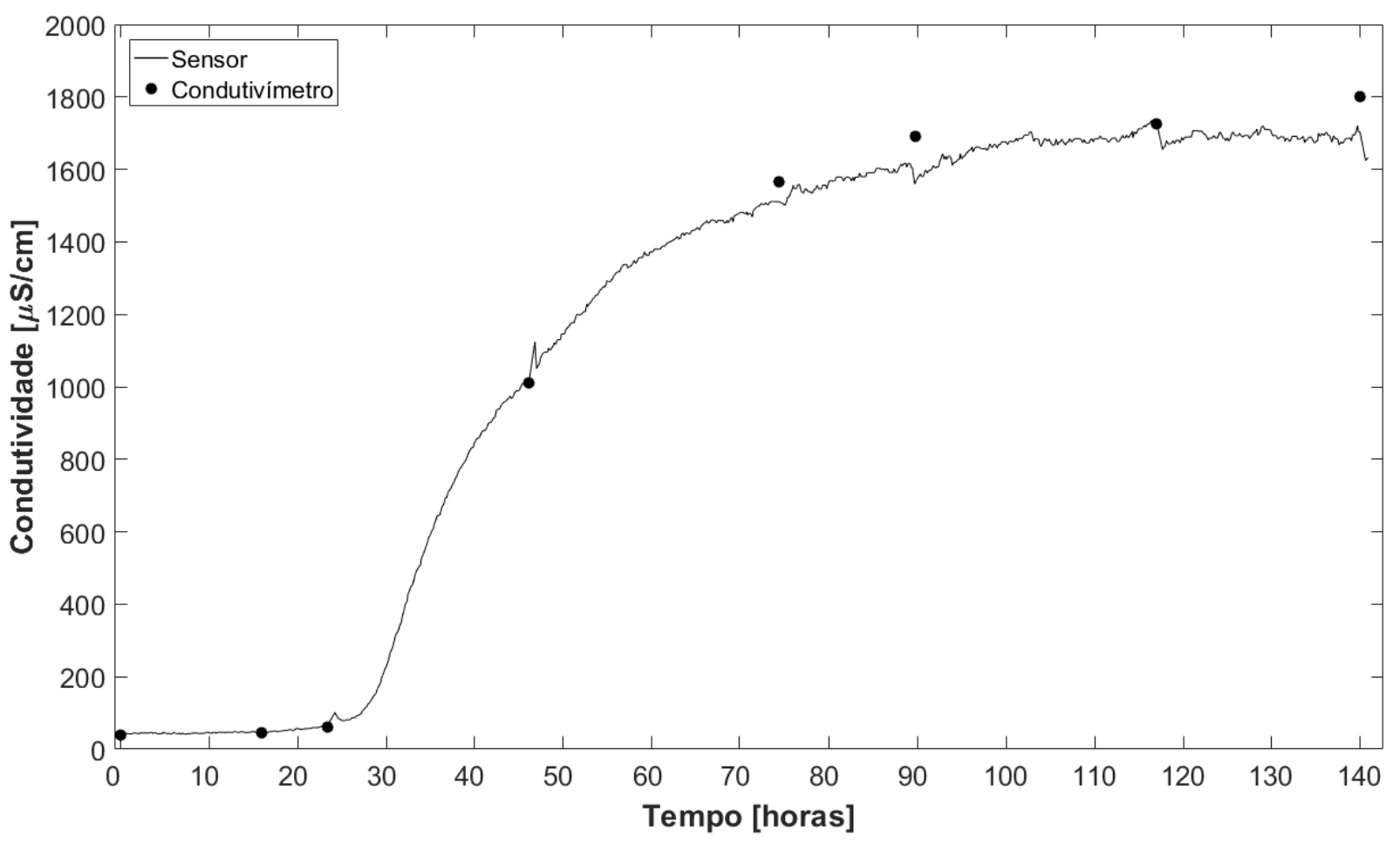

Monitoramento do ponto S14

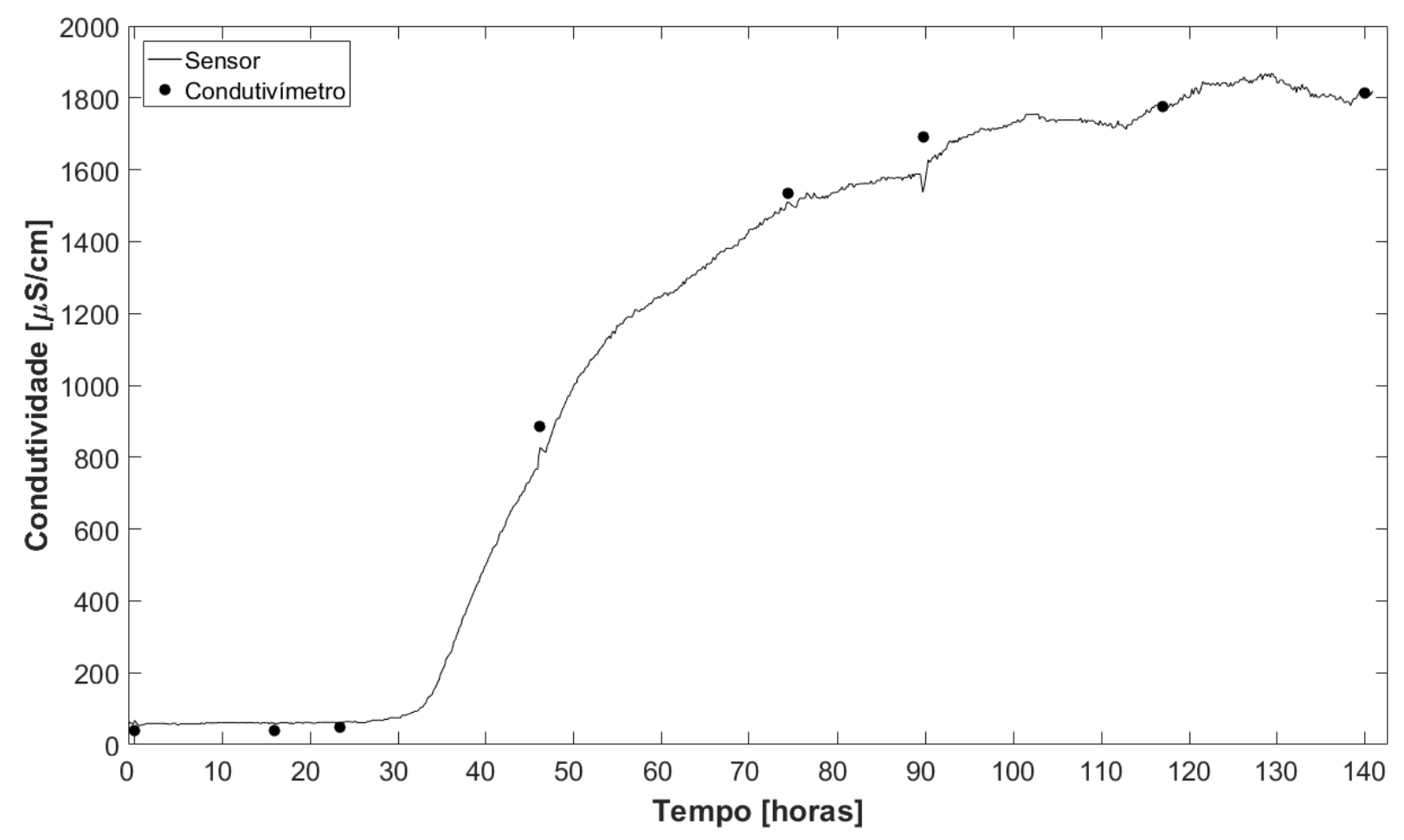

